\title{
Die expliziten Rollen- und Regieangaben der Rosenplütschen Fastnachtspiele
}

\section{Text-apparative Elemente eines dramatischen Dispositivs}

\author{
Rebekka Nöcker
}

Online publiziert: 12 . Oktober 2020

(C) Der/die Autor(en) 2020

Zusammenfassung Der Beitrag untersucht die Rosenplütschen Fastnachtspiele in ihrer Funktionsweise als ein dramatisches Dispositiv anhand ihrer Nebentexte. In Abgrenzung zu den Spielen der Folz-Tradition verschafft er einen Überblick über die charakteristischen Typen der Regieangaben und ihre Performanzstrategien. Auf dieser Basis zeigt er charakteristische dispositive Wirkungsstrukturen auf, die durch poetische und dramatische Verfahren der Schriftnotation, der Episierung und der Semantisierung theatrale Wahrnehmung und Imagination steuern.

Schlüsselwörter Aufführung · Dispositiv · Fastnachtspiel · Imagination · Handschrift $\cdot$ Regieangabe $\cdot$ Nebentext

\section{The Explicit Speaker Names and Stage Directions of the Shrovetide Plays of the Rosenplüt Tradition}

Text-Apparatus Elements of a Dramatic Dispositif

\begin{abstract}
This article examines the shrovetide plays of the Rosenplüt tradition in its function as a dramatic dispositif on the basis of its secondary texts. In contrast to the games of the later Folz tradition, it provides an overview of the characteristic types of stage directions and their performance strategies. On this basis, characteristic dispositive effect structures are shown, that control theatrical perception and imagination through poetic and dramatic procedures of script notation, epization and semantization.
\end{abstract}

Keywords Shrovetide Play · Dispositive - Imagination · Manuscript ·

Performance $\cdot$ Secondary Text $\cdot$ Stage Direction

R. Nöcker $(\bowtie)$

Deutsches Seminar, Eberhard Karls Universität Tübingen, Tübingen, Deutschland

E-Mail: rebekka.noecker@uni-tuebingen.de 


\section{Ausgangsthese}

Bekanntlich rekurriert die von Michel Foucault nachhaltig angestoßene Diskussion um die »Philosophie der Dispositive $^{1}$ auf die in verschiedenen institutionellen Kontexten geläufige Bedeutung des französischen dispositif, welche »die (materiellen) Vorkehrungen, die eine strategische Operation durchzuführen erlauben $\ll,{ }^{2}$ erfasst. ${ }^{3}$ Zentral für das Dispositiv-Konzept sind unsichtbar bleibende Anordnungen, die historisch spezifische Konfigurationen von Diskursen, Medien und Institutionen im Blick auf ihre semiotisch-kulturelle Wahrnehmungsordnung offenlegen. ${ }^{4}$ Eine solche Anordnungskonfiguration ist in den »mehr oder weniger stabile[n] Verbindungen von Aussagemonumenten und Vermittlungspraktiken« jener »Regularitäten« gegeben, welche Genres darstellen. ${ }^{5}$ Regularitäten in diesem Sinne, die offen sind für mediale Interferenzen, sind genuin mit der historisch spezifischen Praxis theatralen Handelns (neben der des rituellen Handelns) verbunden, das kulturelles Wissen vermittelt und am Diskurs gesellschaftlicher Selbstbeschreibung teilhat. Damit erzeugt es aber auch die kulturellen Codes für Subjektivierungseffekte des Erfahrens, Verstehens und Handelns, an denen die dispositive Wirkungsweise, welche die sozialen Wahrnehmungsmodi regelt, sichtbar werden.

Obwohl Hans Ulrich Gumbrecht keine wissenschaftstheoretische Kontextualisierung ausführt, scheint sein Verständnis des mittelalterlichen Theaters »als ein[es] historisch spezifische[n] Erfahrungsdispositiv[s] $\ll^{6}$ hier anzuknüpfen, wenn er den »hermeneutische[n] Bezug zum >mittelalterlichen Theater« als Desiderat infolge einer »doppelte[n] Diskontinuität« begreift: »Wir können nicht [...] sicher sein, woher die Formen des >mittelalterlichen Theaters < kamen, aber es ist uns auch zu-

\footnotetext{
1 Deleuze, Gilles: »Was ist ein Dispositiv?«In: Spiele der Wahrheit. Michel Foucaults Denken. Hg. von François Ewald/Bernhard Waldenfels. Frankfurt a. M. 1991, S. 153-162 [frz.: 1989], hier S. 157.

2 Foucault, Michel: Sexualität und Wahrheit. Bd. 1: Der Wille zum Wissen. Übersetzt von Ulrich Raulff/ Walter Seitter. 17. Aufl. Frankfurt a. M. 2017 [frz. 1977], S. 29 (Anm. der Übersetzer).

3 Foucault bestimmt das mit den soziokulturellen Feldern >Wissen < und >Macht< verbundene Dispositiv erstens als »ein entschieden heterogenes Ensemble, das Diskurse, Institutionen, architekturale Einrichtungen, reglementierende Entscheidungen, Gesetze, administrative Maßnahmen, wissenschaftliche Aussagen, philosophische, moralische oder philanthropische Lehrsätze, kurz: Gesagtes ebensowohl wie Ungesagtes umfaßt. Soweit die Elemente des Dispositivs. Das Dispositiv selbst ist das Netz, das zwischen diesen Elementen geknüpft werden kann« (Foucault, Michel: Dispositive der Macht. Über Sexualität, Wissen und Wahrheit. Berlin 1978, S. 118-175 [»Ein Spiel um die Psychoanalyse. Gespräch mit Angehörigen des Département de Psychanalyse der Universität Paris/Vincennes«; frz.: 1977], hier S. 119 f.). Zweitens geht es ihm um die »Natur der Verbindungen« zwischen den Elementen im »Spiel von Positionswechseln und Funktionsveränderungen« und drittens um eine »Formation« mit »vorwiegend strategische[r] Funktion« (vgl. ebd., S.120).

4 Zum Aspekt der Wirkungsweise des Dispositivs vgl. mit weiterführender Literatur Wimmer, Mario: »Dispositiv«. In: Ute Frietsch/Jörg Rogge (Hg.): Über die Praxis des kulturwissenschaftlichen Arbeitens. Ein Handbuch. Bielefeld 2013, S. 123-128.

5 Vgl. Gnosa, Tanja: »Re-Konfigurationen im Dispositiv: Genres als Erfolgsmodelle der Vermittlung kulturellen Wissens«. In: Ivo Ritzer/Peter W. Schulze (Hg.): Mediale Dispositive. Wiesbaden 2018, S. 27-44, hier S. 40 f. (Zitate S. 40).

6 Gumbrecht, Hans Ulrich: »Für eine Erfindung des mittelalterlichen Theaters aus der Perspektive der frühen Neuzeit«. In: Johannes Janota u. a. (Hg.): Festschrift Walter Haug und Burghart Wachinger. Bd. 2. Tübingen 1992, S. 827-848, hier S. 833.
} 
nehmend unklar, wie wir es als eine Vorstufe in Bezug zum neuzeitlichen Theater setzen können. «7 Implizit an der materiellen Anordnung des sprachlichen Textes ansetzend, begreift Gumbrecht die Spieltexte »als Indizien für Aufführungs- und Interaktionsformen, die ihrerseits als Dispositive für historisch spezifische Modalitäten des Erfahrens gedeutet werden können. $\aleph^{8}$ Auch Kirsten Kramer und Jörg Dünne begreifen die Historizität der Anordnung als wesentlich, stellen aber ihre mediale Dimension zentral. Sie verstehen

Theatralität als ein komplexes mediales Dispositiv [...], das auf unterschiedlichen Ebenen historisch variable Ordnungen und Praktiken des Raums implementiert und darin je besondere kulturgeschichtliche Modelle und Konzepte theatraler Performanz generiert. ${ }^{9}$

Die strategischen Vorkehrungen erzeugen ein »Dispositiv, das technische Körperextensionen vornimmt $\ll,{ }^{10}$ und das

nur durch die Interferenz von Körperpraktiken und technisch-materiell gestützten Inszenierungs-, Interaktions- und Wahrnehmungsformen beschreibbar ist, wobei sich je nach historischem und kulturellem Kontext divergierende Relationierungen der genannten Teilaspekte theatraler Performanz ergeben. ${ }^{11}$

Das den nachfolgenden Ausführungen zugrunde liegende Verständnis des dramatischen Dispositivs greift dieses Konzept auf. Es soll ein mediales theatrales Dispositiv bezeichnen, das sich zusätzlich über die Medialität seiner Textkonstitution geriert, und zwar stets bezogen auf die darin inhärente, Subjektivierungseffekte zeitigende Performanzdimension.

Für die historisch spezifische Performanzdimension des mittelalterlichen Fastnachtspiels wird jedoch gemeinhin der Terminus $>$ Drama< vermieden und stattdessen ein weiter Theaterbegriff angesetzt. Er trägt sowohl der besonderen, an den Festanlass der Fastnacht gebundenen performativen Kommunikationssituation des theatralen Spiel-Vollzugs mit der Verschränkung von Spiel- und Zuschauerebene sowie der Überlagerung von ästhetischer und sozialer Wirklichkeit Rechnung als auch der offenen Gattungsvorstellung, die in den zeitgenössischen, textierte wie nichttextierte Schaustellungsformen erfassenden Bezeichnungen spil und vasnacht spil zum Ausdruck kommt. ${ }^{12}$ Für Aussagen zur Theatralität der Nürnberger Fastnachtspiele des 15. Jahrhunderts ist man aber angesichts der Quellenlage, die sich fast ausnahmslos auf die überlieferten Spieltexte beschränkt, auf die im Lesemedium

\footnotetext{
7 Ebd., S. 831.

8 Ebd., S. 829.

9 Kramer, Kirsten/Dünne, Jörg: »Einleitung. Theatralität und Räumlichkeit«. In: Jörg Dünne/Sabine Friedrich/Kirsten Kramer (Hg.): Theatralität und Räumlichkeit. Raumordnungen und Raumpraktiken im theatralen Mediendispositiv. Würzburg 2009, S. 15-32, hier S. 10.

10 Ebd., S. 19.

11 Ebd., S. 17, im Anschluss an das Theatralitätskonzept von Erika Fischer-Lichte.

12 Vgl. Ridder, Klaus/Nöcker, Rebekka/Schuler, Martina: »Spiel und Schrift. Nürnberger Fastnachtspiele zwischen Aufführung und Überlieferung«. In: Thomas Anz/Heinrich Kaulen (Hg.): Literatur als Spiel. Evolutionsbiologische, ästhetische und pädagogische Konzepte. Beiträge zum Deutschen Germanistentag 2007. Berlin/New York 2009, S. 195-208, hier S. 195-197.
} 
der mittelalterlichen Handschrift schriftlich fixierten Aufführungstexte angewiesen. Nähert man sich vor dem Hintergrund dieser divergenten kulturhistorischen Situation den Bedingungen eines medialen dramatischen Dispositivs im genannten Sinne, scheint es daher geboten, das Prädikat >dramatisch< auf das im Spiel-Text medial konstituierte szenische Aufführungs-Potenzial zu beziehen.

Dieses Potenzial erschließt sich für die Nürnberger Einkehrspiele, die zur Fastnacht von Laiendarstellern in Wirts- und Bürgerhäusern auf dort ad hoc vorgefundenen Spielflächen aufgeführt wurden, vor allem aus den zahlreichen impliziten Aufführungshinweisen der Sprechtexte, die das Genre kennzeichnen. ${ }^{13}$ Daher ist von einer in der Aufführung je neu zu aktualisierenden sprachlichen Improvisationsbasis mit inhärenten Performanzstrategien auszugehen, auf die sich die Texte hin befragen lassen. Die so für ein Spiel abstrahierten Hinweise bilden kein unveränderliches Regiesetting seiner inszenatorischen Umsetzung $a b$, sondern je für sich denkbare punktuelle, stellenbezogene Aufführungspraktiken, die, abhängig von den äußeren Rahmenbedingungen (körperliche und sprachliche Voraussetzungen der Darsteller, Kostüm- und Requisitenfundus, >Architektur < der Spielfläche etc.), in jeder Darbietungsaktualisierung variieren und ebenso entfallen konnten und möglicherweise in der Kombination aller nie realisiert worden sind. Daneben zeitigt sich das inhärente theatrale Potenzial aber auch wesentlich in den expliziten Rollen- und Regieangaben. Sie bilden nicht nur gemeinsam mit den impliziten Angaben den perzeptionsbezogenen »Textraum «. ${ }^{14}$ Vielmehr kommt ihnen, so die Ausgangsthese, »eine Schlüsselposition in Bezug auf die gattungsspezifischen, medialen und kommunikativen Implikationen ${ }^{15} \mathrm{zu}$. Denn mit ihnen führt ein Nebentext ${ }^{16} \mathrm{zu} z$ wei Ebenen des inszenatorischen Entwurfs: der Ebene der genuinen Aufführungsrealisierung, aus der die Sprechtexte stammen, und der Ebene der Bühnenimagination im durch die Nebentexte regulierten Lektürevorgang. Entsprechend kommen für den Wahrnehmungsort ${ }^{17}$ im dramatischen Dispositiv zwei dispositiv entworfene Subjektpositionen in den Blick: die des Zuschauers der realen Aufführung und die des zeitgenössischen Lesers des mittelalterlichen Spieltextes im Schriftmedium. Beide Positionen sind im überlieferten Textsubstrat sedimentiert und beide gilt es im Blick auf die je divergierenden Inszenierungsmöglichkeiten daraus zu abstrahieren. So

\footnotetext{
13 Allgemein zur Unterscheidung expliziter und impliziter Anweisungen für die Inszenierung s. Pfister, Manfred: Das Drama. 11. Aufl. Köln/Weimar/Wien 2001, S. 36-38. Vgl. auch Detken, Anke: Im Nebenraum des Textes. Regiebemerkungen in Dramen des 18. Jahrhunderts. Tübingen 2009, S. $10 \mathrm{f}$.

14 Detken (s. Anm. 13), S. 10. Detken sieht den Vorteil des Begriffs darin, dass er »zunächst ein nichthierarchisches Verhältnis der beiden Textbereiche abbildet « und dass er es ermöglicht, »beiden Bereichen zunächst gleiches analytisches Interesse entgegenzubringen« (ebd.). Zur Notwendigkeit, angesichts der Überlieferungsvarianz des Fastnachtspiels je nach Frageinteresse zu hierarchisieren, s.u. 4.

15 Tonger-Erk, Lily/Werber, Niels: »Nebensächlich? Vorwort zum Nebentext«. In: LiLi 48 (2018), S. 411-419, hier S. 413 (zu Nebentexten im Drama allgemein).

16 Die begriffliche Differenzierung von Haupt- und Nebentext folgt Ingarden, Roman: Das literarische Kunstwerk. Mit einem Anhang von den Funktionen der Sprache im Theaterschauspiel. 3. Aufl. Tübingen 1965 [zuerst 1931], S. 20-222, 340; vgl. auch Pfister (s. Anm. 13), S. 35 f. Eine kritische Zusammenschau konkurrierender Bezeichnungen bietet Detken (s. Anm. 13), S. 6-9; vgl. auch Tonger-Erk, Lily: »Das Drama als intermedialer Text. Eine systematische Skizze zur Funktion des Nebentextes «. In: LiLi 48 (2018), S. 421-444, hier S. 424-427.

17 Vgl. dazu Dünne/Kramer (s. Anm. 9), S. 23-26.
} 
verstanden, sind die expliziten Regieangaben text- und schriftmaterielle Elemente eines Vorkehrungskomplexes, das die Operation einer Inszenierung im Kommunikationssystem des theatralen Spiel(texte)s durchzuführen erlaubt. Sie bilden eine wichtige Text-apparative Struktur des Fastnachtspiel-Dispositivs.

Der vorliegende Beitrag untersucht anhand ausgewählter Beispiele die sogenannten Rosenplütschen Fastnachtspiele des 15. Jahrhunderts in ihrer Funktionsweise als eines medialen dramatischen Dispositivs und stellt dabei das Funktionsspektrum der in der Regel nur knappen Nebentexte zentral. Dazu wird zunächst eine Typik der Rollenbezeichnungen und Regieangaben ermittelt (2) und mögliche Performanzstrategien, die in der Interferenz oder in der Diskrepanz von impliziten und expliziten Regieangaben sichtbar werden können, exemplarisch aufgezeigt (3). Weil anders als bei den nicht selten mit präziseren Nebentexten versehenen Spielen der Folz-Tradition der performative Rahmen fast ausschließlich aus den impliziten Hinweisen der Redetexte erschlossen werden muss, aber die zahlreichen Revuen der Rosenplütschen Spiele, die lediglich aus Reihenauftritten der Darsteller bestehen, so gut wie keine raumgreifende Handlung abbilden, welcher Informationen zum äußeren Bühnengeschehen zu entnehmen wären, zielt die Untersuchung auf den medialen Status der Nebentexte (4), auf ihre Narrativierungsabsicht (5) und auf ihre Sinngebung bei der Enumeration im Reihungsprinzip (6).

\section{Typik der expliziten Rollenbezeichnungen und Regieangaben}

Im deutlichen Unterschied zu den mittelalterlichen geistlichen Spielen weisen die 111 Nürnberger Fastnachtspiele des 15. Jahrhunderts keine so zahlreich beigefügten expliziten Regieangaben auf, die innerhalb eines Spiels mehr oder minder durchgängig und mehr oder minder ausführlich die performative Gestaltung konturieren helfen. ${ }^{18}$ Den überlieferten Spieltexten sind entweder keine (über bloße Sprecherbezeichnungen hinausgehende) Nebentexte zum Bühnengeschehen beigefügt oder,

\footnotetext{
18 Über die Regieangaben der geistlichen Spiele informiert einführend Schulze, Ursula: Geistliche Spiele im Mittelalter und in der Frühen Neuzeit. Von der liturgischen Feier zum Schauspiel. Eine Einführung. Berlin 2012, S. 30-33. Vgl. etwa für das mit bemerkenswert vielen und ausführlichen Anweisungen aufbereitete »Donaueschinger Passionsspiel« ebd., S. 32, 103 f., sowie Wolf, Gerhard: »Inszenierte Wirklichkeit und literarisierte Aufführung. Bedingungen und Funktion der >performance $<$ in Spiel- und Chroniktexten des Spätmittelalters«. In: Jan-Dirk Müller (Hg.): >Aufführung und >Schriftく in Mittelalter und früher Neuzeit. Stuttgart/Weimar 1996, S. 381-405, hier S. 386-392; Toepfer, Regina: »Implizite Performativität. Zum medialen Status des Donaueschinger Passionsspiels«. In: Beiträge 131 (2009), S. 106-132. Kennzeichnend sind »vielfältige Informationen, die sich auf das Verhalten, die Anordnung und die Ausstattung der Darsteller beziehen können. Unter den zahlreichen Angaben fällt vor allem die ausgeprägte Gebärdensprache auf« (ebd., S. 112) sowie die »Detailliertheit und Ausführlichkeit der Bühnenanweisungen, die sich von der Gestik über Körperhaltung und Requisiten bis hin zu Affekten erstrecken« (ebd., S. 113). Für das »Redentiner Osterspiel« konstatiert Johan Nowé hingegen eine weitaus geringere Frequenz expliziter Regieangaben, die »vor allem in Sequenzen mit viel Bewegung und Dynamik vorkommen, während statische Sequenzen weithin ohne sie auskommen«, vgl. Nowé, Johan: » Wy willen ju eyn bilde gheven Explizite und implizite Regieanweisungen als Grundlagen für Inszenierung und Aufführung des Redentiner Osterspiels«. In: Leuvense bijdragen 90 (2001), S. 325-359, hier S. 327.
} 
falls doch, in der Regel nur sehr knapp gehaltene. ${ }^{19}$ Immerhin enthält die sogenannte späte Nürnberger Spieltradition des 15. Jahrhunderts ${ }^{20}$ präzisere Angaben zu pantomimischem Bühnengeschehen, Figurenbewegung, Gestik, Stimmführung, Requisiten oder Kostümierung. Sie finden sich in knapp der Hälfte jenes Corpus von insgesamt 31 Spielen, die der Handwerkerdichter Hans Folz (ca. 1435/40-1513) verfasste oder die dem Umkreis seiner Spiele zugerechnet werden, ${ }^{21}$ sowie ferner in der davon unabhängigen kleinen Gruppe der vier in Handschrift E überlieferten Spiele literarischen Stoffs. ${ }^{22}$ Zumeist befördern die beiden Strukturformen des handlungsorientierten Reihenspiels und des Handlungsspiels ${ }^{23}$ das Erfordernis re-

19 Exemplarische Hinweise zu den expliziten Regieangaben im Fastnachtspiel des deutschen Sprachraums gibt Mauermann, Siegfried: Die Bühnenanweisungen im deutschen Drama bis 1700. Berlin 1911, S. 31-38. $\mathrm{Zu}$ textkritischem Status und überlieferungsbezogenen Aspekten der Nebentexte in den Nürnberger Fastnachtspielen des 15. Jahrhunderts s. Simon, Gerd: Die erste deutsche Fastnachtsspieltradition. Zur Überlieferung, Textkritik und Chronologie der Nürnberger Fastnachtsspiele des 15. Jahrhunderts (mit kurzen Einführungen in Verfahren der quantitativen Linguistik). Lübeck 1970, S. 27-35.

${ }^{20} \mathrm{Zu}$ den Kriterien der Unterscheidung einer frühen und einer späten Nürnberger Spieltradition im 15. Jahrhundert vgl. Simon (s. Anm. 19), S. 70-86, 88-90. Letztere ist nicht zu verwechseln mit der späten Nürnberger Fastnachtspieltradition, die Hans Sachs und Jakob Ayrer prägen. Nebentexte in den Fastnachtspielen von Hans Sachs berücksichtigen z. B. Merkel, Johannes Mathias: Form und Funktion der Komik im Nürnberger Fastnachtspiel. Diss. Freiburg i. Br. 1971, S. 88-143, passim; Freund, Karolin: Der Theatermonolog in den Schauspielen von Hans Sachs und die Literarisierung des Fastnachtspiels. Tübingen 2018, passim.

21 Die editorische Erschließung der Spiele aus der sogenannten Folz-Tradition ist jüngst mit einer kommentierten Neuausgabe auf eine moderne Grundlage gestellt: Nürnberger Fastnachtspiele des 15. Jahrhunderts von Hans Folz und aus seinem Umkreis. Edition und Kommentar. Hg. von Stefan Hannes Greil/ Martin Przybilski unter Mitarbeit von Theresia Biehl/Christoph Gerhardt/Mark Ritz. Mit einem Beitrag von Nikolaus Ruge. Berlin/Boston 2020 (im Folgenden: >F<; Unterstreichungen, die aufgelöste Abbreviaturen markieren, werden nicht übernommen). Folz-Neuzuweisungen erfolgen ebd., S. XVf.; für die Corpusbildung ist weiterhin relevant Janota, Johannes: »Hans Folz«. In: Kurt Ruh u. a. (Hg.): Die deutsche Literatur des Mittelalters. Verfasserlexikon. Bd. 2. 2., völlig neu bearb. Aufl. Berlin 1980, Sp. 769-793, hier Sp. 779. - Folgende 15 Spiele zeigen präzisere Regieangaben: F81, F83, F85, F86 (Fassung I), F87-F91, F95, F101, F102, F103 (Fassung I und II), F105, F111.

22 Vgl. Vier ungedruckte Fastnachtspiele des 15. Jahrhunderts. Hg. von Franz Schnorr von Carolsfeld. In: Archiv für Literaturgeschichte 3 (1874), S. 1-25 (im Folgenden: >S $<$ ). Es handelt sich um die drei Spiele S2-S4. - Zur Fastnachtspielüberlieferung, die »einerseits von der schmalen Einzel-Broschüre bis zum umfangreichen Sammel-Kodex und andererseits von der reinen Spiel-Handschrift bis zur gattungsübergreifenden Literatur-Sammlung [reicht]«, vgl. Simon (s. Anm. 19), S. 12-22; Habel, Thomas: »Vom Zeugniswert der Überlieferungsträger. Bemerkungen zum frühen Nürnberger Fastnachtspiel«. In: Stephan Füssel/Gert Hübner/Joachim Knape (Hg.): ARTIBVS. Kulturwissenschaft und deutsche Philologie des Mittelalters und der frühen Neuzeit. Festschrift für Dieter Wuttke zum 65. Geburtstag. Wiesbaden 1994, S. 103-134 (Zitat S. 110). Im Folgenden werden in der Regel nur die eingeführten Handschriftensiglen verwendet; für die Signaturen sei verwiesen auf die Übersicht bei Simon (s. Anm. 19), S. 87 f., und auf Habel (diese Anm.), S. 110-128. Online verfügbare Digitalisate sowie Hinweise zur kodikologischen Forschungsliteratur sind greifbar über den Handschriftencensus: http://www.handschriftencensus.de/ (12.07.2020).

23 Zur Typologie der Spielformen s. Catholy, Eckehard: Das Fastnachtspiel des Spätmittelalters. Gestalt und Funktion. Tübingen 1961, S. 142-163; Wuttke, Dieter: »Versuch einer Physiognomie der Gattung Fastnachtspiel«. In: Ders. (s. u. Anm. 35), S 441-462, hier S. 443-446. Die differenzierteste Unterscheidung in unverbundenes, verbundenes und handlungsorientiertes Reihenspiel sowie Handlungsspiel nimmt vor Habel, Thomas: »Zum Motiv- und Stoff-Bestand des frühen Nürnberger Fastnachtspiels: Forschungsgeschichtliche, methodische und gattungsspezifische Aspekte $\ll$. In: Theodor Wolpers (Hg.): Ergebnisse und Perspektiven der literaturwissenschaftlichen Motiv- und Themenforschung. Bericht über Kolloquien der Kommission für literaturwissenschaftliche Motiv- und Themenforschung 1998-2000. Göttingen 2002, S. 121-161, hier S. 147-156. 
gielenkender Nebentexte, insbesondere bei einer komplexen Ausformung mit »beträchtliche[n] bühnentechnische[n] Anforderungen«, wie sie vor allem für Folz' »Agitationsdrama $\ll^{24} »$ Der Herzog von Burgund « $(\mathrm{F} 88)^{25}$ bestehen. Ihre Ausprägung illustrieren folgende zufällig gewählte Beispiele:

Hie get ein das gluckßrat vnd des fursten figur stet oben vnd des messias vnden (F88,24f.)

Neithart spricht zu der hertzogin vnd setzt den feyel heimlich nieder vnd deckt jn mit eim hutlein zu $(\mathrm{F} 89,26)$

Die weil hat die meit die kupplerin geslagen. So spricht der eman zu der kupplerin vnd greint den reymen vnd schlechtz zu letz $(\mathrm{F} 95,38){ }^{26}$

also kumen zwu frawen vnd tretten hinzu. vnd die ein tregt ein kint an dem arm, DIE ANDER tregt das todt kind vnd legt es an die erden vnd hebt an zu klagen vor dem kunig vber die ander (S3, S. 14)

Ob Folz seinen eigenen Texten die Regieanmerkungen dieses Typs selbst beigegeben hat, ist nicht mit Sicherheit zu sagen. In den beiden Inkunabeln, die höchstwahrscheinlich aus seiner den eigenen Werken vorbehaltenen Offizin stammen, gehören die Zwischenüberschriften zu der von ihm verantworteten Ausstattung der für den Druck bestimmten, dezidierten Lektüretexte (1/1 »Weibernarren« F98; 1/2: »Weibernarren vor Venus« F96), bieten in dieser Frage aber keinen Anhalt, weil sie aus Ziffern (F98) oder einfachen Rollenbezeichnungen (F96) bestehen. Auch der Autograph X mit dem »Marktschreierspiel« (F109) hilft nicht weiter, insofern er als »Entwurf« des Folz-Stücks »Die Handwerker« (F99) keine Redeeinleitungen bietet $^{27}$ und auch die Bearbeitung F99 nur Rollennamen aufweist (z. B. Gotz Speckkuch Z. 59). Allerdings enthält der späte Druck b mit dem Folz-Spiel »Von einem Arzt und einem Kranken« (F111), der einem Erzeugnis der Folzschen Presse nach-

\footnotetext{
24 Simon, Eckehard: Die Anfänge des weltichen deutschen Schauspiels 1370-1530. Untersuchung und Dokumentation. Tübingen 2003, S. 314 (beide Zitate).

25 Die Spieltitel sind - der Vergabe von Hansjürgen Linke folgend - abgedruckt bei Glier, Ingeborg: »Rosenplütsche Fastnachtspiele«. In: Kurt Ruh u. a. (Hg.): Die deutsche Literatur des Mittelalters. Verfasserlexikon. Bd. 8. 2., völlig neu bearb. Aufl. Berlin 1992, Sp. 211-232, hier Sp. 211-214, sowie bei Janota (s. Anm. 21), Sp. 779 (leichte Anpassungen erfolgen in der Neuedition von Greil/Przybilski [s. Anm. 21]). Vgl. ferner die auch weitere Spiele berücksichtigende Gesamtübersicht in der Auswahledition Ridder/ Steinhoff (s. u. Anm. 35), S. 171-188.

26 In den in Anm. 21 genannten 15 Stücken von Folz und aus seinem Umkreis finden sich ca. 60 Regieangaben dieses präziseren Typs. Mitunter weist ein Spiel nur eine einzige dieser Angaben auf (z. B. F86,35), zumeist aber mehrere, in F88 sogar an die 20. Entsprechend lassen sich die Beispiele leicht vermehren: Das weyb wirff den pauren nyder vnd schlecht in, das er also schreit (F83,105); Messias trinckt, laufft auff vnd geschwilt vnd fellt hin (F88,304). Der mulner kumpt in der kutten vnd spricht zu dem apt (F90,195); $N w$ sitzt der mulner auff das wegenlein, so zyehen jn die pauren in die stuben fur den keyßer (F90,33); Der paur, der den dreck geschissen hat, der hebt jn auff, dicit (F91,180); Thumherr get auß vnd tut den langen mantel ab, als sej er der frauen man. kuplerin dicit zu der frawen (F95,60); Nu sucht der paur dem kremer jm korb vnd zeucht zwey stucklein herau $\beta(\mathrm{F} 101,66) ;$ Markolffus wirft dem glatzeten ritter auff den kopff (F103,32 Fassung I); Do kumen die zwu frawen. Die gut fraw spricht, so tregt die poß das kint. (F103,190 Fassung I); Marckolffus wirdt husten vnd ein glatzeter ritter spricht (F103,30 Fassung II).

27 Vgl. zu dieser Annahme Greil, Hannes/Przybilski, Martin/Ritz, Mark: »Kommentar«. In: Greil/ Przybilski (s. Anm. 21), S. 642-645, hier S. 642 (Rubrik »Textkritik«; Referat der Forschungsdiskussion in Rubrik »Autor $\ll)$.
} 
gedruckt worden sein dürfte, ${ }^{28}$ mehrere präzise Regieangaben. ${ }^{29}$ Schließlich sind die für Folz gesicherten Stücke entweder unikal bezeugt, weshalb Lesarten aus Parallelzeugen nicht vergleichend hinzugezogen werden können, oder - dies im Fall der drei mehrfach überlieferten Folz-Stücke (F86, F96, F98) - die Textvarianz ist marginal, weil es sich um Nachdrucke oder Druckabschriften handelt. ${ }^{30}$ Aber Folz' Spiel »Die Bauernhochzeit« (F86) liegt in zwei Fassungen vor, deren zweite (Ga) wegen »zahlreiche[r] Änderungen [...] eine gezielte Nachbearbeitung und Verbesserung $\ll^{31}$ der ersten $(\mathrm{Gb})$ darstellen dürfte. Insbesondere aufgrund »präzisierte[r] Sprecheranweisungen« nehmen die Bearbeiter der Neuedition an, dass »die ältere Fassung I weiterentwickelt wurde, in Folzens Druck erschien und von Ga abgeschrieben wurde. Der dem Autor nahe stehende Schreiber Gb hatte ferner Zugriff auf den Entwurf und steuerte eine Abschrift bei.« ${ }^{32}$ Weil nun tatsächlich Handschrift Gb, in der die meisten der 31 Spiele von Folz und aus seinem Umkreis überliefert sind, der Hauptzeuge für den ausführlichen Regieangaben-Typ ist, ${ }^{33}$ diese zugleich aber in keinem Spiel der frühen Tradition begegnen (Rosenplütsche Fastnachtspiele, s.u.), für die $\mathrm{Gb}$ ebenfalls ein wichtiger Überlieferungsträger ist, ${ }^{34}$ darf ein handschriften- und corpus-, mit Einschränkung auch ein handschriften- und autorbezogener Zusammenhang angenommen werden, hinter dem vielleicht die medienspezifische Ausrichtung auf die Erfordernisse eines im Druck verbreiteten Lesetextes steht.

Den strukturell vielfach einfacher gestalteten Spielen aus der frühen Nürnberger Spieltradition - d.h. den 76 sogenannten Rosenplütschen Fastnachtspielen, ${ }^{35}$ welche unter dem Namen des um ein oder zwei Generationen älteren Handwerkerdichters

${ }_{28}$ Vgl. Greil, Hannes/Przybilski, Martin: »Kommentar«. In: Greil/Przybilski (s. Anm. 21), S. 678-658, hier S. 678 (Rubrik »Datierung«).

${ }^{29}$ Zum Beispiel Hie stossen sie den krancken mit der krucken von der panck $(\mathrm{F} 111,69)$; ferner Z. 107, 387.

${ }^{30} \mathrm{Vgl}$. dazu die Ausführungen in den Endkommentaren zu den drei Spielen bei Greil/Przybilski (s. Anm. 21), S. 121, 337, 366 (jeweils Rubrik »Textkritik«).

31 Greil, Hannes/Przybilski, Martin: »Kommentar«. In: Greil/Przybilski (s. Anm. 21), S. 121-127, hier S. 121.

32 Ebd.

$33 \mathrm{Vgl}$. auch Habel (s. Anm. 22), S. 119, Anm. 73.

34 Die 28 in Handschrift G überlieferten Stücke sind der Übersicht bei Simon (s. Anm. 19), S. 88-90, zu entnehmen. Dass Gb aber auch für die frühe Tradition zu präziseren Angaben tendiert, zeigt die Textvarianz einiger ausgewählter Redeeinleitungen des Stücks »Eheliche Verdächtigungen « (K19, R/S5; D, B1. 199v-203v; Wa, B1. 120v-121v, 128r-131v; Gb, B1. 105r-109v): Die kupplerin (D) - 10 kupplerin (Wa) - Die kuplerin kumpt vnd dicit (Gb); Die kupplerin (D) - 12 (Wa) - Die kuplerin dicit tzu der haußmeid (Gb); Die eefrau (D) - 13 mulier (Wa) - Die efraw enpfecht iren man (Gb); Die hawßmeÿt (D) - 15 ancilla (Wa) - Die haußmeit spricht zum herren $(\mathrm{Gb})$. Zur Logik des Bezifferungsverfahren in Handschrift W vgl. Catholy (s. Anm. 23), S. 234.

35 Eine kommentierte Neuedition, an der die Verfasserin mitarbeitet, wird an der Universität Tübingen vorbereitet. Die nachfolgenden Ausführungen stützen sich auf die im Rahmen der Kommentierungsarbeit zusammengetragenen Aufführungshinweise. Vorerst ist die Zitiergrundlage Fastnachtspiele aus dem fünfzehnten Jahrhundert. Hg. von Adelbert von Keller. 3 Tle. und Nachlese. Stuttgart 1853-1858 [Nachdr. Darmstadt 1965-1966] (im Folgenden: $>\mathrm{K} \prec$ ). Moderne Auswahleditionen bieten Fastnachtspiele des 15. und 16. Jahrhunderts. Unter Mitarbeit von Walter Wuttke, ausgewählt und hg. von Dieter Wuttke. 6. Aufl. Stuttgart 1998 (im Folgenden: >W $\prec$ ), sowie Frühe Nürnberger Fastnachtspiele. Zusammen mit Oliver Huck u. a. hg. von Klaus Ridder/Hans-Hugo Steinhoff. Paderborn u. a. 1998 (im Folgenden: >R/S $<$ ). 
Hans Rosenplüt (ca. 1400 - ca. 1460) überliefert oder als von ihm beeinflusst einzuordnen sind ${ }^{36}$ - fehlen hingegen, abgesehen von einer zu relativierenden Ausnahme (s.u.), Regieangaben des ausführlicheren Typs. Der Großteil der überlieferten Spieltexte ist nur mit einfachen Sprecherbezeichnungen in inquit-Formeln ausgestattet, d.h. mit jenem elementaren Typ, der das »Minimum von Nebentext ${ }^{37}$ bildet (und auch in der Folz-Tradition am häufigsten vorkommt). Einige Handschriften bezeugen nicht einmal dies. ${ }^{38}$ Wo die einfachen expliziten Rollenbezeichnungen anzutreffen sind, handelt es sich um $^{39}$

- eine durchlaufende numerische Zählung der Sprechpartien in Ziffern, ${ }^{40} \mathrm{zu}$ meist aber mit Zahlworten (der erst, der ander, der dritt usw.),

- einen typisierten (z. B. der narr, ein paur, der puoler, der richter, die frau, der eeman) oder individuelleren (z. B. die kremerin, die siech frau, der vater, der bote, der burgermaÿster zu N., der grostt liebhaber, die künigin von Zypern) Figurennamen, auch eine Figurengruppe (z. B. die frauen, die man, zwen purger, die schergen, die jüden, die lamen und plinden)

- eine Personifikation (z. B. die faßtnacht, die fast, die grün, frau Sunnreich), - einen Personennamen (z. B. Eberspis von Erleinstegen, der docter Strutzel die junckfrau Geut, die Diemut, Elias, Aristotelis),

- einen Satznamen, dessen Textstruktur auf der Rollenidentifizierung mittels eines Gegenstands oder einer sozialen Funktion basiert (Die frau mit dem apfel K14, 121,16; Die auf dem esel K26, 228,14; Der diener mit der kron K80, 655,20; Der mit dem ersten brunn K85, 696,18; vgl. 697,10, 698,8; Der dem kaiser daz schwert vortregt $\mathrm{K} 78,645,26$ ) oder

- eine Objektbezeichnung mit kommunikativer Funktion (Der prief K100, $766,1)$.

\footnotetext{
${ }^{36}$ Vgl. Glier (s. Anm. 25), Sp. 217; zur Unschärfe der Zuschreibungskriterien ebd., Sp. 216f. Weil lediglich ein Spiel eine Autorsignatur aufweist (»Das Fest des Königs von England« K100), werden für die Zugehörigkeit zur frühen Spieltradition sammlungsbezogene (autor- oder gattungszentrierte Handschriften, darunter der Cgm 714 [M] mit Verfasserzuweisung im Spielregister) und stilistische Aspekte zugrunde gelegt, vgl. Michels, Victor: Studien über die ältesten deutschen Fastnachtspiele. Straßburg 1896, S. 119-214; Catholy (s. Anm. 23); Simon (s. Anm. 19), S. 70-86. Zum Corpus s. im Einzelnen ebd., S. 88-90; Glier (s. Anm. 25), Sp. 211-214.

37 Pfister (s. Anm. 13), S. 37. Zur historischen Entwicklung der Sprecherbezeichnungen s. im knappen Überblick Detken (s. Anm. 13), S. 13-16.

38 Als nicht zufällig ist der Befund zu bewerten, dass alle der partiell oder vollständig ohne Sprecherangaben (abgesehen von der zumeist unbezeichneten Einschreierrede, vgl. dazu Simon [s. Anm. 19], S. 28 mit Anm. 26f.) überlieferten Spielaufzeichnungen bis auf eine Ausnahme, dem unikal im Folz-Autograph X überlieferten, wohl einen Entwurf darstellenden Stück F109 (vgl. Greil/Przybilski/Ritz [s. Anm. 27]), den Handschriften der Rosenplüt-Tradition zuzurechnen sind (insgesamt 16 Spiele in mindestens einem Textzeugen), vgl. Simon [s. Anm. 19], S. 27f. mit Anm. 23-25, 28. Die Spiele von Folz und aus seinem Umkreis sind neben einigen, stets mit Sprecherangaben aufbereiteten Drucken ausschließlich in Handschrift G (Schreiber Ga und Gb) überliefert, in der in der Regel Redeeinleitungen stehen (Ausnahme: F94, s.u.).

$39 \mathrm{Vgl}$. im Einzelnen Blosen, Hans/Pors, Harald: Rollenregister zu Adelbert von Kellers Sammlung: Fastnachtspiele aus dem 15. Jahrhundert. Göppingen 1981.

${ }^{40}$ Der Fall ist in den Handschriften der frühen Spieltradition höchst selten, z. B. Handschrift W (vgl. Anm. 34).
} 
Nicht selten sind verba dicendi hinzugesetzt (in der Regel in Verbzweitstellung), welche die Rollenbezeichnung zur inquit-Formel erweitern: zumeist das »Standardinquit-Verb im Mittelhochdeutschen $\aleph^{41}$ spricht oder als lateinisches Äquivalent $d i$ cit und ferner die Sprechaktbezeichnungen antwurt bzw. thut/geit (die) antwurt, bit, clagt, danckt, enpfecht, fragt (rats), ruft, sagt, ${ }^{42}$ urteilt. Während spricht/dicit »semantisch neutral «33 bleibt, spezifizieren die übrigen Verben die kommunikative Funktion der Sprachhandlungen und bestimmen teilweise, aber nur vage, die zugehörige Qualität von Intonation und Emphase. Dass zwischen der illokutionären Sprechabsicht und der lokutionären Sprechäußerung genau differenziert wird, zeigt die Redeeinleitung Der anclager clagt sprechend (K10, 98,31). Auch dienen in den Gerichtsspielen die rechtssprachlichen Bezeichnungen der Sprachhandlungen - clagt (Darlegung der Klage), antwurt (Verteidigungsrede) und fragt (Urteilserfragung) nicht nur der Wiedergabe von Rechtswirklichkeit im gerichtlichen Verfahren, sondern bilden auf lexikalischer Ebene wesentlich die Spielstruktur ab, die sie auf semantischer Ebene zugleich erzeugen.

Aber auch Rollenangaben ohne verbum dicendi kommen nicht selten vor und sind in der umfangreichen Spielhandschrift M (Cgm 714) bis auf ganz vereinzelte Ausnahmen sogar die Regel (s.u. 5). Sie lassen sich als (elliptisch verkürzte) inquit-Formeln verstehen, ${ }^{44}$ weil sie in gleicher Funktion wie diese den Rede-Einsatz markieren und in diesem Sinne Sprech-Anweisungen bilden. Dabei erfordert es die Spielstruktur - vor allem wenn individuellere Einzelfiguren und mehrere typisierte Rollencharaktere zusammen auftreten oder wenn sie auf der mehrfachen Wiederholung kleinerer gleichaufgebauter Szene-Einheiten basiert - die Kombination der genannten Typen in einer Rollenangabe (z. B. Der erst nachpaur spricht K66, $574,19)$, und ebenso kommen in einem Spiel verschiedene Typen vor, ${ }^{45}$ ohne dass jedoch darüber hinaus eine systematische Verwendung zu erkennen wäre.

Explizite Regieangaben, unter denen hier alle requisiten-, körper- oder bewegungsbezogenen Erweiterungen der bloßen Sprecherbezeichnung oder der inquit-

\footnotetext{
41 Hundsnurscher, Franz: »Das literarisch-stilistische Potential der inquit-Formel«. In: Nine Miedema/ Franz Hundsnurscher (Hg.): Formen und Funktionen von Redeszenen in der mittelhochdeutschen Großepik. Tübingen 2007, S. 103-115, hier S. 105.

42 Die nur in Redeeinleitungen von K63 (dreimal) vorkommende Form sagt bezeichnet dort einen Sprechakt, der die Äußerung des Redesinns betont und auf Erläuterung zielt, vgl. Anm. 53. Es handelt sich nicht um das sich im inquit-System des Frühneuhochdeutschen gegenüber sprechen durchsetzende sagen, vgl. dazu Hundsnurscher, Franz: »Sprechen und sagen im Spätmittelalter und in der frühen Neuzeit. Zum Wechsel der inquit-Formel er sprach / er sagte«. In: Nine Miedema/Rudolf Suntrup (Hg.): Literatur - Geschichte - Literaturgeschichte. Beiträge zur mediävistischen Literaturwissenschaft. Festschrift für Volker Hohnemann zum 60. Geburtstag. Frankfurt a. M. u. a. 2003, S. 31-52, hier S. 42-45.

43 Urscheler, Andreas: Kommunikation in Wolframs »Parzival«. Eine Untersuchung zu Form und Funktion der Dialoge. Bern u. a. 2002, S. 52, 54.

44 In der Wortfrequenz-Analyse von Simon handelt es sich um die »Ein-Wort-Regieanweisung « und die »Zwei-Wort-Regieanweisung«, bestehend aus der Rollenbezeichnung, die gegebenenfalls mit einem Artikel versehen ist, vgl. Simon (s. Anm. 19), S. 30.

45 Zum Beispiel besonders deutlich im Stück »Des Entchrist Vasnacht« (K68).
} 
Formel verstanden werden sollen, ${ }^{46}$ zeigt die umfangreiche frühe Spieltradition dagegen weitaus seltener als die späte und überwiegend in handlungsorientierten Reihenspielen und Handlungsspielen. Dort erfolgt gelegentlich die Angabe

- eines oder mehrerer Adressaten, die eine Geste der Hinwendung impliziert (z. B. Die efrau enpfecht iren man K19, 164,23; Der putel rufft den dreyen mannen K42, nach 321,6 [Lesart Kb, Bl. 117r] ${ }^{47}$ Der official Spricht zu der frawen K42, 327,23 [Lesart Kb, B1. 121r]; Der münch zum preutigan K66, 577,9; Der bischof fragt seinn caplan K68, 604,948; Der bruder antwort der kunigin K80, 662,14; Die frawen dancken dem richter vnd denn schopffen K87, 707,28 [Lesart $\left.\mathrm{Kb}, \mathrm{Bl} .132 \mathrm{r}]^{49}\right),{ }^{50}$

- zur Dialogstruktur (So spricht er wider/darauf K26, 229,6.16u. ö.),

- einer Figurenbewegung oder -handlung (nur folgende Fälle: Der tot steet auf und spricht K68, 607,7; Ein herolt tregt das pild dar et dicit K17, 146,10; Das weip kumt, dicit $\mathrm{K} 31,253,12^{51}$ ), auch ohne verbum dicendi zumeist als Redeeinleitung (im Wesentlichen folgende Fälle: Der kneht zaigt di erst puchs K82, 680,14, ebenso 680,23.30, 681,3; Da tregt man zum artzt K82, 683,28; Der eman setzt sich hintern tisch $\mathrm{K} 31,252,22)$,

46 Vgl. diese Unterscheidung auch bei Williams-Krapp, Werner: Überlieferung und Gattung. Zur Gattung >Spiel< im Mittelalter. Mit einer Edition von »Sündenfall und Erlösung « aus der Berliner Handschrift mgq 496. Tübingen 1980, S. 7 Anm. 4.

47 Mit folgenden Worten ruft der Gerichtsbüttel im Spiel »Das Chorgericht I« (K42) die drei Beklagten auf: Herman Sumerglanz,/ Dietrich Seidinswanz,/ Eberhart Bluomental,/ Verantwurtet euch vor dem official! (321,7-10).

48 In diesem Fall (»Des Entchrist Vasnacht«) markiert die Regieangabe den Adressatenwechsel innerhalb einer eigentlich zusammenhängenden, für ihren ersten Teil mit Der bischof überschriebenen Sprechpartie: Der Bischof spricht zunächst (mit einem Reimpaar) den Entkrist und dann (mit drei Reimpaaren) seinen Kaplan an. Die Präsentationsweise auf dem Handschriftenblatt (M, B1. 319r) mit der zwischengestellten Regieangabe, die den Adressatenwechsel transparent macht, stellt daher eine Lesehilfe dar. - Ein anderes Verfahren, den Adressatenwechsel zu regeln, liegt vor, wenn zwar die optische Separierung der betreffenden Redeanteile auf dem Handschriftenblatt unterbleibt, die erweiterte inquit-Formel aber beide Adressaten zugleich nennt: Der kneht zum baurn[,] zum arzt (K82, 686,9; Ergänzung R. N.). Hier muss der lesende Rezipient (ebenso wie Spielleiter und Darsteller) die Zuordnung, welche Reimpaarsegmente an den ersten und welche an den zweiten Adressaten gerichtet sind, selbst vornehmen.

49 Hier, im Spiel »Die verhinderten Ehemänner«, entbehrt die explizite Regieangabe nicht einer gewissen (proleptischen) Redundanz, wenn sie die implizite Regieangabe des Redetextes aufgreift, der mit folgendem performativen Sprechakt einsetzt: Herr der richter, wir wollen euch imer danken/ Und auch den schöpfen in den schranken (K86, 707,29f.; Wortlaut in Kb identisch).

50 Dieser Typus, den gelegentlich auch das verbundene Reihenspiel zeigt, kommt in 12 Spielen vor, neben den aufgeführten außerdem in K10, K17, K26, K30, K31, K81 und K89.

51 Das Handlungsverb kumpt ist die gängige Bezeichnung für den Bühnenauftritt, das Hervortreten auf die Spielfläche, vgl. Mauermann (s. Anm. 19), S. 35 f. Vgl. die Beispiele in Anm. 26 und 34 sowie ferner Die kuplerin kumpt und dicit (K19, 163,19); Hie kumen zwen[] anclager (K24, 220,11; Ergänzung R. N.); Da kümpt der Entkrist zum volk $(\mathrm{K} 68,595,25)$. Vgl. auch oben die Regieangaben aus der späten Spieltradition. 
- zur Rollenfunktion (Der antworter spricht für die frau K27, 235,11; Das mù s der herolt sein vnd des turggen wauppentrager vnd ain gemalten stab $\mathrm{Ga} / \mathrm{Gc}$, B1. $188 \mathrm{v}^{52}$,

- des Redeinhalts (Er sagt des ersten konigs conplex K17, 142,21 ${ }^{53}$ ) oder

- (nur in K3) der Körperaktionen mehrerer Figuren und ihrer Abfolge (Itzund slecht der erst paur sein weib und kumpt ein ander paur und scheidt 44,8). ${ }^{54}$

Im letzten Fall, der nur im Spiel »Ehekrieg « (K3) vorkommt, weisen die Regieangaben die Struktur genau jenes mehrere Figurenbewegungen summierenden Typs auf, der für die Spiele von Hans Folz und aus seinem Umkreis signifikant ist (s. o.). Das Stück, das mit Gerd Simon als den Rosenplütschen Fastnachtspielen zugehörig gerechnet wird, ${ }^{55}$ wäre damit allerdings die einzige Ausnahme in der umfangreichen frühen Tradition mit dieser ausführlicheren Nebentextausstattung. Weil es auch weitere Merkmale aufweist, die nur das Corpus der Spiele von Folz und aus seinem Umkreis zeigt, ${ }^{56}$ es ferner in engem inhaltlich-thematischen Zusammenhang zu den Folz nahestehenden Stücken »Das böse Weib« (F83) und »Der Ehestreit« (F84) steht und nicht zuletzt Handschrift Gb, der Hauptzeuge für diesen Regieangabentyp, sein (einziger) Überlieferungsträger ist, sind abweichende Zuweisungen zur späten Tradition $^{57}$ in Perspektive des spielbezogenen Nebentextes belastbar.

52 Diese Einleitung überschreibt im siebenmal überlieferten Stück »Des Türken Fastnachtspils« (K39) die Rede des Einschreiers, der als Wappenträger und Herold des türkischen Kaisers auftritt. Es handelt sich um einen Nachtrag von der Hand Claus Spauns (s. u. 4) zur Abschrift des Schreibers Gc. Spaun nahm diese Redeeinleitung auch in die Abschrift des Schreibers Ac (B1. 135v) wieder auf.

53 Vgl. in »Das Aristotelesspiel« (K17) ferner die im Wesentlichen gleichgestalteten Regieangaben zum zweiten bis vierten König: Do sagt er des andern konigs conplexen (142,29), Des dritten konigs conplex $(143,2)$, Des vierden konigs conplex sagt Aristotiles (143,9). Die vier Angaben gliedern die lange, 31 Verse umfassende Rede des Meisters Aristoteles $(142,18-143,19)$, in der er nacheinander die complex von vier Königen erläutert (sagt), in fünf Sprechpartien; wie es die wiederholte Anrede (Eur, Her kunig) nahelegt, dürfte sich der Aristoteles-Darsteller den einzelnen König-Darstellern mit entsprechender Gestik zuwenden. Den Beginn seiner Rede bildet die erste, nur aus einem Reimpaar bestehende Sprechpartie mit der Ankündigung des Unternehmens (Ich sag euch allen in kurzer frist,/ Was eur conplex ist 142,19f.). Sie ist mit der Sprecherbezeichnung Aristoteles dicit $(142,18)$ überschrieben, auf die sich das Personalpronomen er der Regieangaben als Mittel der Referenzialisierung rückbezieht. - Während Simon (s. Anm. 19), S. 36, die Zugehörigkeit des Stücks zur frühen Spieltradition für wahrscheinlich hält, stellt Bernhard Sowinski es aufgrund seines komplexen Aufbaus in die Nähe der Folz-Stücke, vgl. Sowinski, Bernhard: »Zur Stofftradition und Handlungsstruktur des Fastnachtspiels >Von fürsten und herren« (Keller 17). In: Joseph P. Strelka/Jörg Jungmayr (Hg.): Virtus et Fortuna. Zur Deutschen Literatur zwischen 1400 und 1720. Festschrift für Hans-Gert Roloff zu seinem 50. Geburtstag. Bern 1983, S. 106-117, hier S. 115.

54 Ferner: Nu klagt die schwiger die tochter und die weil schimpft der erst paur mit den/ meiden und das ersicht sie und spricht also (K3, 44,17f.); Do sicht sie den pauren mit den meiden schimpfen und spricht (K3, 44,35); Do schlecht die frau den man und ein paur schaidt und spricht (K3, 45,33). Vgl. auch Des pauren weib, die jung peurin, spricht zu dem man (K3, 41,32).

55 Vgl. Simon (s. Anm. 19), S. 90; Glier (s. Anm. 25), Sp. 213.

56 Zum Beispiel: Interjektionen wie samer pox trost (K3, 42,23), Flüche wie Der teufel schlah zu solchem spil! $(\mathrm{K} 3,44,3)$ und Beschimpfungen wie Ach du verheiter, herkumer schalk,/ Das man dir nit zerzaust dein palk (K3, 42,34f.).

57 Vgl. die Argumente bei Michels (s. Anm. 36), S. 214, 226, 229f.; Catholy (s. Anm. 23), S. 150f., 182, 185; Janota (s. Anm. 21), Sp. 779. 
Die expliziten Regieangaben der Rosenplütschen Fastnachtspiele geben weder Hinweise auf die Bühnenausstattung und -raumbildung, die Kostümierung oder die äußere Erscheinung der Rollenträger noch auf die Vortragsweise. Trotz eines differenzierteren Spektrums verwendeter verba dicendi sind Informationen zu Lautstärke oder emotionaler Ausdrucksweise nur latent inbegriffen. Requisiten werden äußerst selten genannt (Apfel, Bild, Esel, Harnglas, Heroldsstab, Krone, Salbentigel, Schwert, Tisch, Wappen) und stärker in den impliziten Angaben der Sprechtexte eingeführt wie beispielsweise das für die Tugendprobe des Spiels »Luneten Mantel« (K81) zentrale Mantel-Requisit. ${ }^{58}$ Mit Blick auf ihren propositionalen Gehalt geben die wenigen expliziten Regieangaben im Wesentlichen lediglich eine Adressatenhinwendung oder eine einfache, d. h. nicht in einer zeitlichen oder kausalen Abfolge mit weiteren (im selben Nebentext genannten) Figurenhandlungen stehende Figurenbewegung vor. Im Unterschied zur Nebentextausstattung anderer mittelalterlicher Spieltraditionen, etwa der liturgischen Dramen oder einiger geistlicher Spiele, sind die in den Rosenplütschen Fastnachtspielen überlieferten expliziten Angaben somit kein »vorrangiges Mittel zur Bestimmung von Inszenierung und Regie «. ${ }^{59}$

Hingegen enthalten die Haupttexte selbst, die entsprechend ihrer genuinen Anlage ihr dramatisches Potenzial als Sprachhandlung erst in der Realisierung einer Performanzsituation voll entfalten, vielfach implizite Aufführungshinweise. Sie stellen »die Konstituierung der Sprechsituation im Sprechakt $\ll^{60}$ sicher. Über ein differenziertes methodisches Instrumentarium lassen sich aus ihnen begründete, der Spekulation weitgehend enthobene Aussagen zu einer möglichen Ausformung der Inszenierung ableiten. Auch insgesamt ist man für die Nürnberger Fastnachtspiele des 15. Jahrhunderts in Performanzfragen in erster Linie auf die Sprechtexte angewiesen, machen doch die sekundären Spielbelege der Nürnberger Akten nur ganz vereinzelt (und nur zur Kostümierung) Angaben dazu. ${ }^{61}$ Das prominente Beispiel für konkrete Beschreibungen innerhalb der Redetexte ist der Entwurf des Aufführungsorts, die Wortkulisse zu Beginn des Folz-Spiels »Ecclesia und Synagoga« (F81, 3-16). Daneben ergeben sich Aufführungsbezüge aus dem auf Figurentypen ausgerichteten $»$ mimischen Charakter der Sprache $«,{ }^{62}$ eventuell auch aus dem Redegestus der $»$ gesprochene[n] Sprache $«{ }^{63}$ und vor allem aus jenen impliziten Angaben etwa zu Rollenbesetzung und -identifizierung, Figurenauftritt und -abgang, Figurenbewegung, nonverbalem Bühnengeschehen und ebenso zu Requisiteneinsatz und Kostü-

\footnotetext{
58 Gleich zu Beginn führt der Einschreier mit deiktischem Duktus das zentrale Requisit ein: Ir herrn, wolt ir schweigen und betagen,/Ich wolt euch hübsch obenteur sagen./ Es ist her kumen ain magethein,/ Die hat den allerhübschten mantel fein./ Wolt es euch nit verschmohen, frauen und herrn,/Die maget wolt euch den mantel vereern,/ Den zarten frauen wol gethan;/ [...] (K81, 664,4-10). Es gibt keine Angaben dazu, wie die unterschiedliche Passform des Mantels in der Aufführung realisiert wurde oder ob es sich um gesprochene Passformen handelt, die die Zuschauer imaginieren sollten.

59 Nowé (s. Anm. 18), S. 357, vgl. auch S. 330.

60 Pfister (s. Anm. 13), S. 37.

61 Vgl. dazu den Belegkatalog bei Simon (s. Anm. 24), S. 291-348, sowie die zugehörige Auswertung ebd., S. 420-443.

62 Catholy (s. Anm. 23), S. 84.

63 Ruge, Nikolaus: »Zur Sprache der vorreformatorischen Nürnberger Fastnachtspiele (Folz und Anonymi)«. In: Greil/Przybilski (s. Anm. 21), S. LI-LXXXVI, hier S. LXXIX-LXXXI.
} 
mierung. Den Erkenntniswert, den die Betrachtung gerade dieser Textebene für die Spielinterpretation birgt, zeigen die exemplarischen Untersuchungen von Eckehard Catholy, Johannes Merkel und insbesondere Johannes Janota auf ${ }^{64}$ sowie jüngst die für jedes Spiel vorgenommenen aufführungsbezogenen Auswertungen in der von Hannes Greil und Martin Przybilski herausgegebenen Neuedition der Nürnberger Fastnachtspiele von Folz und aus seinem Umkreis. ${ }^{65}$

\section{Performanzstrategien}

In die Diskussion um die Bewertung des obigen Befundes kaum vorhandener expliziter Regieangaben in der frühen Spieltradition, der auch auf eine Reihe von Spielen aus der späten Spieltradition zutrifft, ist einerseits die Überlegung eingebracht worden, ob ein Großteil der relevanten Informationen zur konkreten inszenatorischen Umsetzung gar nicht schriftlich festgehalten, sondern »gewohnheitsmäßig mündlich weitergegeben ${ }^{66}$ wurde, und andererseits, ob »diese[ ] Textebene dem Literarisierungsprozess zum Opfer gefallen ist $\ll .{ }^{67} \mathrm{Hinzu}$ tritt die - das Vermögen gesprochener Aufführungshinweise, Bühnenwirklichkeit performativ herzustellen, ins Blickfeld rückende - Auffassung, »durch die verbalen Parallelhandlungen erübrig[t]en sich [...] ausführliche Beschreibungen der praktischen Handlung « ${ }^{68}$ Auch der Textstatus der expliziten Rollen- und Regieangaben ist unklar. G. Simon hat gezeigt, dass sie aufgrund mitunter fehlerhafter, dem Redetext widersprechender Angaben sowie aufgrund teils erheblicher Überlieferungsvarianz vielfach nicht aus der Textschicht originärer Spielvorlagen und Rollenskripte resultieren, sondern im Zuge der nachgelagerten Aufzeichnung und Archivierung im Sammlungskontext einer Handschrift von Schreibern oder Bearbeitern ergänzt worden sind. ${ }^{69}$ Schließlich kommen lateinische Angaben - abgesehen vom beigefügten dicit - nur in Handschrift W vor

64 Vgl. Catholy (s. Anm. 23), passim; Merkel (s. Anm. 20), S. 88-143 passim (mit Blick auf die Aufführungskomik); Janota, Johannes: »Performanz und Rezeption. Plädoyer für ihre Berücksichtigung im Kommentar zur Edition spätmittelalterlicher Spiele. Die Nürnberger Fastnachtspiele als Beispiel«. In: Klaus Ridder (Hg.): Fastnachtspiele. Weltliches Schauspiel in literarischen und kulturellen Kontexten. Tübingen 2009, S. 381-402. Eine Analyse der impliziten Regieangaben im »Redentiner Osterspiel« hat Nowé (s. Anm. 18) unternommen.

65 Zur Nürnberger Aufführungspraxis vgl. allgemein Greil/Przybilski (s. Anm. 21), S. XXXVIII-XL, sowie zum Inszenierungspotenzial der einzelnen Spiele ebd. jeweils im Endkommentar die Rubrik »Aufführungshinweise«. Eine Studie, welche die Nürnberger Fastnachtspiele des 15. Jahrhunderts insgesamt und umfassend nach systematischen Gesichtspunkten auf Performanzaspekte hin untersuchte und Kriterien für den methodischen Zugang samt einer adäquaten Terminologie entwickelte, steht bislang aus.

66 Catholy (s. Anm. 23), S. 11.

67 Coxon, Sebastian: »Weltliches Spiel und Lachen. Überlegungen zur Literarizität, Theatralität und Performativität des Nürnberger Fastnachtspiels im 15. Jahrhundert«. In: Ridder (s. Anm. 64), S. 221-238, hier S. 229.

68 Knühl, Birgit: Die Komik in Heinrich Wittenwilers »Ring « im Vergleich zu den Fastnachtspielen des 15. Jahrhunderts. Göppingen 1981, S. 268. Vgl. ähnlich auch das Ergebnis der Analyse expliziter und impliziter Regieangaben im »Redentiner Passionsspiel« von Nowé (s. Anm. 18), bes. S. $357 \mathrm{f}$.

69 Vgl. Simon (s. Anm. 19), S. 27-35. Dass wie in der Hessischen Spielgruppe Gestaltungsunterschiede auf die theatrale Realisation durch die Spielleiter zurückzuführen sind (vgl. Schulze [s. Anm. 18], S. 31), lässt sich anhand des Materials der frühen Nürnberger Fastnachtspiele nicht erweisen. 
und dort nur als Rollenbezeichnung. ${ }^{70}$ In den Rollen- und Regieangaben stellt der Gebrauch der Volkssprache deshalb ein signifikantes Textualitätssignal für die frühe Nürnberger Spieltradition dar. ${ }^{71}$ Es lässt darauf schließen, dass die Nebentexte »für dieselbe Rezeptionsform und die gleichen Adressaten bestimmt sind wie der Haupttext $\ll .{ }^{72}$ Die damit verbundenen intendierten Performanzstrategien des dramatischen Fastnachtspiel-Dispositivs sollen im Folgenden an drei Spielen aufgezeigt werden.

Beispiel 1: Wenn auch die Rollenangaben der frühen Spieltradition, einzeln betrachtet, einen relativ geringen propositionalen Gehalt besitzen (s.o.), können sie zusammen »- für sich gelesen - ein episches Gerüst der gespielten Vorgänge $^{73}$ ergeben. Selbst die knappen Sprecherbezeichnungen lassen sich als ein narratives Strukturgeflecht verstehen, das die Art der inszenatorischen Realisierung zu entscheiden vermag: So dient in einigen Handschriften die durchgehende Zählung der Sprechpartien zunächst einmal deren numerischer Indexierung. Im Fall nacheinander auftretender Einzelsprecher besitzt sie jedoch auch einen darüber hinausgehenden Informationswert, der nicht nur die Anzahl der Figurenauftritte bestimmt, sondern vor allem auch die semantische Struktur des Reihumauftritts mit einfachstem Gestaltungsmittel augenfällig macht (s.u. 6). Dass sich aber beim Rezipienten Irritationen ergeben, sobald die Zählung in Diskrepanz zu Mehrfachauftritten einer Figur oder zur unterlegten Dialogstruktur steht, illustriert das Spiel »Der kurze Hahnentanz« (K89). Angesichts der für die Spieltexte der frühen Tradition signifikanten theatralen Textaufbereitung, bei der selbst einfache Nebentexte zur Figurenbewegung selten sind, tragen ebendiese, so vorhanden, umso entscheidender zum Inszenierungsentwurf bei. In den beiden Textzeugen, M (Bl. 406v-409v) und Kb (Bl. 139r-141v), führen bei gleicher Reihenfolge der Sprechtexte zwei divergierende Regieangaben zu einer vollkommen anderen inszenatorischen Darbietung: ${ }^{74}$

Einschreier: unbezeichnet $(\mathrm{M})$ - unbezeichnet $(\mathrm{Kb})$

Der erst $(\mathrm{M})-$ Der erst spricht $(\mathrm{Kb})$

Der ander $(\mathrm{M})-$ Der ander spricht $(\mathrm{Kb})$

Der dritt $(\mathrm{M})-$ Der dritt spricht $(\mathrm{Kb})$

Der vierd $(\mathrm{M})$ - Hÿe pit er die jungkfrawen mit ÿm zu ta $\langle n\rangle c z e n(\mathrm{~Kb})$

D̈̈e fraw $(\mathrm{M})$ - Die jungkfraw antwort $(\mathrm{Kb})$

Der funfft $(\mathrm{M})-$ Er antwort jr $(\mathrm{Kb})$

\footnotetext{
70 Vgl. das Beispiel in Anm. 34.

71 In den Spielen der Folz-Tradition finden sich hingegen gelegentlich Regieangaben in (teils fehlerhaftem) Latein, z. B. stellenweise in »Die Heilung eines kranken Bauern« (F85): Hulletusch, $2 s$ [= secundus] servus (Z. 48, Auflösung R. N.), Idem laycus (Z. 100), Et silet parum aspicundo. Viuiam (Z. 166); oder durchgehend in Folz' »Der Ehevertrag «(F102), z. B.: Hans Knot, pater, vocat filium suum dicens (Z. 24), Tunc accidentes habent $[$ es] consilium et eunt ad \langle\rangle sponsum et pater sponse. Nagjmarß dicit (Z. 59, vgl. den Kommentar zu Stelle sowie Greil, Hannes/Przybilski, Martin: »Kommentar«. In: Dies. [s. Anm. 21], S. 434-439, hier S. 434). Sie kommen nur in Handschrift Gb vor, vgl. Habel (s. Anm. 22), S. 119, Anm. 73.

72 Toepfer (s. Anm. 18), S. 114 (zum »Donaueschinger Passionsspiel«).

73 Schulze (s. Anm. 18), S. 32, mit Blick auf sehr viel ausführlichere und umfangreichere epische Nebentexte im geistlichen Spiel.

74 Vgl. auch Simon (s. Anm. 19), S. 31.
} 
Die fraw/Junkfraw $(\mathrm{M})^{75}-$ Die jungkfraw antwort $(\mathrm{Kb})$

Der sechst $(\mathrm{M})-$ Ein fraw spricht $(\mathrm{Kb})$

Der peßt $(\mathrm{M})-$ Der gesell antwort $(\mathrm{Kb})$

Der außschrë̈er $(\mathrm{M})$ - Vrlaup nemen $(\mathrm{Kb})$

Die Spielhandlung gliedert sich in drei Abschnitte: Tanzeröffnung, Wetttanz und Preisvergabe. Während der Eröffnung wirbt der (unbezeichnete) Einschreier Tänzer an und lobt im Auftrag der anwesenden frauen $(715,14)^{76}$ einen Hahn als Preis aus. Zwei weitere Sprecher, wohl Zeremonienmeister, mahnen die Tanzordnung an, vor allem das Gebot sexueller Zurückhaltung (Der erst), und fordern den Platzmeister Götz, eine stumme Rolle, auf, für Musik zu sorgen und Zuwiderhandlung gegen die Vorschriften zu ahnden (Der ander).

Den nun folgenden Wetttanz eröffnet ein Tänzer, indem er den Platzmeister um die Vergabe eines Tanzes bittet und ankündigt, wunder $(716,14) \mathrm{zu}$ vollbringen, die sich im Sinne fastnächtlicher Logik als sexuelle entpuppen (Der dritt). Bis zu dieser Stelle verläuft die dramatische Inszenierung nach $\mathrm{M}$ und nach $\mathrm{Kb}$ gleich. In Handschrift $M$ zählen die Rollenbezeichnungen dann auch weiterhin alle männlichen Sprecher durch, sodass zwei weitere Tänzer auftreten (Der viert und Der $f_{u n f f t}^{e}$, die jeweils einer jungen Frau (derselben?) eine sexuelle Gegenleistung dafür versprechen, wenn sie mit ihnen den Tanz anführt, ${ }^{77}$ was sie aber mit Argumenten im Stil der Priameltradition ablehnt (D̈̈e fraw bzw. Die fraw/Junkfraw). Vielleicht haben die je ähnlichen Schlagverse der beiden Reden der Tänzer und der beiden Gegenreden ihrer Dialogpartnerin ${ }^{78}$ dazu beigetragen, dass die stärker regielenkenden Nebentexte der Handschrift Kb hingegen nur einen einzigen Tänzer identifizieren und ihn in einen längeren Dialog mit nur einer jungen Frau treten lassen: Nachdem hier der Tänzer die Wundertat in Aussicht gestellt hat, bittet er die sich ausgeguckte Tanzpartnerin ein erstes Mal um den Vortanz (Hÿe pit er die jungkfrawen mit $\ddot{y}$ z zu ta $\langle n\rangle c z e n)$ und unternimmt, obwohl er eine abschlägige Antwort erhält (Die jungkfraw antwort), einen erneuten Versuch, sie zu überzeugen (Er antwort jr), abermals ohne Erfolg (Die jungkfraw antwort). In dieser Konstellation erscheint der zweite Versuch, der in dem Angebot mündet, die jungkfraw im Maienbad mit [s]einem ailften vinger zu krauen $(717,11)$ als argumentativ-metaphorische Überbie-

\footnotetext{
75 In $M$ trug der Hauptschreiber zunächst Die fraw ein. Eine nur wenig jüngere Hand strich fraw und ersetzte es durch Junkfraw (B1. 408r).

76 Vgl. das deiktische disen frauen $(717,12)$, außerdem 717,27 - Textzitate, die nicht die Rollenbezeichnungen oder relevante Lesarten betreffen, werden zum besseren Nachvollzug nach der Keller-Ausgabe geboten, die der Handschrift $\mathrm{M}$ folgt.

77 Die Wendung vor tanzen $(716,24 ; 717,1 ; 717,5 ; 717,15)$ kann entweder als Partikelverb vortanzen >den Reigen anführen < bedeuten (vom ersten Tänzer oder vom ersten Tanzpaar, dem die weiteren Tänzer in einer Kette folgen, vgl. Böhme, Franz Magnus: Geschichte des Tanzes in Deutschland. Beitrag zur deutschen Sitten-, Litteratur- und Musikgeschichte. Nach den Quellen zum erstenmal bearbeitet und mit alten Tanzliedern und Musikproben. Bd. 1. Leipzig 1886, S. 27) oder mit vor als temporalem Adverb >zuvor/ vorher tanzen<.

78 Ir außderwelte, ich fleh euch ser $(716,20)$ und Ir außderwelte junkfrau zart $(717,3)$ sowie Hört, junger man, es hat nit fug $(716,29)$ und Hört, junger man, es taugt nit wol $(717,14)$.
} 
tung des ersten sexuellen Angebots, ihr auf $[s]$ einen knieen zu dienen (716,27). ${ }^{79}$ Die Tanzhandlung selbst, in der die Tänzer ihr Können zeigen, das möglicherweise die aufgerufene Sexualmetaphorik ${ }^{80}$ in Bewegungsmetaphorik überträgt, ist textlich nicht repräsentiert, erfolgt aber als sichtbares Bühnengeschehen und dient als »Szenentrenner «: ${ }^{81}$ in $\mathrm{M}$ drei Rollentänze, einer nach der Rede des ersten Tänzers (nach 716,18) und jeweils einer nach der Aufforderung der Tänzerin, der Werber möge selbst den Tanz anführen (Den krieg den macht selber schlecht/ Und tanzt vor! Des habt ir recht 717,22f., vgl. 717,1); in Kb ein Rollentanz zwischen dem Dialog der beiden Protagonisten und der Bekanntgabe des Siegers, mit welcher der dritte Handlungsabschnitt beginnt.

Während in M ein (weiterer?) Zeremonienmeister den Preis im Auftrag der anwesenden Frauen, die den Sieger erwählt haben, überreicht (Der sechst), übernimmt in $\mathrm{Kb}$ eine der Frauen selbst die Vergabe (Ein fraw spricht). Dadurch erscheint ihre (in $\mathrm{M}$ vom Zeremonienmeister übermittelte) Einladung zu einem gemeinsamen Bad mit dem Sieger (717,34f.) umso glaubwürdiger, die er in seiner Replik mit halsen und küssen under den hecken $(718,11)$ im Mai zu vergelten verspricht, worin er >eigentlich $<$ maister mit tanzen sei $(718,15)$. So wird am Spielschluss die Sexualmetapher des Tanzes mit einer retrospektiven Sinnfolie explizit gemacht. - Gemäß der unterschiedlichen dramaturgischen Gestaltung als eines verbundenen (M) bzw. als eines handlungsorientierten $(\mathrm{Kb})$ Reihenspiels lautet die Rollenbezeichnung für den Sieger in M Der peßt, wobei der Text im Unklaren belässt, wer der drei Tänzer als Sieger hervorgeht, und in Kb Der gesell antwort, wo der einzige Tänzer den Preis erhält - letzteres lässt sich als dramaturgische Schwachstelle begreifen oder aber als dramaturgische Pointe der Fastnachtskomik, die jedes Ringen um das Primat, jede auf Eindeutigkeit angelegte Bestrebung ins Leere laufen lässt. Insofern sind auch elementare Formen der unbestimmten Episierung in den Rollenangaben ein konstitutives Merkmal des dramatischen Dispositivs gerade des Fastnachtspiels.

Die von Hans Ulrich Gumbrecht für das neuzeitliche Theater vorgesehene Forschungsstrategie der $\gg$ Spannung zwischen Dramentext und Drameninszenierung $^{82}$ zeigt, dass im mittelalterlichen Nürnberger Fastnachtspiel die Spannung zwischen Sprechtexten und szenischer Umsetzung ausschließlich über auch noch so knappe epische Nebentexte erzeugt werden kann, welche die Sprechtexte zunächst der im-

\footnotetext{
79 Nimmt man das ästhetische Verweissystem sprachlicher Metaphern ernst, entspricht dieser inszenatorischen Klimax auch die Textvarianz in Kb dort, wo die Frau, die den Preis überreicht, im letzten Reimpaar (717,35-718,3) die Metapher des Bades und elften Fingers wiederaufgreift: Do wollen die frawen tanczen vnd paden/ Darczu habens euch frewntlich geladen/ Dasselb wollen sie euch nicht versagen/ Wenn euch der ailfft vinger wirt ragen $(\mathrm{Kb}, \mathrm{Bl}$. 141r) gegenüber der M-Aussage Da wollen die frawen tanczen vnd paden/Darczu haben sie euch freuntlich geladen/Da selbst wolln sie euch nichtz versagen,/On das [>außer das $<$ ], das ir von dannen wolt tragen (M, B1. 409r).

80 Zur sexuellen Metaphorik im Fastnachtspiel s. zuletzt Klimczak, Franziska: Bildlichkeit und Metaphorik in den spätmittelalterlichen Fastnachtspielen des 15. Jahrhunderts - Wie Sexualität von sich reden macht. Potsdam 2018.

$81 \mathrm{Zu}$ Tanz und Musik als »strukturbildende[n] Elemente[n], die einzelne Szenen trennen«, vgl. Henkel, Nikolaus: »Mediale Wirkungsstrategien des mittelalterlichen >Dramasく. Ein Beitrag zur Konstruktion historischer Intermedialität«. In: Karl-Heinz Spieß (Hg.): Medien der Kommunikation im Mittelalter. Redaktion: Oliver Auge. Stuttgart 2003, S. 237-263, hier S. 254 (für das »[Tiroler] Große Neidhartspiel«).
}

82 Gumbrecht (s. Anm. 6), S. 835, vgl. auch S. 846. 
pliziten Ebene einer möglichen idealen Inszenierung zuführen, die wiederum offen für die Anforderungen der realen Aufführungen sein konnte. In diesem Verständnis bringt das dramatische Dispositiv in Ansätzen dem modernen Dramenkonzept nahekommende Strukturierungsprozesse hervor, die sich in ihrer Funktion auf die Lektürepraxis und dort auf die Handlungsvermittlung ausrichten.

Beispiel 2: Gelegentlich erscheinen Rollenbezeichnungen völlig arbiträr gewählt, weil sie in der Spielhandlung keine Entsprechung haben. Ein solcher Fall liegt vor in der unikal in Handschrift M überlieferten Narrenrevue »Das Narrenseil« (K26) mit dem Satznamen der zentralen Figur Die frau auf dem esel $(228,14)$, auch Die konigin auff dem esel $(229,9)$, die im Spiel Liebesnarren an einen strick $(228,19)$ bindet. Die Funktion des Tier-Requisits erklärt sich weder aus der Struktur des Reihenspiels noch aus dem Inhalt der Reden, in denen die Sprecher ihre eigene Narrheit reflektieren, weshalb G. Simon zu »äußerste[r] Vorsicht und Skepsis« geraten und das Spiel als Nachweis für die »Unzuverlässigkeiten der Regieanweisungen« angeführt hat. ${ }^{83}$ An Eselreiter-Figuren wird jedoch die »kommunikative Dimension des Topos >asinitas « von der transzendierenden Grenze zwischen inkommensurabler göttlicher Kraft und menschlich-animalischer Natur exemplifiziert, welche ferner auf die liminale, ordnungsrelativierende Denkfigur des Tricksters verweist. ${ }^{84}$ Unabhängig davon, ob die Rollenbezeichnung aus der originären Textschicht stammt oder von einem Bearbeiter hinzugefügt wurde, fügt sich im Spiel eine königliche Eselsreiterin, die (wie in anderen Narrenrevuen die göttliche Frau Venus oder eine Preisrichterin ${ }^{85}$ auf der Fastnachtsbühne Liebesnarren einfängt, nur um in Tricksterabsicht den Zuschauern die eigene (Fastnachts-)Narrheit vorzuführen, ${ }^{86}$ gut in die liminale karnevaleske Ordnung ein.

Beispiel 3: Dass in der frühen Spieltradition keine umfänglicheren Regieangaben vorhanden sind, bedeutet nicht, dass die Inszenierungen ohne ausgreifendes räumliches Bühnengeschehen und ohne Hintergrundszenen auskommen. Am verbundenen Reihenspiel »Mönch Berchtolt« (K66), unikal in Handschrift M überliefert, lässt sich das Gegenteil aufzeigen. Im Mittelpunkt des Spiels steht die Eheschließung der Bauernkinder Hilla und Hans. ${ }^{87}$ Es gliedert sich in vier szenenhafte Abschnitte, von denen zunächst die ersten drei knapp ausgeführt seien: Nachdem im Rahmen der Eheberedung der Mönch Perchtolt die Ehefähigkeit der Braut, d.h. im Sinne der Fastnachtskomik ihre sexuelle Erfahrung, mittels selbsttätiger Prüfung bestätigt hat (1), präsentieren der Vater des Bräutigams und die Brauteltern sowie sechs Nachbarn nacheinander - in der Bauform unverbundener Reihenspiele - (wertlose) Mitgiftgeschenke (2). Das Brautpaar willigt in die Ehe ein, der Mönch vollzieht die

\footnotetext{
83 Simon (s. Anm. 19), S. 34.

84 Vgl. dazu Scheuer, Hans Jürgen: »Topos `asinitasく. Editorial«. In: Zeitschrift für Germanistik N. F. 25,1 (2015), S. 8-13, hier S. 10f. (Zitat S. 11).

85 Vgl. Glier, Ingeborg: »Personifikationen im deutschen Fastnachtspiel des Spätmittelalters«. In: DVjs 39 (1965), S. 542-587, hier S. 575 f.

86 Vgl. dazu Barton, Ulrich: »Was wir do machen, das ist schimpf. Zum Selbstverständnis des Nürnberger Fastnachtspiels«. In: Ridder (s. Anm. 64), S. 167-189, hier S. 174.

87 Zum Spiel s. zuletzt von Lüpke, Beatrice: Nürnberger Fastnachtspiele und städtische Ordnung. Tübingen 2017, S. 63f., 205 f.; Weis-Diel, Alexandra: Gewaltstrategien: Codierung und Inszenierung von Gewalt im vorreformatorischen Nürnberger Fastnachtspiel. Wiesbaden 2018, S. 175-179.
} 
Eheschließung und der Bräutigam fordert die Musiker auf, zum Tanz aufzuspielen (3).

Auf der Bühne gewährleisten implizite Regieangaben, welche die Selbsteinführung der Rollendarsteller (z. B. So haiß ich pruder Perchtolt 571,20; So haiß ich Kunz Leuschenstil 573,33) und die direkte Figurenanrede (Nu laß sehen, tohter mein 572,19; Vater, du hast oft und vil gesehen 572,26; Hilla, gib her dein hant 578,9) betreffen, die konzise Dialogabfolge der Eheberedung und der Eheschließung. Auch die expliziten Rollenbezeichnungen vollziehen mit einer Adressatenangabe die Redeszene samt Sprecherbeteiligung nach (z. B.: Der münch zum preutigan 577,9; Der preutigan zum münch 577, 20; Der munch zu der preut 577,29; Der münch zu der preut 578,8) und zählen den Reihumauftritt der Nachbarn systematisch durch (Der erst nachpaur spricht 574,19; Der ander nachpaur 574,28 usw.). Insbesondere für die Figurenhandlung des Mönchs sind sprechbegleitende Körperaktionen anzunehmen. Vor allem das credenzen $(572,33)$ ist Gegenstand der Inszenierung, d.h. die pantomimische Erprobung der Ehefähigkeit mittels sexueller Handlung, die zwischen Perchtolts Ankündigung, sich Hilla anzuschauen (573,1-5), und seiner allgemeinen Verkündung des Ergebnisses (573,6-16) ein weder durch den Haupt- noch durch den Nebentext repräsentiertes Bühnengeschehen darstellen muss. Gegen die Annahme, dass man in diesem Spiel auf eine entsprechende Regieangabe verzichtete, um sich »vor zensierender Sanktion « zu bewahren, ${ }^{88}$ spricht nicht nur grundsätzlich die Lesartenvarianz der Nebentexte, die nicht selten die sekundäre Produktionsschicht im Zuge der schriftlichen Fixierung zu erkennen gibt, sondern auch jene Fälle der - zwischen zwei Sprechpartien desselben oder verschiedener Sprecher - sichtbaren Bühnenhandlung, die ebenso wenig durch Regieangaben erfasst ist, aber keine verfängliche Aktion zeigt, wie etwa der Akt der Eheschließung, in dem der Mönch ebenfalls zweimal hintereinander spricht $(578,8-12 ; 577,29-578,7){ }^{89}$ Dort wird die Zeremonie mit der Einwilligungserklärung der beiden Brautleute, dem besiegelnden Zusammengeben ihrer Hände durch den Geistlichen (gesprochene Regieangabe) und mit dessen performativer, an biblische Autorität anknüpfender Sprachhandlung Und habt neur zwu sel und ainn leib! (578,12; vgl. Gn 2,24) als symbolische Vollzugsform im Aufführungsakt vorgeführt $(576,21-578,12) .{ }^{90}$

\footnotetext{
88 Ebd., S. 176 (Zitat ebd.).

89 Es ist eine interessante Überlegung, das die frühe Spieltradition kennzeichnende Merkmal nicht vorhandener ausführlicher Regieangaben (s.o.) als Reaktion auf die rigide Ratszensur zurückzuführen (zu dieser Simon [s. Anm. 24], S. 295-302, 310). Mit Blick auf die Darstellung sexueller Komik zeigen die Spieltexte, die wahrscheinlich stets genehmigt werden mussten, allerdings überaus häufig drastische verbale Obszönität, die während der Inszenierung prinzipiell die Option zur parallelen Figurengestik und Körperbewegung eröffnete, etwa wenn die sprachlich-metaphorische Koitus-Darstellung von entsprechenden Körperbewegungen mit Koitus-Nachahmung begleitet wurde, wie beispielsweise in »Der kurze Hahnentanz« (K89), in dem die Tanz-Metapher Hinten auf und vor nider in der Redeabsicht deutlich sexuelle Konnotation erfährt (716,13-16).

90 In K66 besteht sicher auch eine besondere Ebene der Komik in der Parodie realer Elemente zeitgenössischer Hochzeitsbrauchformen (Ehetauglichkeitsprüfung, Geschenkevergabe, Trauzeremonie), die sich ergibt, wenn in der Wirklichkeit der Fastnachtsbühne ein Mann an einem als Frau verkleideten männli-
} 
Im Anschluss an die Zeremonie soll nun getanzt werden, und der Bräutigam fordert, dies ein gängiger Spielschluss, die Musiker zum Spiel auf: ${ }^{11}$

DER PREUTIGAN ZUNN PFEIFERN:

Pfeift auf, ir lieben knecht,

Und machet mir den reien recht!

Ich greif in mein taschen geschwind

Und gib euch sicher, was ich vind.

Wann ich iezund nit vil parschaft han,

So pfeift auf und laßt es umbhin gan! (578,13-19)

Die beiden darauffolgenden Sprechpartien, die den vierten Abschnitt bilden, wirken demgegenüber nurmehr unmotiviert angefügt. Dennoch geben ihre Redeinhalte gut Aufschluss über die Ausgestaltung der Inszenierung: Hans wirft einem am Tanz Beteiligten, einer stummen Rolle, vor, ihm durch unzulässige Berührung mit seiner unseligen hant beim Tanz den spiegel zuprochen zu haben, ${ }^{92}$ sinnt auf Rache und droht ihm mit Schlägen:

\section{DER BREUTIGAM:}

Hörstu, du pöser feilant,

Du hast mit deiner unseligen hant

Mir meinen spiegel zuprochen.

Das laß ich nit ungerochen,

Wann ich hab es mit meinen augen gesehen,

Das es mir von dir ist geschehen.

Darumb so wil ich dich so ser schlagen,

Das dir enpfellt das krös und den magen. (578,20-28)

Dass der Bräutigam bereits bei seinen letzten Worten heftigst auf den Widersacher eingedroschen haben wird, welcher infolgedessen ärztlich versorgt werden muss, macht erst die Rede des sodann auftretenden Arztes Rubein ${ }^{93}$ deutlich. In sprechbegleitender Bühnenaktion führt er die aus den Arztspielen bekannte »Wein-

chen Darsteller sexuelle Handlungen vornimmt oder ihn mit einem Mann verheiratet, vgl. auch von Lüpke (s. Anm. 87), S. 206. Zu diskutieren wäre aber, ob das Fastnachtspiel-Dispositiv daneben nicht doch ein Illusionsniveau zu erreichen vermag, das diese Ebene in der Zuschauerwahrnehmung auszublenden hilft, unterlägen doch andernfalls alle Frauenrollen nicht mehr nur potenziell dieser Lesart, die dann auch auf das geistliche Spiel zutreffen müsste.

91 Der Tanzschluss war ein geeignetes performatives Mittel, aus der Spielwirklichkeit in die Realität der Fastnachtsfeier zurückzuführen. Vgl. Catholy (s. Anm. 23), S. 164-198; zu K66 vgl. ebd., S. 180 f.

92 Aus inszenatorischer Sicht fungiert Hans' gesprochene (vergebliche oder vorgebliche?) Suche in seiner taschen nach parschaft zur Entlohnung der Musiker (s.o.), die der Darsteller in eine zugehörige sprechbegleitende Figurenbewegung überführt haben dürfte, als regielenkendes Mittel, die Aufmerksamkeit der Zuschauer auf seine Tasche zu richten, in welcher sich der Spiegel befinden dürfte.

93 Im geistlichen Spiel ist Rubein häufig der Name des Arztknechtes, vgl. die Belege bei Arndt, Wilhelm: Die Personennamen der deutschen Schauspiele des Mittelalters. Hildesheim 1977 [Nachdr. der Ausg. Breslau 1904], S. 26; Streif, Johannes: Das Arztspiel des vorreformatorischen Nürnberger Fastnachtspiels. Krankheit und Heilshoffnung im Spätmittelalter. Diss. masch. München 1999, S. 182, Anm. 799, 192f., Anm. 834, 252, Anm. 1102, 290, Anm. 1283.

94 Ebd., S. 252, mit Beispielen S. 253, Anm. 1103. 
Therapie ${ }^{94}$ durch und setzt dazu dem verletzten $\operatorname{paur}[n]^{95}$ ein fleschlein mit gute $[m]$ wein an den Mund, welcher sich, wie ein entsprechendes pantomimisches Agieren des betreffenden Darstellers den Zuschauern zu erkennen geben dürfte, der ärztlichen Prognose gemäß zusehends erholt. Damit sind zugleich auch die fastnachtsfeiernden Zuschauer zum Trank aufgefordert, ${ }^{96}$ bevor der Arzt-Darsteller das Spiel mit typischer Verabschiedung des wirt $[s]$ in Ausschreier-Manier beschließt:

DER ARZT:

So haiß ich maister Rubein

Und gib im zu trinken guten wein.

Ich setz im das fleschlein an den munt,

Zu hant so wirt der paur gesunt,

Und daß im die krankhait wirt weichen.

Herr wirt, gebt uns urlaup und last uns hin schleichen! $(578,29-579,4)$

Die beiden kleinen - durch je eine Sprechpartie repräsentierten - separaten Szenen, die sich aus dem Tanz entwickeln, erscheinen nur deshalb fragmentarisch, weil explizite regielenkende Angaben fehlen, welche die theatrale Leerstelle des nonverbalen Bühnengeschehens mit dem neu eingeführten Motiv des zerbrochenen Spiegels semantisch füllen könnten. Es muss daher nicht notwendig von einem »offensichtlich falsch angefügten Schluß ${ }^{97}$ ausgegangen werden. Denn beim realen Anblick der stummen Zwischenhandlung (Tanz mit Spiegelzerbrechen, Rauferei mit Verletzung), die dem Zuschauer in der sichtbaren Aufführungssituation gegenwärtig war, fügte sich sowohl die Drohrede des Bräutigams als auch die Kur des Arztes gut in den Spielzusammenhang ein. Auf den lesenden Rezipienten musste die neue Handlung hingegen überraschend wirken. ${ }^{98} \mathrm{Ihm}$ erschloss sich das theatrale Potenzial nur voll, wenn er Kenntnis der dramatischen und literarischen Tradition besaß (Krämerszenen des Osterspiels, ${ }^{99}$ Neidhart-Motivik $\left.{ }^{100}\right)$. Dass der Textbestand der beiden Szenen im Prozess der schriftlichen Fixierung aber offenbar prekär, vielleicht unvollständig war und daher seine Aufzeichnung in drei Schritten erfolgen musste, geben im Überlieferungsträger, Codex M, gestaffelte Nachträge in unterschiedli-

95 Wenn auch unwahrscheinlich, ist nicht auszuschließen, dass Hans Schlauch - (seinem Namen gemäß) der exzesshaften Völlerei frönend und deshalb von unbeholfener und schwerfälliger Leibesfülle (Ich haiß Hanns Schlauch/ Und darf alle tag in meinem pauch/Vier kelber und ain rint;/Darumb so gee ich, als ich trag ain kint 576,22-25) - im Kampf unterliegt, weil nicht wendig genug, und selbst das Opfer ist.

96 Beispiele für »Wein als Gegenstand der Fastnachtsgeselligkeit« nennt Streif (s. Anm. 93), S. 253, Anm. 1103 (Zitat ebd.).

97 Ebd., S 252.

98 Vgl. Catholy (s. Anm. 23), S. 180.

99 Vgl. Wolf, Gerhard: »Komische Inszenierung und Diskursvielfalt im geistlichen und weltlichen Spiel. Das > Erlauer Osterspiel< und die Nürnberger Arztspiele K 82 und K 6«. In: Ridder (s. Anm. 64), S. 301-326; Velten, Hans Rudolf: »Kontrastmedium - Lachritual - Unterhaltung. Zur Bewertung der Komik im Krämerspiel«. In: Jörn Bockmann/Regina Toepfer (Hg.): Ambivalenzen des geistlichen Spiels. Revisionen von Texten und Methoden. Göttingen 2018, S. 79-100.

100 Die Tanzszene greift mit dem in der Neidhart-Tradition (so im »[Tiroler] Großen Neidhartspiel«) stehenden Motiv des zerbrochenen Spiegels den auch in Metzen hochzit und Wittenwilers Ring geprägten Handlungsverlauf auf, bei dem der Spiegel während des Tanzes zerbricht und dies Anlass für eine handfeste Prügelei ist. 
cher (brauner) Tintenfarbe - höchstwahrscheinlich der gleichen Hand - zu erkennen (B1. 296v). ${ }^{101}$ Sie zeugen aber zugleich von einer dynamischen Produktivität des Spieltextes. Auszuschließen ist daher nicht, dass es sich um eine literarisierende Anpassung des Spieltextes an gängige Schlussformen anderer Spiele ${ }^{102}$ handelt, die gleichsam eine Transformation des theatralen in das dramatische Dispositiv bewirkt. Die Schlusssequenz des Spiels zeigt vor allem aber das für das dramatische Dispositiv der Fastnachtspiele charakteristische »Schwanken zwischen epischem und dramatischem Stil« dort, wo implizite Aufführungshinweise nicht sprechbegleitete simultan-gegenwartsbezogene Bühnenhandlung zum Ausdruck bringen, sondern sich berichtend oder konstatierend auf vergangene Geschehnisse beziehen. ${ }^{103}$

\section{Der Nebentext als Medium eines dramatischen Erfahrungsdispositivs}

Johannes Janota hat im Zusammenhang mit seiner Forderung, bei der kommentierenden Erschließung der Fastnachtspieltexte den Aufführungszusammenhang zu berücksichtigen, aufgezeigt, wie sehr die Informationsebene der den Spieltexten entnommenen zahlreichen impliziten Hinweisen einer Spielinterpretation dienlich ist. ${ }^{104}$ Ein solches Verfahren bedarf der methodischen Differenzierung zwischen einer Textebene der expliziten Rollenbezeichnungen und Regieangaben einerseits und einer Textebene der Sprechpartien andererseits, statt (mit Blick auf eine denkbare Aufführungssituation) ihr jeweiliges Aussagepotenzial ungebrochen aufeinander zu beziehen. Denn die in den Redetexten selbst zur Sprache kommenden impliziten Aufführungsangaben (u. a. Raum- und Zeitdeixis, Kostümierung und Requisiten, Figurenauftritte und -abgänge, nonverbale Bühnenaktion) verweisen auf eine genuin zugrunde liegende Performanzsituation. ${ }^{105}$ Deren authentische Ausgestaltung

\footnotetext{
101 Zunächst war, vielleicht noch zusammen mit dem vorausgehenden Text, allerdings ohne Sprecherbezeichnung, zunächst die Drohrede des Bräutigams eingetragen worden, jedoch nur bis einschließlich des ersten Wortes des letzten Reimpaars (Darumb 578,25). Sodann wurde in blasserer Tinte und ein wenig größerer Schrift der restliche Text ab so wil $(578,27)$ bis einschließlich Vers 579,2 und ebenso die fehlende Sprecherbezeichnung $(578,20)$ ergänzt. Erst nach der Rubrizierung erfolgte in nochmals anderer, dunklerer Tinte, der (vielleicht vom Schreiber selbst verfasste) Zusatz des sich syntaktisch gut anschließenden letzten Reimpaars der Arzt-Rede (579,3f.) und mit ihm zugleich ein Spielschluss, welcher der Gattungsanforderung nach ausschreiertypischen Wendungen entsprach. Vgl. dazu auch Keller (s. Anm. 35), S. 578, 1515, der, wie auch zuletzt Streif (s. Anm. 93), S. 252, eine andere Nachtragshand annimmt. Michels (s. Anm. 36) vermutet, dass »die Vorlage zerlesen und nicht ganz vollständig war « (S. 87).

102 Auch im »Nürnberger (kleinen) Neidhartspiel« (F89) tritt ein Arzt (Laurein) auf, der einen während einer Prügelei Verwundeten behandelt. Im Spiel »Der alte Hahnentanz« (K67) mündet ein Wetttanz in eine Schlägerei, hier ebenfalls mit fast tödlichem Ausgang; dort nimmt sich aber ein Richter des Falls an.

103 Vgl. dazu für das geistliche Spiel auch Nowé (s. Anm. 18), S. 358 (Zitat ebd.).

104 Janota (s. Anm. 64). Vgl. auch Linke, Hansjürgen: »Die Gratwanderung des Spieleditors«. In: Rolf Bergmann/Kurt Gärtner (Hg.): Methoden und Probleme der Edition mittelalterlicher deutscher Texte. Bamberger Fachtagung 26.-29. Juni 1991. Unter Mitwirkung von Volker Mertens. Tübingen 1993, S. 137-155, hier S. 137-139. Vgl. ferner Henkels (s. Anm. 81) Empfehlung, »die erhaltenen Schriftzeugnisse auf ihren Zeugniswert hinsichtlich der Performanz der Texte und der Strategien zu befragen, mittels deren Sprache mit anderen Medien in Interaktion gesetzt wird « (S. 256).

105 Auch wenn (oder: eben weil) der Textbestand im Überlieferungsprozess variiert und umgearbeitet werden konnte, dürfen gerade die >ins Leere laufenden<, d. h. nicht sinnvoll auf den Handlungsablauf zu bezie-
} 
lässt sich aus dem überlieferten Lesetext - infolge der Separierung aus dem Inszenierungskontext - nur selten voll erfassen (oder bleibt gar rätselhaft). Weil die theatralen Anspielungen im Lektürevorgang des mittelalterlichen Rezipienten aber in jedem Fall auf eine nicht zu ignorierende Sinndimension verweisen, evozieren sie unweigerlich den imaginierenden Nachvollzug des theatralen Geschehens auf der inneren Bühne (s.u. 5). Dies trifft auch für jene Bühnenaktionen zu, die weder in den expliziten noch impliziten Performanzangaben sprachlich repräsentiert sind, sondern aus dem Gefüge der Redeinhalte im Sinne der Handlungs- oder Dialoglogik erschlossen werden können. Nicht zuletzt ist immer auch mit nur gesprochenen Elementen der Bühnenausstattung und Aufführungspraktiken zu rechnen. Diese Inszenierungsebene kommt neben der Lesebühne auch in der realen Aufführung zur inneren Anschauung. Sie bezieht die Zuschauer in besonderer Intensität als Teilnehmer der Spielwirklichkeit mit ein, indem sie sie aktivieren, die bühnenrelevante apparative Ausstattung kraft ihrer Vorstellung zu realisieren und an der inszenatorischen Gestaltung mitzuwirken.

Dagegen gehören, wie bereits angedeutet (s. o. 3), die expliziten Performanzangaben der Nürnberger Fastnachtspiele nachweislich (als spätere Zusätze in Überlieferungsträgern ohne Rollenangaben) oder weil sie im Widerspruch zum Redeinhalt stehen (d.h. auf Fehlern und Missverständnissen basieren) oder ganz fehlen sowie insgesamt der stark divergierenden Textvarianz zufolge (im Unterschied zur demgegenüber weniger unfesten Varianz der Spieltexte) nur selten der gleichen Textschicht an wie die Sprechpartien. ${ }^{106}$ Vielmehr stellen die Rollen- und Regieangaben einerseits Informationen bereit, die den Transfer der theatral-mündlichen Vortragsrede in den verschriftlichten Text annehmbar machen und lesegerechte Verständnishilfen bieten. Andererseits spiegelt sich in ihnen der Versuch der Schreiber und Bearbeiter (auf verschiedenen Überlieferungsstufen) wider, ebenjene Frage zu beantworten, wie die Aufführung ausgesehen haben könnte, indem sie die theatralen Leerstellen, die dadurch zustande kommen, dass die Texte im Lesemedium aus der sichtund hörbaren Bühnenhandlung isoliert sind, ${ }^{107}$ mittels schrifttextlicher Angaben zum Vorverständnis aufzufangen suchen. ${ }^{108}$ In diesem Spannungsfeld zwischen Aufführung und Schrift bilden sie insofern einen »Indikator der Medialität «, ${ }^{109}$ als in ihnen »das Spiel als Spiel kenntlich gemacht [wird] «. ${ }^{110}$

henden, impliziten Aufführungshinweise als residuale Elemente der Aufführungspraxis betrachtet werden, und mit ihnen dann auch Hinweise, die sich wiederum leicht in die Inszenierungslogik fügen (etwa Requisiten, deren Einsatz die deiktische Benennung nahelegt).

106 Vgl. dazu auch Simon (s. Anm. 19), S. 43f. Als Beispiel dafür, dass Neben- und Haupttext hingegen »auf den Archetypus zurück[zu]führen« seien, weil sie in allen Textzeugen in Abweichung vom sonst darin charakteristischen Nebentext-Stil miteinander übereinstimmen, nennt Simon das dreifach überlieferte Spiel »Meister Uncian« (K48), vgl. ebd., S. 28, Anm. 30.

107 Vgl. dazu auch Catholy (s. Anm. 23), S. 8f.

108 Diese Ambiguität hat Toepfer (s. Anm. 18) für das »Donaueschinger Passionsspiel« mit Blick auf eine reale Aufführung beschrieben: »Einerseits bleiben die Bühnenanweisungen - im Unterschied zur Figurenrede - in ihrer Versprachlichung an die Schriftlichkeit gebunden und sind per se für die Lektüre bestimmt, andererseits wollen sie eine Anleitung für den performativen Vollzug geben und werden bei der Aufführung in eine >Kommunikation der Körper< überführt« (S. 111).

109 Ebd., S. 111.

110 Wolf (s. Anm. 18), S. 389. 
So erklären sich die divergierenden Resultate im Bemühen der Schreiber und Redaktoren, den Vorlagen des gleichen Spiels, die keine Regie- oder Sprecherangaben aufwiesen, ebensolche sinngestaltenden Informationen hinzuzufügen oder vorhandene zu erweitern. Es ist anzunehmen, dass die Bearbeiter erstens in Kohärenz mit dem sich ihnen (als Produktions- wie Rezeptionssubjekten) über die Redeinhalte eröffnenden inneren visuellen und akustischen Bühnenraum verfuhren und dass sie sich zweitens an der ihnen bekannten zeitgenössischen Praxis fastnächtlicher Aufführung orientierten, die sich als allgemeiner Typ von Gumbrechts Verständnis des mittelalterlichen Theaters als eines historisch spezifischen Erfahrungsdispositivs begreifen lässt. ${ }^{111}$

Dies soll nicht heißen, dass sich, wie es G. Simon aus textkritischer Sicht resümiert, »[a]uf Regieanweisungen [...] bei den Nürnberger F[a]s[tnachts]p[ielen] des 15. Jahrh[underts] keine Argumentation aufbauen [lässt]. «112 Folgende Unterscheidung könnte jedoch hilfreich sein: Interessiert die Ebene einer authentischen Inszenierung, die sich am ehesten aus den impliziten Hinweisen der originären Redetexte erschließen lässt (s. o. 2), ${ }^{113}$ rechtfertigt es der oben genannte zweite Aspekt, das bühnenpraktische Erfahrungsdispositiv des mittelalterlichen Theaters im Sinne Gumbrechts, explizite und implizite Aufführungshinweise mit gebotener Vorsicht dort miteinander in Bezug zu setzen, wo es »auf beiden Textebenen Belege gibt «114 oder sich sinnvolle Bezüge herstellen lassen. Interessiert hingegen die Ebene des Bühnenhandlungs-Raums, der sich im Nachvollzug des schriftlichen Spieltextes, wie ihn die Handschriften der Fastnachtspielüberlieferung präsentieren, vor dem inneren Auge des zeitgenössischen Rezipienten auftut (s.u. 5), ergeben neben den impliziten gerade die expliziten Aufführungshinweise wichtige Impulse. Auch hier wird das zeitgenössische Erfahrungsdispositiv das innere Auge des mittelalterlichen Rezipienten der Lesetexte geleitet haben. Das trifft sowohl auf den Redaktor der

111 Die von Werner Williams-Krapp in die Diskussion um das Differenzmerkmal der imaginären Aufführung eingebrachten Bedenken, die Rezipienten der Lesetexte müssten irgendwann einer Spielaufführung beigewohnt haben, um fähig zu sein, eine solche zu imaginieren (vgl. Anm. 195), können für die Nürnberger Fastnachtspiele im Wesentlichen entkräftet werden. Denn die umfangreichen Faszikel der Fastnachtspielsammlungen (Gb, Gd, M) entstanden in der zweiten Hälfte des 15. Jahrhunderts in Nürnberg (vgl. Simon [s. Anm. 19], S. 113) und somit zeitlich und räumlich in engem Bezug zur intensiven Spielpraxis der Stadt, die an den von allen Sozialschichten begangenen Anlass der Fastnacht gebunden war. Den Nürnbergern Schreibern und wohl auch den Redaktoren ihrer Vorlagen dürften Fastnachtspielaufführungen mit Sicherheit bekannt gewesen sein.

112 Simon (s. Anm. 19), S. 34 f.

113 Es soll nicht übersehen werden, dass auch die Spieltexte im Überlieferungsprozess Veränderungen unterliegen. Aber die Nähe der Sprech- oder Bühnentexte zur Inszenierung, auf deren theatrale Wirklichkeit hin sie (re)produziert wurden und deren akustisch-performatives, konstitutiv-vollzugsgebundenes Element sie waren (vgl. Gumbrecht [s. Anm. 6], S. 846), ist größer als der außerhalb einer Existenzweise als mündliche Sprachhandlung stehende Regietext, selbst wenn sie demselben Produktionsprozess entstammen. Denn so sehr den textlich fixierten Regieangaben eine kommunikative Funktion inhärent ist, verstehen sie sich doch als variable Anleitung, insofern sie nicht zwingend berücksichtigt, sondern an die Möglichkeiten des Spielorts, der Requisiten und Kostüme sowie des darstellerischen Vermögens der Sprecher angepasst werden müssen. Als in der Aufführungssituation vollzogene Sprachhandlung ist der Sprechtext, der durchaus eine Umarbeitung erfahren kann (etwa bei der Aktualisierung realer Orts- und Personennamen), hingegen nicht mehr zu revidieren.

114 Janota (s. Anm. 64), S. 391. 
Textbasis einer künftigen Aufführung und ebenso auf den Spielleiter zu, der den Text unmittelbar als Aufführungsskript konsultierte, als auch auf einen nur an der Lektüre interessierten Nutzer. ${ }^{115}$ Denn auch für die überlieferten Fastnachtspiele, in denen die Rollen- und Regieangaben integrale Textelemente bilden, gilt für jede Nutzungsabsicht die basale Prämisse, dass ein verschriftlichter, buchtechnisch eingerichteter Text im Sinne Wolfgang Isers einen »im Text vorgezeichneten Aktcharakter des Lesens « $^{116}$ voraussetzt (impliziter Leser), an den der Akt des Zuhörens sekundär gebunden sein kann (impliziter Hörer). ${ }^{117}$ Die oben beschriebene, durch das theatrale Erfahrungsdispositiv beeinflusste Bearbeitungspraxis lässt sich für den Augsburger Kaufmann Claus Spaun belegen, den Kompilator, Korrektor und Redaktor der umfangreichen Sammelhandschrift G (Wolfenbüttel, HAB, Cod. 18.12 Aug. $\left.4^{\circ}\right) .{ }^{118}$ Zwar sind für Augsburg keine Aufführungen von Fastnachtspielen nachgewiesen, die Nachbearbeitung der Texte gibt aber Spauns intensive Kenntnis der Spielpraxis und der Gattungsbedingungen zu erkennen. Zum einen nahm Spaun (Hand $\mathrm{Ga}$ ) für einige der von ihm systematisch zusammengetragenen Spiele der Handschrift G selbst die Rubrizierung vor: Er führte beim ersten Spielvers die Lombarden aus und durchstrichelte die Versanfänge. Ferner hob er die abgesetzt und eingerückt gebotenen Sprecher- und Regieangaben durch rote Unterstreichung

115 Zur intensiv geführten Diskussion um das Verhältnis von Aufführungs- und Lesetext s. u.a. die Beiträge von Williams-Krapp (s. Anm. 46) und präzisierend ders.: »Überlieferung und Gattung. Zur Gattung >Spiel< im Mittelalter - revisited«. In: Bockmann/Toepfer (s. Anm. 99), S. 178-193; Linke, Hansjürgen: »Versuch über deutsche Handschriften mittelalterlicher Spiele«. In: Volker Honemann/Nigel F. Palmer (Hg.): Deutsche Handschriften 1100-1400. Oxforder Kolloquium 1985. Tübingen 1988, S. 527-589; Neumann, Bernd/Trauden, Dieter: »Überlegungen zu einer Neubewertung des spätmittelalterlichen religiösen Spiels«. In: Hans-Joachim Ziegeler (Hg.): Ritual und Inszenierung. Geistliches und weltliches Drama des Mittelalters und der Frühen Neuzeit. Tübingen 2004, S. 31-48. Vgl. auch den Überblick bei Grafetstätter, Andrea: Ludus compleatu: Theatralisierungsstrategien epischer Stoffe im spätmittelalterlichen und frühneuzeitlichen Spiel. Wiesbaden 2013, S. 5-9; Toepfer (s. Anm. 18), S. 107-109.

116 Iser, Wolfgang: Der implizite Leser. Kommunikationsformen des Romans von Bunyan bis Beckett. 3. Aufl. München 1994, S. 8.

117 Drei von Claus Spaun im Codex G (s.u.) nachgetragenen Spielüberschriften oder Registereinträgen (zu Folz-Spielen) zufolge waren die dort aufgezeichneten Spieltexte potenziell für die private Lektüre (lesen) und für das an den Vorgang des mündlichen (Vorlese-)Vortrag geknüpfte Zuhören (hören) bestimmt: Gar ain vast spotisch $[e]$ pauren spill, gar kurtzweyllig zu lesen, sagt yetlicher, waß jm auff der pulschafft gegent ist (»Zwölf buhlerische Bauern«, F97,1, Überschrift); Gar ain vast spotische pauren hë̈rat, gar kurtzweÿlig zu lesen, jn der vasnacht zu prauchen (»Die Bauerhochzeit«, Fassung II, F86,1, Überschrift und Register; statt lesen haben die späteren Drucke lachen, vgl. [...] kurtzweylig vnd gut zu lachen; zum vollständigen Wortlaut s. ebd. den textkritischen Apparat zur Stelle); Gar ain aubewtewrlichs spill von ainem kramer wie er ainem paurn sein kram vertawschet an ainen hoff kurtzweilig zu hören (»Der törichte Tausch« F101, Register, s. ebd. im textkritischen Apparat zu Z. 1). Einen Akt des >Zuschauens $<$ umfasst Spauns kleine Typik der Rezeptionsformen nicht (vorausgesetzt, hören bezeichnet nicht ebendiesen als Akt der visuellen und zugleich auditiven Wahrnehmung). Beim rezitierenden Vortrag des Spieltextes vor Zuhörern ist gut denkbar, dass - mit geeignetem Wechsel der Stimmmodulation - auch die Nebentexte vorgelesen wurden. - Zu Codex G als Lesemedium s. auch Anm. 142.

118 Spaun (Hand Ga) sammelte die Faszikel und ordnete sie an, fertigte auch mehrere Spielabschriften teilweise (Spielanfänge und -schlüsse) oder vollständig (neun Stück) selbst an, teils vermutlich nach Druckvorlagen. Ferner trug er vielfach Regie- und Rollenangaben nach und bereitete den Codex buchtechnisch auf: Er nahm eine durchgängige Foliierung (in brauner Tinte) vor und erstellte am Beginn der Handschrift ein Register (in brauner Tinte), zu dem er (in roter Tinte) bei vielen Stücken korrespondierende Spieltitel oder kleine Inhaltsbeschreibungen nachtrug. Vgl. auch Habel (s. Anm. 22), S. $120 \mathrm{f}$. 
hervor und ebenso den Beginn der Schlagverse, vor die er vielfach zusätzlich ein Paragraphenzeichen setzte. ${ }^{119}$ Spaun folgte damit der für die Aufzeichnung dramatischer Texte etablierten buchtechnischen Konvention in Sinne einer frühen Form des »typographischen Dispositiv[s] « des Dramas, das die materielle Anordnung der textsortenbezogenen Zeichen auf dem Handschriftenblatt organisiert, wenn sie eine »vom Einzeltext unabhängige Form angenommen hat und damit eine generische Funktion erfüllt «. ${ }^{120}$ Es ist daher mit Hansjürgen Linke nicht auszuschließen, dass Spauns Sammlung potenziell als Textfundus für Inszenierungsvorhaben bestimmt war, ${ }^{121}$ wenn auch seine $\gg$ stark redigierende Eigenleistung [...] ein Interesse am Gebrauchswert der Handschrift als Lesetexte [verrät] «. ${ }^{122}$ Dass aber für einen Lesetext »[d]iese übersichtliche und differenzierte Form der Textaufzeichnung [...] für bloße Lektüre funktionslos und mithin unnötig [ist] $\ll,{ }^{123}$ muss nicht zwingend gegeben sein. Denn wer den Codex solchermaßen als Lesemedium konsultierte, dem hielten die mnemotechnisch-visuellen Indikatoren gesprochener Rede im medialen Funktionsspektrum den genuinen Aufführungscharakter der Texte bewusst und versahen sie mit der Aura dramatischer Sprechsituation, die »dem Leser auch einen ästhetischen Genuß $\ll^{124}$ bereitete.

119 Zu Spauns Textüberarbeitung vgl. Linke (s. Anm. 115), S. 549f.; Simon (s. Anm. 19), S. 112-114. Spaun rubrizierte nicht nur seine eigenhändig aufgezeichneten Textpassagen selbst, sondern höchstwahrscheinlich auch jene Texte aus dem von der Hand Gd niedergeschriebenen Faszikel, bei denen er die äußeren Blätter zur Einpassung in das Gesamtkonvolut entfernte (denn er ordnete die zusammengetragenen Texte verschiedener Literaturgattungen in mehreren Codices inhaltlich neu an), den betreffenden Text dann auf vorausgehenden leeren oder neu eingebundenen Blättern selbst ergänzte und die dort eigenhändig vorgenommene Rubrizierung auch auf den Text der anderen Hand ausweitete (B1. 227v-249r, Ga/Gd). Die Gegenprobe liefert das von Hand Gc (einzig) aufgeschriebene Spiel: Zwischen der von Gc aufgezeichneten und der von Spaun ergänzten Partie unterscheiden sich die Rubrizierungsweise (Gc fehlt als einzigem Text der Handschrift die Schlagvers-Unterstreichung) und die Tintenfarbe deutlich (B1. 188v-196v). Ausgehend davon, dass Spaun die genannten Elemente der Rubrizierung ganz konsequent anwandte, hat er wahrscheinlich auch die Faszikel des Schreibers Gb rubriziert (so auch Simon [s. Anm. 19], S. 114; Linke [s. Anm. 115], S. 550, mit dem Hinweis auf die gleiche Rubrizierungsweise in der ebenfalls von Spaun angelegten »Augsburger Komplementärhandschrift A« [vgl. auch Anm. 52]; zurückhaltender Greil/ Przybilski [s. Anm. 21], S. XLII: »möglicherweise aber erst nachträglich von Spaun«), in denen sie sich (und zusätzlich die Unterstreichung der Spieltitel) systematisch wiederfinden; darauf lassen zudem das häufig leuchtende Tintenrot schließen, das zumeist mit jenem der von ihm dort nachgetragenen Überschriften und Sprecherbezeichnungen übereinstimmt, und ebenso die im Wesentlichen stets gleich ausgeführten Paragraphenzeichen (z. B. Bl. 28r, 32v, 36r, 68v, 264v, 272v, 332r). Wenn in Gb mitunter einige Redeeinleitungen nicht unterstrichen sind (B1. 37r-38r), ist dies vielleicht ein Hinweis darauf, dass Spaun die Gb-Faszikel insgesamt unrubriziert erhielt. Hingegen hatten die beiden Schreiber Gc (B1. 189r-196v) und Ge (B1. 274r-328v, 345r-364r) in ihren Faszikeln bereits die Redeeinleitungen und Regieangaben in roter Tinte eingetragen und vermutlich auch die Sprechpartien rubriziert.

120 Vgl. dazu jeweils mit der grundlegenden Literatur Boyken, Thomas: »Der Nebentext eines Lesedramas. Sprecherbezeichnung und Komik in Kleists Der zerbrochne Krug«. In: LiLi (2018), S. 463-480 (Zitat S. 470); Tonger-Erk (s. Anm. 16), S. 431-434.

121 Dies nimmt Linke (s. Anm. 115), S. 550 an.

122 Griese, Sabine: Salomon und Markolf. Ein literarischer Komplex im Mittelalter und in der frühen Neuzeit. Studien zur Überlieferung und Interpretation. Tübingen 1999, S. 242.

123 Linke (s. Anm. 115), S. 550.

124 Wolf (s. Anm. 18), S. 391 (zum »einheitliche[n] und sorgfältige[n] Schriftbild « des »Donaueschinger Passionsspiel $\ll)$. 
Zum anderen gab der $»\left(\right.$ Auftrags-)Schreiber ${ }^{125} \mathrm{~Gb}$ sieben seiner Spielniederschriften keine Sprecherbezeichnungen bei (Bl. 61r-84r, 178r-197v). ${ }^{126}$ Sechs Stücke bereitete aber Claus Spaun (Ga) nachträglich auf, indem er selbständig formulierte Angaben in die ausgesparten Zwischenräume eintrug (K10-K14, F94). ${ }^{127}$ Beispielsweise überschreibt Spaun im unikal bezeugten Spiel »Buhlerrevue« $(\mathrm{K} 13)^{128}$ die zweite Einschreierrede, in der zunächst dieser paur der Molthunt $(114,18)$ vorgestellt wird, dessen zehn Söhnen der Ruf als größte Liebhaber der Gegend vorauseilt, mit Ein nachpaur spricht $(114,16)$. In der nachfolgenden Sprechpartie fordert Molthunt seine Söhne auf, von ihrem Erfolg bei Frauen zu erzählen, und brüstet sich selbst im Redegestus drastischer Obszönität, mit seiner Frau Geisel zahlreich Nachwuchs gezeugt zu haben. Er eröffnet also bereits die Reihe der Prahlreden, jedoch unter umgekehrten Vorzeichen, insofern sich die Ruhmestaten der Söhne, die nicht an das Vorbild des Vaters anknüpfen können, demgegenüber als Fehlschläge entpuppen, weil sie von Frauen »durch Fäkalien, Prügel und missliche Verwechslungen ${ }^{129}$ gedemütigt wurden. ${ }^{130}$ Spaun überschrieb nun die Rede des Vaters, anders als es etwa Usus der Handschrift $M$ wäre, nicht mit dem Personennamen Molthunt oder mit einer Angabe zum verwandtschaftlichen Verhältnis (Der vater), sondern mit Ein ander alter pawr spricht $(\mathrm{K} 13,115,1)$; demnach hat Spaun auch den Nachbarn und - dies ist evident - ebenso die Söhne als (alten bzw. junge) Bauern gedacht. Deren zehn Berichte zählte Spaun dann nach gängigem einfachen Muster durch und ergänzte für den zentralen Rollentypus der Buhleroder Narrenspiele die Varianten buler oder narr (Der erst narr spricht, Der ander puoler spricht usw.). ${ }^{131}$ Spaun kam es offenbar zum einen darauf an, zu Beginn des Spiels das bäuerliche Kolorit zu betonen, das die Bildwelt der Werber-Geschichten konturiert (die mairin 115,35; dorffar [>Dorfpfarrer $<$ 118,35; geiß 119,9 hunerloch 119,28) und für die er die Zugehörigkeit der Figuren zu einem bäuerlichen

125 Habel (s. Anm. 22), S. 119, Anm. 73.

126 Vgl. Simon (s. Anm. 19), S. 27.

127 Bei dem siebten Stück (K9) hat der Schreiber Gb keinen solchen Zwischenraum belassen, sondern den Sprecherwechsel nur durch freien Raum bei den Schlagversen für die nachzutragenden Initialen markiert. Spaun war daher eine Textpräparierung wie bei den anderen sechs Stücken nicht möglich, aber er führte wahrscheinlich auch hier die Initialen aus und unterstrich die Schlagverse.

128 Gb, Bl. 75r-79v. Zum Spiel vgl. zuletzt von Lüpke (s. Anm. 87), S. 195 f.

129 Ebd., S. 196.

130 von Lüpke paraphrasiert die Narrenreden wie folgt: »[...] berichtet der erst narr, wie er in Erwartung eines Liebesabenteuers mit Urin übergossen wurde; der zweite prahlt mit seiner unermüdlichen $>$ Nachtarbeit<; der dritte ist, während er bei einer Frau eingeschlafen ist, mit Bier übergossen, des Einnässens beschuldigt und um Geld für die Reinigung des Bettes geprellt worden; den vierten hat eine Frau in einen Bach gelockt; der fünfte hat statt der Tochter die Mutter im Bett vorgefunden; der sechste wäre in Erwartung einer Liebesnacht beinahe erfroren; der siebte ist von einer Ehefrau zu einem Stelldichein geladen und dann vom Ehemann verprügelt worden; der achte prahlt mit seinem >junge[n] narr[en]< [...]; dem neunten ist statt seiner Geliebten eine Geiß untergeschoben worden; der zehnte schließlich ist in Erwartung von Buhlschaft in einen Abort gefallen. Der elfte Narr fasst daraufhin zusammen, dass den Männern recht geschehen sei, und rät den Frauen, sich vor ihnen in Acht zu nehmen, bevor ein Ausschreier die Spielgruppe verabschiedet« (ebd., S. 195f.).

131 Auch die Rede des elften Narren, der den Frauen Prügel als Mittel gegen zudringliche Buhler empfiehlt, und ebenso die Ausschreierrede integrierte Spaun in seine Zählung (Der ailft narr spricht 119,29 bzw. Der zwelft spricht 120,8). Die Einschreierrede überschrieb er mit Ausschreier (114,3). 
Nachbarschaftskollektiv sowie die Kenntnis seiner Angehörigen voneinander in lebensweltlichen Belangen als konstitutiv erachtete. Indem er zum anderen den literarischen Typus der Bauernfigur eigens exponierte, versah er das Stück mit einem für die Gattung >Fastnachtspiel« signifikanten »poetologische[n] Signal ${ }^{132}$ und diskursivierte mittels der Sprecherbezeichnungen sowie des Spieltitels Von der pulschaft (Gb, Bl. 75r), den er ebenfalls vergab, ${ }^{133}$ auch metasprachlich jene für das Fastnachtspiel konstitutive Tradition des Dörperhaften, in der die Narrenfigur und die Bauernfigur mit ihren Repräsentationsfeldern >Wahrheitsanspruch< und >ordoRelativierung< kulminieren. ${ }^{134}$

Hingegen übernahm Spaun in der eigenhändig aufgezeichneten Abschrift des Folz-Spiels »Weibernarren« (F98) im Wesentlichen die Rollenbezeichnungen, die er in Folz' Druck (1/1) oder in einer direkt hierauf zurückgehenden Vorlage vorfand. Im Druck ${ }^{135}$ bleibt die erste Einschreierrede unbezeichnet, die zweite ist mit Der hoffnarr (Z. 14) überschrieben. Danach folgen die sieben Reden der Liebesnarren und die Ausschreierrede; sie sind mit 1 bis 8 beziffert. Diese graphische Nummerierung korrespondiert zwar grundsätzlich mit der literarischen Enumeration ${ }^{136}$ allgemeiner Schimpf- und Narrennamen in der Vorstellungsrunde des Hofnarren:

Her wirt, ob ir vnß gern wolt kennen,

So wol wir vnß mit namen nennen:

Ich pin der erst vnd heiß der Mol,

Der ander Tolp, der drit heist Drol,

Der fird Schnip vnd der funfft heist Schnap,

Der sechst heist Kußjt vns die ars kap,

Der sybend Gocz, der acht heist Francz

Vnd sint die pesten zwen am tancz,

Der neund heist Schlick, der 〈zechent〉 Treck,

Der far euch aln im hals hin weg.

Also hapt ir vns all benent,

Wo ir sechs dorfft, das ir kein kent. (Z. 15-26)

132 von Lüpke (s. Anm. 87), S. 175.

133 Spaun trug den Spieltitel nach der vorgefundenen Überschrift Aliud etc. (in dieselbe Zeile) ein, die von der Hand Gb stammt (und als Überleitungsformel zugleich das vorausgehende Spiel beschließt). In der Ausgabe Kellers ist es als Aliud von der buolschaft $(114,2)$ zusammengeführt.

134 Zur Bauernfigur im Fastnachtspiel s. Ragotzky, Hedda: »Der Bauer in der Narrenrolle. Zur Funktion >verkehrter Welt< im frühen Nürnberger Fastnachtspiel«. In: Horst Wenzel (Hg.): Typus und Individualität im Mittelalter. München 1983, S. 77-101; von Lüpke (s. Anm. 87), S. 163-175. Zur Narrenfigur s. etwa Ridder, Klaus: »Der Gelehrte als Narr. Das Lachen über artes und Wissen im Fastnachtspiel«. In: Ursula Schäfer (Hg.): Artes im Mittelalter. Berlin 1999, S. 391-409.

135 Der Druck 1/1 ist Leitzeuge der Ausgabe von Greil/Przybilski (s. Anm. 21); ihm folgen die Textzitate.

136 Zum literarischen Verfahren der Aufzählung im Medium der Liste s. von Contzen, Eva: »Listen im Transferprozess: Zur englischen und deutschen Rabelais-Übersetzung«. In: Literaturwissenschaftliches Jahrbuch 58 (2017), S. 193-220; dies.: »Grenzfälle des Erzählens: Die Liste als einfache Form«. In: Albrecht Koschorke (Hg.): Komplexität und Einfachheit. DFG-Symposion 2015. Stuttgart 2017, S. 221-239; dies.: »Die Affordanzen der Liste«. In: $\mathrm{LiLi} 47$ (2017), S. 317-326. Vgl. auch Schaffrick, Matthias/Werber, Niels: »Einleitung. Die Liste, paradigmatisch«. In: LiLi 47 (2017), S. 303-316. 
Jedoch übernimmt der Hofnarr - abgesehen von der Selbstbezeichnung Ich pin der erst [...] - nicht die regietechnische Aufgabe der Figurenidentifizierung oder -zuordnung eines Personenverzeichnisses, ${ }^{137}$ das in anderen Spielen - mit Tendenz zum epischen Theater - in die Vorstellungsrede zumeist des Einschreiers integriert ist und im weiteren Spielverlauf bei Wiederaufnahme des Wortlauts auf das positive Moment des Wiedererkennens und der Erwartungsbestätigung (oder -relativierung) setzt oder sonst aus Gründen der Regielogik den Zuschauer befähigt, für den Handlungsverlauf relevante Zuordnungen vorzunehmen, oder den Darstellern ein mnemotechnisches Hilfsmittel zur Verfügung stellt, den Rollenauftritt auszuführen oder untereinander in Interaktion zu treten. ${ }^{138}$ Die Anzahl der zehn angekündigten Narren korrespondiert nicht mit jener der sieben oder, rechnet man den Hofnarren und auch den Ausschreier mit ein, der neun Narrenfiguren, die dem Spieltext nach auftreten. Die Diskrepanz besteht aber dann nicht mehr, wenn die eingangs gebotene Aufzählung dem Zweck dient, die Zuschauer auf den Rollentypus des Narren und den mit ihm verbundenen spezifischen kommunikativen Modus der Komik, Hyperbolik und Verkehrung einzustellen. Gleichwohl ist denkbar, dass der Darsteller des Hofnarren in der Aufführungspraxis zunächst auf sich selbst sowie sukzessive auf seine Mitspieler zeigt und gegebenenfalls bei einzelnen Personen unter den Zuschauern solange fortfährt, wie es der Aufzählungstext vorgibt. Denn wegen der Bindung der Namen an den Reim lässt sich der Text kaum umformulieren, wenn nicht Verspaare gekürzt werden sollen. Ein solches Einführungsverfahren ließe es auch zu, die Darstellerzahl zu variieren und Narrenreden auszulassen oder zu ergänzen. ${ }^{139}$

Spaun belässt nun in seiner Abschrift die Einschreierrede ebenfalls unbezeichnet, ergänzt aber die Rollenbezeichnung des zweiten Sprechers zu Des pischoffs hoffnar (Ga, Bl. 224v) und bezieht, wahrscheinlich in Ausrichtung auf die Selbstbezeichnung des Hofnarren, zu der die Ich-Aussage der Einschreierrede in Spauns Regiekonzept gerät, bereits diesen Sprecher implizit in seine Narren-Zählung mit ein, weshalb er die übrigen Reden mit Der ander bis Der neundt überschreibt. ${ }^{140}$ Daraus ergibt sich zum einen, dass abweichende Zählungen in den Nebentexten nicht zwingend aus unterschiedlichen Aufführungsrealisationen herzurühren brauchen, und zum anderen, dass Spaun für die unmotiviert wirkende Besetzung des zweiten Einschreiers vielleicht einen konkreten Rollencharakter vor Augen hatte, denn ein >Bischof $\prec$ ist an keiner Stelle Inhalt der Reden oder ergäbe sich aus ihrem Kontext. Es muss Spe-

137 Vgl. Greil, Hannes/Ritz, Mark: »Kommentar«. In: Greil/Przybilski (s. Anm. 21), S. 366-368, hier S. 367. Vgl. ähnlich zu einer »Namenkaskade« in (F92), die keinen genauen Bezug zu den einzelnen Figuren herstellt, Glier (s. Anm. 85), S. 576f. (Zitat S. 577).

138 Als Beispiel sei das Fastnachtspiel »Lügenmärchen und Prahlreden« (K9) genannt. Das integrierte Personenverzeichnis, das mit der impliziten Regieangabe eingeleitet ist, die Figuren mögen auf die Spielfläche treten (Wol her), lautet: Wol her, Hainz von Trewetz/ Und Cuntz von Tramin ge zu der Metzen/ Und Gundelwein von Tribilant/ Und Heinz Gotz mit der lamen hant/ Und du Herman Hans von Trimatei,/ Und du Ruben schlunt von Safferei,/ Und Fullendrussel Wissmirdasgeseß/ Und Piersieder von dem Gefreß,/ Last horen, Was euch sei geschehen,/ Was ieder wunders hab gesehen (92,28-93,2). Die Figuren greifen zu Beginn ihrer Rede in einer Selbstnennung zumindest die Herkunftsbezeichnungen, vielfach den gesamten Wortlaut aus der Namensauflistung auf und reden sich teils auch gegenseitig demgemäß an. Sprecherbezeichnungen fehlen diesem Spiel, weil im Textzeugen Gb kein Platz dafür belassen wurde (vgl. Anm. 127).

139 Vgl. auch mit anderer Akzentuierung Greil/Ritz (s. Anm. 137), S. 368.

140 Vgl. die Lesarten im textkritischen Apparat zu F98. 
kulation bleiben, ob die Rollenbezeichnung die Figur des Narrenbischofs aufgreift, der zentralen Figur im Verkehrungsfest junger Kleriker, ${ }^{141}$ in dessen karnevalesker Entourage sich dann der Hofnarr befände, und ebenso, ob man Spaun eine indirekte Anspielung auf den Augsburger Bischof oder - in übernommener Nürnberger Perspektive - den Bamberger Bischof attestieren darf, die kühn wäre, weil der kirchliche Würdenträger als dem Umkreis der Fastnachtsnarren zugehörig gedacht erschiene.

\section{Narrativierung der inneren Bühne}

Trotz der vielfach einem sekundären Bearbeitungsprozess entstammenden Textschicht der Regie- und Rollenangaben handelt es sich bei den überlieferten Spieltexten nicht um Lesedramen sui generis, ${ }^{142}$ wiewohl sie - in der Existenzweise eines Buchtextes - als solche rezipiert wurden. Im dramatischen Dispositiv des Fastnachtspiels ist der Text mit seinen vielen impliziten Performanzverweisen vielmehr »ein Zeichen, das auf die Aufführung hinweist «, ${ }^{143}$ und zusammen mit ihnen führen die expliziten regie- und rollenbezogenen Informationen die verschriftlichte Reihe von Sprechpartien, als welche die Textzeugen die jeweiligen, ihren vormaligen Aufführungskontexten enthobenen Rollentexte präsentieren, einer neu konstruierten, vor dem »inneren Auge « des Rezipienten imaginierten Performanzsituation zu. ${ }^{144}$ Christian Kiening hat betont, dass die Spieltexte in den Überlieferungsträgern »nicht die

\footnotetext{
141 Vgl. Skambraks, Tanja: Das Kinderbischofsfest in der Vormoderne. Florenz 2014.

142 Dass die im Buchmedium überlieferten Texte primär für einen Leser bestimmt waren, gibt eine Leseanleitung in Handschrift G zu erkennen, die der Schreiber Gb in Teil I notierte (zur Lagen- und Faszikelanordnung s. Simon [s. Anm. 19], S. 111-113). Statt in der Aufzeichnung des aus dem Folz-Umkreis stammenden Stücks »Die Heilung eines Kranken« (F85) die spielausleitende Rede vollständig zu notieren, verweist der Schreiber seinen Auftraggeber (wohl Spaun) auf ein weisses puch, zu dem dieser offenbar Zugang hatte, um den restlichen Text dort einzusehen. Indem der Schreiber mehrmals etc-Zeichen verwendet, die den Fragmentcharakter anzeigen, markiert er die Verse gut erkennbar als Anzitat: Precursor etc./ Herr wirt ein ende hat vnser schallen/ Laßt euch vnsern schimpff wol gefallen etc./ Das hort wir gern etc. Du findest das in dem/ weissen puch geschriben etc. (Gb, Bl. 44r; vgl. F85, 235-239). Offen bleibt, ob der Schreiber Gb einen gebundenen Codex meinte oder ein Spaun vorliegendes Faszikel (das vielleicht weiß gekennzeichnet war?), was Simon (s. Anm. 19), S. 35, ausschließt. Jedenfalls findet sich in Teil III der Handschrift G, den Gb ebenfalls anfertigte, im Stück »Das Aristotelesspiel« (K17; vgl. Anm. 53), die vollständige Ausschreierrede: Vrlaub Nehmen/ Herr wirt ein ende hat vnser schallen/ Hett vnser schimpff euch wol gefallen/ Das horet wir gern zu aller frist/ Nit lenger vnser beleibens ist/ [...] (B1. 100v-101r; vgl. K17, 153,6-24 und ähnlich K14, 127,3-21).
}

143 Catholy (s. Anm. 23), S. 9.

144 Die Metapher des >inneren Auges` hat Carla Dauven-van Knippenberg für die Inbeziehungsetzung eines schriftlichen Spieltextes und eines bildlichen Mediums geistlicher Betrachtung in die Diskussion eingebracht, vgl. Dauven-van Knippenberg, Carla: »Ein Schauspiel für das innere Auge? Notiz zur Benutzerfunktion des Wienhäuser Osterspielfragment«. In: Christa Tuczay/Ulrike Hirhager/Karin Lichtblau (Hg.): Ir sult sprechen willekomen. Grenzenlose Mediävistik. Festschrift für Helmut Birkhan zum 60. Geburtstag. Bern 1998, S. 778-787, hier S. 787; Neumann/Trauden (s. Anm. 115), S. 35, sprechen vom »geistigen Auge eines Lesers«, vor dem »das Bild einer solchen Aufführung« entsteht. - Im Fastnachtspiel geht es nicht um die für das geistliche Spiel konstitutive meditativ-imaginative Vergegenwärtigung heilsgeschichtlicher Inhalte in einem andachts-, gebets- oder liturgienahen Rezeptionsmodus, vgl. zu diesem Schmidt, Christian: Drama und Betrachtung. Meditative Theaterästhetiken im 16. Jahrhundert. Berlin/ Boston 2018, passim. Vielmehr erzeugt hier die »innere Performanz« (ebd., S. 174) sowohl in der zeitgenössischen Lesepraxis als auch in der realen Aufführung mittels Wortkulissen wie mittels nur gesproche- 
Stillstellung der Aufführungen, die ihrer Niederschrift vorangehen und nachfolgen «, manifestieren, sondern »selbst in ihrer materiellen Realisierung nicht zu trennen [sind] von der imaginativen Dimension, in der sie sich >abspielen « ${ }^{145} \mathrm{In}$ ihr wird »die Schrift zur Vollzugsform« für die »lebhafte Imagination von Anwesenheit«. ${ }^{146}$ Dies ist insbesondere auch für die auf die Herausstellung von Mündlichkeit zielende buchtechnische Einrichtung zu reklamieren, die sich nicht nur an Handschrift G (s.o. 4), sondern auch am Beispiel der 50 Spiele der zweiten Haupthandschrift der Rosenplütschen Fastnachtspiele, Codex M (Cgm 714), musterhaft illustrieren lässt. ${ }^{147}$

Den Einsatz eines Spiels markiert neben einer roten Spielüberschrift eine rote Lombarde, den Beginn der Sprechpartien (Schlagvers) eine Initiale, ihr Ende ein rotes, deutliches Schlusszeichen (etc-Zeichen oder zeilenauffüllende Schlängellinie). Diese Hierarchisierung ist konsequent durchgeführt. Die einzelnen Sprechpartien sind auf dem Handschriftenblatt durch ausgesparten Zwischenraum gut sichtbar voneinander getrennt und ihrerseits versmäßig abgesetzt, die Versanfänge rot durchstrichelt. Dieser relativ einfache, so oder ähnlich auch in den anderen Handschriften der Nürnberger Fastnachtspieltradition des 15. Jahrhunderts regelmäßig vorzufindende Einrichtungstyp ermöglicht zum einen eine zügige Niederschrift und einen unaufwändigen Rubrizierungsdurchgang. Er bietet zum anderen eine gute Lesehilfe, insofern die visuelle Scheidung der Partien die Sprecherwechsel offensichtlich macht und - anders als bei fortlaufender Niederschrift, wie sie etwa Regiebücher zeigen, die aber für die Nürnberger Fastnachtspiele nicht bezeugt sind - die gereimte Rede als augenfällig wird. Auf diese Weise wird die nicht mehr präsente akustische Klangqualität des Sprech-Textes, die für das artifizielle Sprechen in der Aufführungssituation von essenzieller performativer Bedeutung ist, ästhetisch transferiert in die materielle Blickqualität des Lese-Textes (versmäßige Zeilenabsetzung, vergrößerter Anfangsbuchstabe, rote Durchstrichelung). Dabei ist die optische Freistellung des Reimworts am Zeilenende im Lesevollzug jenem kurzen retardierenden Moment der physischen Augenbewegung vor dem Zeilenwechsel zuträglich, welcher auch im Schriftnachvollzug der >inneren Stimme< die ästhetische Erfahrung ermöglicht, dass die Intonation der metrisch-rhythmischen Dynamik des Knittelverses auf die klangliche Akzentuierung des Versendes hin zuläuft. Und auch auf der grundsätzlich denkbaren Rezeptionsebene, auf welcher der Dramentext aus den schriftlich fixierten Sammlungen heraus bei der Eigenlektüre oder für einen Zuhörer laut wahrnehmbar vorgelesen wird (pronuntiatio), konturiert die äußere Präparation der Textstimme den inneren akustischen Bühnenraum.

ner Ereignisinhalte eine fiktionale Schaubühne, auf der karnevaleske Komik und gemeinschaftsstiftendes (Ver-)Lachen mediale Gestaltungsmittel für die dispositive Vergegenwärtigung der verkehrten Welt sind.

145 Kiening, Christian: »Präsenz - Memoria - Performativität. Überlegungen im Blick auf das Innsbrucker Osterspiel«. In: Ingrid Kasten/Erika Fischer-Lichte (Hg.): Transformationen des Religiösen. Performativität und Textualität im geistlichen Spiel. Berlin/New York 2007, S. 139-168, hier S. 149.

146 Kiening, Christian: »Medialität«. In: Christiane Ackermann/Michael Egerding (Hg.): Literatur- und Kulturtheorien der germanistischen Mediävistik. Ein Handbuch. Berlin/Boston 2015, S. 349-381, hier S. 367.

147 Zur Präsentationsweise dramatischer Texte in den Handschriften s. im Überblick Linke (s. Anm. 115). 
Die Zwischenräume dienen aber nicht nur der Textgliederung, sondern sind zugleich der Ort für freistehende, mittig eingerückte Zwischenüberschriften: Spieltitel sowie einfache Rollen- oder Regieangaben mit markierender Funktion. In der Regel füllen sie nur eine Zeile und diese selten vollständig, nehmen also gegenüber dem Redetext ungleich geringeren Raum ein. Dennoch behaupten sie einen eigenen Textualitätsanspruch, indem sie nicht nur den kommunikativen Status der direkten Reden exponieren und diese strukturell auf eine kohärente Handlungslogik hin verbinden, sondern auch jede einzelne grundsätzlich mit einem Vorverständnis versehen. ${ }^{148}$ Neben den seltenen Angaben zur Figurenhandlung sind es in erster Linie die bloßen Sprechernennungen, welche im Sinne der Fiktionalitätsstrategie eines Lesetextes dem Entwurf der inneren Bühne und ihrer Imaginationskinetik ${ }^{149}$ zuträgliches narrativierendes Potenzial besitzen. Als unscheinbares, aber effektives Informationsgerüst, in das der Haupttext eingebettet ist, bilden sie ein narratives Instrument der Informationsökonomie und Interpretationslenkung, insbesondere, wenn sich die Figurenidentifizierung nicht unmittelbar aus dem Haupttext erschließt. Und sie versehen den Leser auch noch dann mit einem Informationsvorsprung, bezogen auf die dramatische Person, im Sinne einer Nullfokalisierung, wenn sie einen »epische[n] Überschuss $^{150}$ produzieren, weil der Haupttext in einer nahezu isochronen Selbst- oder Fremdbezeichnung ebenfalls den Rollennamen enthält. ${ }^{151}$

Auch stellen die inquit-Formeln in dieser Perspektive weniger »dürftige[...] Bühnenanweisungen ${ }^{152}$ dar, sondern liefern formelhafte Marker für das elementare narrative Verfahren der Wiedergabe von Figurenmono- und -dialogen, die zu den »Grundkonstanten des Erzählens « ${ }^{153}$ gehört. Denn die Markierung der Sprachhandlung ist, wie Franz Hundsnurscher betont, »im Zusammenhang einer Erzählung ein universeller Zug [...]; seine spezifische Funktion besteht darin, die Redekonstellation und die dialogische Abfolge von Redebeiträgen explizit zu machen «. ${ }^{154}$ Die Verwendung der inquit-Formel ist das Resultat einer »elementare[n] Aufgabe des Erzählers«, nämlich der »Referenzsicherung [...] im Hinblick auf die jeweils handelnden Personen: Wer sagt was zu wem. ${ }^{155}$ Zudem konturiert die redeeinlei-

\footnotetext{
148 Auf dem Handschriftenblatt ist diese Funktion auch den nur durchzählenden Rollenüberschriften wie z. B. in der »Liebhaberfastnacht « (K74) zu attestieren (der erst, ..., der sechst; die Ein- und Ausschreierreden sind vom Zählprinzip in der Regel nicht erfasst), insofern sie nämlich wirkungsvoll das für die Formung der spezifischen Medialität der Revuespiele wichtige ästhetische Prinzip der Reihung (dazu s.u. 6) in den >sinnlich-visuellen< Nachvollzug bringen.

149 Zum vormodernen Konzept des inneren Theaters s. Berns, Jörg Jochen: »Inneres Theater und Mnemonik in Antike und Früher Neuzeit«. In: Christina Lechtermann/Carsten Morsch (Hg.): Kunst der Bewegung. Kinästhetische Wahrnehmung und Probehandeln in virtuellen Welten. Bern u. a. 2004, S. 23-43.

150 Toepfer (s. Anm. 18), S. 118.

151 Vgl. auch ähnlich das Beispiel in Anm. 49.

152 Catholy (s. Anm. 23), S. 66.

153 Miedema, Nina: »Zur historischen Narratologie am Beispiel der Dialoganalyse«. In: Harald Haferland/ Matthias Meyer (Hg.): Historische Narratologie. Mediävistische Perspektiven. Berlin/New York 2010, S. 35-67, hier S. 37.

154 Hundsnurscher (s. Anm. 41), S. 106.

155 Hundsnurscher (s. Anm. 42), S. 33. Zur inquit-Formel als narrativem Prinzip mittelhochdeutscher Epik vgl. auch Urscheler (s. Anm. 43), S. 51-58.
} 
tende Formel bei semantisch denotativen verba dicendi vorab den Redesinn (z.B. bit, dankt, enpfecht), zumal, wenn die Angabe des Adressaten folgt. Vermittels der Zugabe dieses Markers, auch in seiner verkürzten Form, ${ }^{156}$ werden die auf die Zweckbestimmung der Aufführung hin formulierten, originär faktualen Sprechpartien der realen Darsteller von einer - sich nicht näher gerierenden und sehr zurückgenommen, aber (zum Zweck einer Imaginationsbefähigung des Lesers) den Eindruck von Augenzeugenschaft und Unmittelbarkeit erzeugenden »dramatische[n] Erzählinstanz $\ll^{157}$ als wiedergegebene fiktionale Figurenrede präsentiert. ${ }^{158}$ Dies mag evident erscheinen, ist aber für die Rezeptionssituation eines dramatischen Lesetextes grundlegend. Insbesondere widerspricht der nur in der Lektüresituation zu bemerkende Formtyp mit der Kombination aus einer Sprechaktbezeichnung und der Äußerungsbezeichnung sprechen (s.o. 2), der die »epischen Ausführungen stets beendet und die Figurenrede einleitet « jener »Schreibökonomie, der ein Regiebuch unterliegt «. ${ }^{159}$ Auch bei diesem epischen Überschuss, und sei er noch so gering, würde sich nämlich der Nebentext, misst man ihn an der »normative[n] Auffassung des Dramas als Spielvorlage ${ }^{160}$, in der Aufführung nicht voll erschöpfen. Als mediales Signal für Performativität verstanden, eröffnet er jedoch den - narrativ vermittelten - Blick auf die innere Bühne. Die narrative Kommunikationsinstanz spiegelt sich zudem in den »Erzähl-Indikatoren « ${ }^{161}$ der temporalen Satzadverbien do, darauf und darnach, mit denen »die narrative tiefenstrukturelle und-dannRelation zum Ausdruck kommt «162 und zusätzlich der zeitlich stärker synchronisierenden Deiktika itzund, $n u$ und so. ${ }^{163}$ Weitere Indikatoren für die vermittelnde

156 Sprecherbezeichnungen weisen den Haupttexten im Sinne Ingardens (s. Anm. 16), S. 220 ein »Anführungszeichen « zu, welche die Figurenrede ausweist. Übertragen auf die mittelalterliche Handschrift bedeutet dies, dass sie den Sprechpartien eine kommunikative Funktion mit inquit-Status zuweisen.

157 Zum Konzept der dramatischen Erzählinstanz s. die Ausführungen bei Weber, Alexander: Episierung im Drama. Ein Beitrag zur transgenerischen Narratologie. Berlin/Boston 2017, S. 157-176.

158 Zur Abgrenzung von narrativer und dramatischer Sprechsituation in der klassischen Dramentheorie, die an der durch Platons Politeia vorgeprägten Klassifizierung der Redesituation in Drama, Lyrik und Epik orientiert ist und eine vermittelnde Erzählfunktion ausschließt, s. Pfister (s. Anm. 13), S. 19-24. Gleichwohl konstatiert er die Möglichkeit » episierende[r]< Tendenzen« in Nebentexten ebd., S. 22f. (Zitat S. 21). Die neuere Forschungsdiskussion, die hingegen das transgenerische und transmediale Verhältnis von Drama und Erzählung zentral stellt, referiert Tonger-Erk (s. Anm. 16), S. 434-437. Zum erweiterten Narrativitätsansatz in diesem Zusammenhang, den insbesondere Ansgar Nünning und Roy Sommer mitentwickelt haben (z. B. Nünning, Ansgar/Sommer, Roy: »Drama und Narratologie. Die Entwicklung erzähltheoretischer Modelle und Kategorien für die Dramenanalyse«. In: Vera Nünning/Ansgar Nünning [Hg.]: Erzähltheorie transgenerisch, intermedial, interdisziplinär. Trier 2002, S. 105-128), vgl. Detken (s. Anm. 13), S. 4-6, und besonders Weber (s. Anm. 157), passim. Zu Problemstellung und Forschungsstand vgl. ebd., S. 1-8.

159 Toepfer (s. Anm. 18), S. 114 (zum »Donaueschinger Passionsspiel «).

160 Tonger-Erk/Werber (s. Anm. 15), S. 418.

161 Hundsnurscher (s. Anm. 41), S. 113 (zu dô). Weitere Marker der Redehervorhebung sind ebd., S. 109, 111-113, aufgeführt.

162 Ebd., S. 113.

163 Vgl. Fludernik, Monika: Einführung in die Erzähltheorie. Darmstadt 2006, S. 54, 57. - Beispiele finden sich in Anm. 54 und 166, vgl. ferner z. B. Darnach fragt der richter den Schweinszagel (K10, 100,14), Nun komen zwen purger von aim raut (K39, 301,11); Ejner des Turckischen kaisers antwort darauff (K39, 292,8; Kd, Bl. 192r). Einen stärker dramatischen Charakter hat dagegen das raumzeitlich-deiktische Adverb Hie, das gelegentlich die Regieangaben einleitet (vgl. Anm. 29, 51). Im »Rosengartenspiel« (1533) tritt es wiederum als systematisches, wahrscheinlich in Zusammenhang mit der Tradition von Bildbei- 
Kommunikationsebene ${ }^{164}$ sind die Referenzsicherung durch Personalpronomina, welche die Textkohärenz zwischen den Nebentexten ${ }^{165}$ oder zwischen einem Nebenund dem vorausgehenden Haupttext intensiviert, ${ }^{166}$ sowie im Einzelfall der - nicht zufällig versehentlichen - Verwendung des epischen, fiktionalitätsgenerierenden Präteritums, eines deutlichen Indizes für einen Lesetext: Der arzt sprach zun baurn $(\mathrm{K} 82,684,18){ }^{167}$

Die Verwendung nahezu ausschließlich verkürzter inquit-Formeln im Fastnachtspielteil der Handschrift M (Cgm 714), die für das Genre des Fastnachtspiels einen textspezifischen Auszeichnungscode zu normieren scheint, findet sich punktuell auch in deren erstem Teil, einer Minnereden- und Kleinepiksammlung. ${ }^{168}$ Wie Elke Koch und Nina Nowakowski gezeigt haben, beginnt dort der Schreiber bei dialogischen Texten, »von epischen Redeeinleitungen zu abgesetzten Sprecherbezeichnungen überzugehen $\ll{ }^{169}$ Weil sie buchtechnisch im Sinne des graphischen Dispositivs der Spieltexte (s.o. 4) genauso wie jene im Fastnachtspielteil eingerichtet sind, ist auf Ebene der visuellen Darbietung kein Unterschied zwischen den Gattungen erkennbar (z. B. B1. 41v-48v). Ebenfalls im ersten Teil findet sich das Schreiberverfahren, in die Verse epischer Texte (vollständige und) »auf ein Pronomen verkürzte«

schriften stehendes Stilmittel auf, vgl. Gerhardt, Christoph: »Eine unbemerkt gebliebene Bilderhandschrift des >Rosengarten zu Worms $<$ und der Funktionswandel von Überschriften im Überlieferungsprozeß«. In: Wirkendes Wort 49 (1999), S. 27-45, hier S. 39.

164 Zum Problem der Ineinssetzung von Autoräußerung und Nebentext und dem Lösungsansatz, eine innere und eine äußere Kommunikationssituation zu unterscheiden, vgl. Detken (s. Anm. 13), S. 16-20.

165 Vgl. dazu Hundsnurscher (s. Anm. 41), S. 108. Verwiesen sei auf das in Anm. 53 aufgeführte Beispiel sowie auf das Gerichtsspiel »Die Unersättlichen« (K29), in dem die Klage- und die Verteidigungsrede der beiden Parteien, eines Ehepaars, überschrieben sind mit Die anclagerin dicit $(241,12)$ und Ir man antwort $(241,25)$.

166 Verwiesen sei z. B. auf die Narrenrevue »Das Narrenseil« (K26) mit der inquit-Formel So spricht derselb $(228,21)$, wo derselb den Narren meint, von dem die Rede der zuvor aufgetretenen Königin-auf-demEsel gehandelt hat, vgl. ebenso 230,28.

167 Ein Großteil der Regieangaben des zur späten Tradition gerechneten Spiels »Das Parisurteil I« (S2) steht im Präteritum, z. B. do ward ein apfel auf den tysch gepracht, dor auf geschriben stund: [...]. also las HERRE JUPPITER. die schryft laut: [...] (S. 6). Zur präteritalen Zeitform als Indikator der Episierung von Spieltexten vgl. z.B. Williams-Krapp (s. Anm. 46), S. 7, 12, 17, 27 mit Anm. 32, 28; Linke (s. Anm. 115), S. 542. - Unabhängig davon rückt in der jüngeren Vergangenheit die Frage nach der Zeitform des Präsens als Erzähltempus in den Blick, vgl. für die Mediävistik etwa Philipowski, Katharina: »Die deiktische Poetik des Präsens, oder: Wie das >jetzt< ein >hier< erschafft«. In: Eva von Contzen/Florian Kragl (Hg.): Narratologie und mittelalterliches Erzählen. Autor, Erzähler, Perspektive, Zeit und Raum. Berlin/Boston 2018, S. 165-192. In der Rezeptionssituation, in der die Spiele als Lesetexte konsultiert werden, intensiviert das Präsens aber auch die Unmittelbarkeit der sich simultan zum Erzählvorgang der Nebentext-Erzählinstanz ereignenden Bühnenhandlung, sogar bei den bloßen inquit-Formeln, die zusammengenommen die narrative Darstellung für eine Abfolge von Sprachhandlungen bilden; es »fungiert als Imaginationsanleitung « (ebd., S. 184).

168 Zum Sammlungsprogramm dieses Teils s. zuletzt Dahm-Kruse, Margit/Felber, Timo: »Lektüreangebote in der mittelalterlichen Manuskriptkultur. Formen der Retextualisierung und Kontextualisierung deutschsprachiger Versnovellen«. In: Seraina Plotke/Stefan Seeber (Hg.): Schwanksammlungen im frühneuzeitlichen Medienumbruch. Transformationen eines sequentiellen Erzählparadigmas. Heidelberg 2019, S. 13-43.

169 Koch, Elke/Nowakowski, Nina: »Sprechen in Kurzerzählungen Zur poetischen und visuellen Reflexion mündlicher Kommunikation in Beichterzählungen des Cgm 714«. In: Monika Unzeitig/Angela Schrott/ Nine Miedema: Stimme und Performanz in der mittelalterlichen Literatur. Berlin/Boston 2017, S. 83-109, hier S. 103, Anm. 55. 
inquit-Formeln zu ergänzen. ${ }^{170}$ Offen bleibt, ob sich der Schreiber »nicht die Mühe einer textlichen Anpassung im Rahmen der epischen Konvention gemacht [hat « $^{171}$ oder ob dieser spezielle, verkürzte Typ in Zusammenhang steht mit der (bei dialogischer Literatur und den Fastnachtspielen) offenbar programmatischen Anlage des gesamten Codex M, für abgesetzt dargebotene Sprecherbezeichnungen insgesamt elliptische inquit-Formeln ohne verbum dicendi zu wählen. Die optische Alternanz von Redeeinleitung und Redetext dient nicht nur der Textgliederung und der Markierung des Sprecherwechsels, sondern macht die Sprecherbezeichnung (verkürzte inquit-Formel) als Sprecherbezeichnung kenntlich, insofern ihre narrative Funktion auf die Illusion eines mündlichen Kommunikationsaktes zielt. Daher ist der Fastnachtspielteil - mit seiner visuellen Darbietung des Sprecherwechsels, der metasprachlichen Formelhaftigkeit in den verkürzten Redeeinleitungen und deren basalen narrativierenden Zweckbestimmung - für die Frage nach dem ästhetischen Status des Sprachhandelns im Wesentlichen in den Befund einzubeziehen, den Koch und Nowakowski für die Ästhetisierung der Figurenrede im ersten Teil der Handschrift herausgearbeitet haben:

Die Verwendung der Gestaltungsmittel für die Kennzeichnung von Sprecherwechseln, zur visuellen Markierung von Aspekten der Stimme sowie der schlicht quantitative Befund des Aufwandes, der auf Figurenrede bezogen ist, lassen aber doch eine Schlussfolgerung zu: Das Sprechen hat den Schreiber beschäftigt. Es geht in seine Wahrnehmung und in seine Bemühung um die Gestaltung der Texte mit ein. Der Cgm 714 bietet Material für die These, dass die Ästhetik der dort versammelten Reimpaardichtungen als Kunst, die sich im Sprechen entfaltet, erfasst und in die Aufzeichnung hineingenommen worden ist. Dies gilt insbesondere für das Sprechen in Mären. ${ }^{172}$

Wenn also in einem Codex die Sprecherwechsel von Dialogszenen epischer oder schildernd-berichtender Texte einer buchtechnischen Ästhetik zugeführt werden, welche der konventionellen materiellen Gestaltung der dramatischen Texte desselben Codex entspricht, dann, um ihnen die gleiche äußere dramatische Aura zu verleihen. Umgekehrt bedeutet dies aber auch, dass die genuin theatralen Sprechpartien der Fastnachtspiele im Codex als - durch Rollenangaben episch verbundene - Monolog- und Dialogszenen erscheinen und somit rezeptionsseitig zwischen einem episch-narrativem und einem dramatisch-inszenatorischem Wahrnehmungsmodus oszillieren: Im dramatischen Dispositiv des Fastnachtspiels sind die Figuren auf der Ebene des epischen Gerüsts, das die Rollen- und Regieangaben konstruieren, einerseits Produkt des narrativen Entwurfs. Andererseits sind sie auf der Ebene der (solchermaßen narrativ eingebundenen) Sprechtexte aufgrund deren deutlichen, impliziten Performanzcharakters Element einer theatralen Aufführungsdimension (auf die sie auch deshalb verweisen, weil die spezifische Nebentexttypik die theatralen Leerstellen, die der Redetext erzeugt, vielfach nicht aufzuheben vermag), die nicht durch ebendiese Erzählerstimme vermittelt ist. (Unabhängig davon lässt sich

\footnotetext{
170 Vgl. ebd., S. 104f. (Zitat S. 105).

171 Ebd., S. 105.

172 Ebd., S. 107.
} 
in der Aufführungssituation wiederum das dramatische Handlungssetting durchaus als Erzählwelt begreifen, insofern auf der äußeren Kommunikationsebene des SpielMediums ein - auf der inneren Kommunikationsebene des fiktiven Spielraums dramatisch entfaltetes - Geschehen ${ }^{173}$ erzählt wird, s. u. 6). Im Rezeptionsvorgang der erzählerisch vermittelten imaginären Bühne führt das fortwährende Gegen- und Ineinander-Kippen der beiden narrativ-epischen und mimetisch-dramatischen Ebenen zu einer unauflöslichen Spannung zwischen zwei inkommensurablen medialen Vermittlungsmodi. Sie birgt latent eine indifferente transmediale Struktur und erzeugt im dispositiven Subjekteffekt ästhetische Distanz gegenüber der metaphorischen Welt theatraler Erfahrung, infolge dessen die dispositive Steuerung des Wahrnehmungsvorgangs selbst potenziell ins Bewusstsein kommt.

\section{Reihung und Enumeration als literarisches Semantisierungsmuster}

Das - seiner Häufigkeit nach zu schließen - so beliebte Reihenspiel besteht in seiner einfachsten Form aus mehreren vom Ein- und Ausschreierauftritt gerahmten Einzelvorträgen zu einem bestimmten Thema. Die ältere Forschung hat ihm einen "primitive[n] Charakter ${ }^{174}$ bescheinigt und es als defizitär beschrieben mit dem Argument, ihm eigne ein »Verzicht auf Handlung « und »zugleich ein Verzicht auf die Darstellung von Raum und Zeit «. ${ }^{175}$ In jüngerer Zeit unternimmt man hingegen den Versuch, die bloße Reihung als Strukturmerkmal zu erklären, das dem Prinzip der »Wiederholung, häufig auch der Steigerung ${ }^{176}$ sowie der $»$ ritualisierten Praxis des Sprechens über sündhaftes Tun und Sexualität « ${ }^{177}$ Rechnung trage, worauf vor allem die erlebten Abenteuer der Werber- und Narrenrevuen sowie die Streitfälle und Schöffenvoten der Gerichtsspiele hin ausgerichtet sind.

In Perspektive der dispositiven Struktur, so lässt sich anknüpfen, bildet das Fastnachtspiel für einen Großteil seiner theatralen Realisierungen die narrative Inszenierung kleinster literarischer Redetexte: Das Genre liefert das performative Setting für den Vortrag nur thematisch verbundener, narrativer Minimaleinheiten hinreichender Ereignisstruktur (vom Umfang einer Sprechpartie, d. h. etwa sechs bis zwölf, vielfach acht Verse). Sie haben einen kleinen kasuistischen Problemfall oder eine kürzeste pointehafte, vielfach am Schwankschema >Frauenlist< orientierte Ereignisfolge zum Inhalt, durch die »rudimentär eine >dramatische< Handlung « innerhalb der einzelnen Sprechpartien entsteht. ${ }^{178}$ Diese Konfiguration erinnert an eine einfache Form

\footnotetext{
$173 \mathrm{Zu}$ den beiden die Überlagerung von Realität und Fiktionalität zeitigenden Kommunikationsebenen im dramatischen Dispositiv vgl. Pfister (s. Anm. 13), S. 327-330.

174 Lier, Leonhard: »Studien zur Geschichte des Nürnberger Fastnachtspiels«. In: Mitteilungen des Vereins für Geschichte der Stadt Nürnberg 8 (1889), S. 87-160, hier S. 91. Vgl. ferner ebd.: »Eine primitivere Form als die Aneinanderreihung unzusammenhängender Monologe ist nicht denkbar.«.

175 Eckardt, Eberhard Johannes: Der Übergang von der Simultanbühne zur Bühne der Neuzeit im deutschen Theaterwesen des 16. Jahrhunderts. Mit einem Anhang: Das Passionstheater von SchwäbischGmünd. Diss. Dresden 1931, S. 56.

176 Habel (s. Anm. 23), S. 149.

177 von Lüpke (s. Anm. 87), S. 199.

178 Vgl. Merkel (s. Anm. 20), S. 208.
} 
im Sinne André Jolles' ${ }^{179}$ Ergänzend treten darlegende oder ekphrastisch entfaltete Redeausführungen hinzu. Bei dieser Spielstruktur besteht das Bühnenereignis aus sukzessiv dargebotenen Narrationen, d.h. aus der wiederholten sprachlichen Äußerung verschiedener Berichte in der Ich-Form über eine (zumeist vergangene, selten künftige) besondere Begebenheit oder Anekdote sowie der seriellen Darlegung oder Bewertung eines gerichtlichen Falls oder eines zur Disposition gestellten Vorwurfs. Vielfach haben sie den Charakter szenischer Drastik, etwa wenn in der »Buhlerrevue (K13) der Werber beim Stelldichein mit Bier oder gar Urin übergossen oder vom Ehemann verprügelt wird. ${ }^{180}$ Mitunter führt die Rahmenhandlung die Berichtsreihung einem übergreifenden Geschehenssetting zu, wie z. B. im Spiel »Das Eggenziehen« (K30, W5) einem fastnächtlichen Rügebrauch oder in den Arztspielen, in denen Krankheitsfälle in Berichtsform vorgebracht werden, einer medizinischen Behandlung.

In vielen Reihenspielen, in denen die Figuren kleine selbsterlebte Geschichten erzählen, ${ }^{181}$ bedient sich der Sprechtext grundlegender narrativer Mittel wie des erzählenden und erlebenden Ichs eines homo- oder autodiegetischen Erzählers, ${ }^{182}$ der mit der Wiedergabe von Figurenrede verbundenen inquit-Formel, des epischen Präteritums (oder Präsens) und des »den Fortgang der Handlungskette ${ }^{183}$ bezeichnenden Satzadverbs do. Im Spiel »Die Narren« (K116) zeigt dies der Sprechtext des zweiten Narren (Der ander M, Der ander narr F):

Ich pin ein narr und muß ein narr pleiben.

Das selb hab ich von zweien weiben.

Die ein het mich lip und wert,

Die ander newr meiner pfenning begert,

Der gab ich ir ein gute sümm.

Die sprach zu mir: Noch heint so kümm!

Do kom ich und klopfet an gar heimlich,

Do goß sie herab ein waßer auf mich,

(Das ist an ir noch ungerochen)

Das selb hat mir sinn und witz zerprochen. $(1009,4-14)^{184}$

Auch im Spiel »Die verhinderten Ehemänner« (K86, R/S1) konstituiert eine dreifache Abfolge sprachlicher und mentaler Handlungen in Form der direkten (zitierten) Figurenrede bzw. des direkten Gedankenzitats die Geschichte des siebten Sprechers (Der Sibent $\mathrm{M}$; Der sibent spricht $\mathrm{Kb}$ ). Sie sind durch inquit-Formeln markiert und

\footnotetext{
179 Vgl. Jolles, André: Einfache Formen. Legende, Sage, Mythe, Rätsel, Spruch, Kasus, Memorabile, Märchen, Witz. 7., unveränderte Aufl. Tübingen 1999 [zuerst 1929].

180 Vgl. Anm. 130.

181 Es handelt sich um die sogenannten Buhler- oder Werber- sowie die Narrenrevuen, vgl. zu diesem Spieltyp von Lüpke (s. Anm. 87), S. 194-201.

182 Zum narratologischen Begriffssystem s. Martínez, Matíaz/Scheffel, Michael: Einführung in die Erzähltheorie. 10., überarbeitete und aktualisierte Aufl. München 2016, S. 79-89.

183 Hundsnurscher (s. Anm. 41), S. 113, Anm. 10.

184 Das gleiche schwankhafte Motiv (Frau bestellt Mann zu sich und übergießt ihn mit Urin) narrativiert auch der Bericht eines abgewiesenen Liebesnarren im Reihenspiel »Buhlerrevue« (KF13, 115,17-30).
} 
infolge »der Unmittelbarkeit des dramatischen Erzählmodus « ${ }^{185}$ einer mimetischen Qualität zuträglich. In extradiegetischer Perspektive, gleichsam gattungskonform mit der mittelalterlichen Kleinepik, wird die Geschichte im Stil eines moraldidaktischen Exempels von einem sentenzhaften Epimythion beschlossen: ${ }^{186}$

\section{Es kom ain hübsche dirn zu mir}

Vnd sprach: ich hab groß lieb zu dir

Vnd wil dich nemen zw eim elichen man,

Wie ser ich wider mein freund würd tan.

Do kom einer, der mir vil gutz gant,

Vnd sprach: sie hat ain eysen abgerant.

Do gedacht ich, laß den wint hin fur sawsen,

Dy katz dy lest nit von irm mausen.

Darümb wer greyffen wöll zu der ee,

Der wiß reht, wa mit er Pmbgee,

Vnd wiß, wie er sich reht pewar,

Das er an keinen stok nit var. $(\mathrm{R} / 13,102-113)$

Eingeleitet wird die Figurenrede beide Male mit dem Handlungsverb komen (Z. 102, 106), dem regietechnischen Signalwort, das in den expliziten Nebentextangaben üblicherweise die Rollenauftritte exponiert. ${ }^{187}$ Die epischen Redeszenen des mittelhochdeutschen Romans verwenden es ebenfalls in dieser Funktion gleich Bühnenanweisungen, weil dies der mündlichen Vortragssituation Rechnung trägt. ${ }^{188}$ Die knappen Geschichten der Sprechpartien des Fastnachtspiels, die häufig kaum mehr als ein gerüsthaftes Handlungsminimum abbilden, folgen dem gleichen epischen Prinzip der Redewiedergabe, für die nonverbale Vortragssignale wie Intonation, verstellte Stimme (vor allem bei Frauenfiguren innerhalb der erzählten Handlung), Redegeschwindigkeit und Affektwiderspiegelung besonders relevant gewesen sein dürften. Auch insgesamt musste beim Binnenvortrag die Bühnenwirkung sicherlich durch Gestik, Mimik und Körperbewegung, eventuell auch Requisiten besonders intensiviert werden.

Mit der dreistufigen Einbettung des dramatischen Erzählmodus in den epischen Binnenvortrag einer theatralen Aufführung gerät die Inszenierung zum metadramatischen bzw. metatheatralen Gegenstand des Fastnachtspiels: Der Darsteller verkörpert eine Rolle, die in einem theatralen Vortrag eine Narration mit von epischen Binnen-

\footnotetext{
185 Martínez/Scheffel (s. Anm. 182), S. 54. Zum Zusammenhang von »zitierte[r] Figurenrede« bzw. »Gedankenzitat« und »dramatische[m] Modus« s. ebd., S. $54 \mathrm{f}$, , S. $64 \mathrm{f}$.

186 Es schiene lohnend, für die Nürnberger Fastnachtspiele die zahlreichen Sprechpartien mit den knappen Erzählungen und ebenso mit den stärker diskursiven Anteilen - in Ergänzung zur übergreifenden Frage nach der Literarizität der Spiele, vgl. dazu Lenk, Werner: Das Nürnberger Fastnachtspiel des 15. Jahrhunderts. Ein Beitrag zur Theorie und zur Interpretation des Fastnachtspiels als Dichtung. Berlin 1966; Grafetstätter (s. Anm. 115), S. 76-126 - auf ihre narratologischen Implikationen, ihre Sprachpragmatik, ihren stofflich-motivischen und gattungsbezogenen Anschluss an mittelalterliche Erzählformen und die Redeliteratur sowie ihren (unten nur angedeuteten) Funktionszusammenhang im dramatischen Dispositiv hin zu untersuchen.

187 Vgl. Anm. 51.

188 Vgl. dazu Urscheler (s. Anm. 43), S. 61-63 (zum »Parzival«).
} 
figuren getragenen dramatischen Redeszenen wiedergibt. In der realen Bühnensituation spiegelt nun das intradiegetische narrative Prinzip der Reihenspiel-Reden, auch jener ohne direkte Figurenrede, samt ihren metadiegetischen Ereignissen die äußere dramatische Transformation des bühnendiegetisch erzählenden Spiels ${ }^{189}$ das z.B. davon erzählt, dass junge Bauern von ihren Liebesabenteuern berichten oder dass Liebesnarren ans Narrenseil gebunden werden, um über die Ursache ihrer Narrheit Rechenschaft abzulegen - und umgekehrt: Innerhalb des Narrationssujets sind die von den auftretenden Figuren erzählten Geschichten von der intradiegetischhomodiegetischen Qualität eines eigenen semantischen Feldes.

Dieses Merkmal liegt auf einer Linie mit der für das Nürnberger Fastnachtspiel insgesamt »überwiegend erzählenden und demonstrierenden Spielweise «. ${ }^{190}$ Erst die Fastnachtsbühne ermöglicht die Überlagerung von auditiver Erzähl- und visueller Performanzform. Diese doppelmediale Spannung zwischen Literatur und Theater, zwischen dramatischem Erzähl- und theatralem Darbietungsmodus führt nicht zur diskursiven Reflexion der Gattungs- und Medieninterferenzen, etwa Schwankschema und Spielstruktur, sondern lotet sie mittels realer theatraler Bühnenpraxis im dramatischen Dispositiv liminal aus: Die Kulturtechnik Erzählen selbst wird im Sprechmedium des Spiels theatral inszeniert. In Bezug auf diese spezifische, an die konkrete Aufführung gebundene Textqualität inszenierter Narrativität bedeutet dies für die Frage nach der Historizität des Fastnachtspiel-Dispositivs, dass die dramatische Konfiguration (noch) vollständig an die mediale Realisation theatraler mündlicher Bühnenpraxis gebunden ist.

Inszeniert wird somit der narrative Darbietungsakt selbst, der illokutionäre Akt des Erzählens-von-etwas. Die Geschichte selbst kommt aber nicht zur äußerlich unmittelbar sichtbaren Aufführung, ${ }^{191}$ sondern ist in der realen Aufführungssituation

\footnotetext{
189 Zum Begriffspaar »Bühnendiegese« und »freie Diegese«s. Weber (s. Anm. 157), S. 171f. - Das Verständnis eines erzählenden Spiels schließt an Webers Konzept der Episierung des Dramas an: »Es muss im Drama nicht mehr punktuell nach epischen Anteilen gesucht werden. Vielmehr ist das ganze Drama episch bzw. narrativ« (ebd., S. 3).

190 Habel, Thomas: Brecht und das Fastnachtspiel. Studien zur nicht-aristotelischen Dramatik. Göttingen 1978, S. 52.

191 Vgl. Catholys (s. Anm. 23) strikte Differenzierung: »In den Reihenspielen wird allenfalls - aber auch nicht immer - eine Geschichte auf engstem Raum erzählt. Das Handlungsspiel hingegen ist darauf angelegt, ein Vorkommnis oder eine Kette von zusammengehörigen Vorkommnissen darzustellen « (S. 149; Hervorhebung im Original). Merkel (s. Anm. 20) macht jedoch deutlich, dass sich die beiden Sinngebungsverfahren tatsächlich nicht ausschließen: »selbst noch in ausgesprochenen Handlungsspielen wurden komische Vorgänge häufig im Bericht wiedergegeben« (S. 130).

192 Zur Frage nach der epischen Form des Fastnachtspiels vgl. Habel (s. Anm. 190). Aufgrund seiner »Zeige- und Demonstrationsabsicht«, die sich in den Fastnachtspielen u. a. in den einführend-kommentierenden Rahmenreden des Ein- und Ausschreiers als Regiefigur, dem gesprochenen Entwurf von Raumund Zeitdeixis, dem Berichtsduktus der Sprecherreden und der Selbstbezüglichkeit der Sprecher im Blick auf Rollendispositionen (z.B. äußere Erscheinung) konstituiert, wird das mittelalterliche Drama insgesamt als »im wesentlichen episches Theater« aufgefasst, vgl. Linke, Hansjürgen: »Vom Sakrament bis zum Exkrement. Ein Überblick über Drama und Theater des deutschen Mittelalters«. In: Günter Holtus (Hg.): Theaterwesen und dramatische Literatur. Beiträge zur Geschichte des Theaters. Tübingen 1987, S. 127-164, hier S. 130f. (Zitate ebd.). - Auf die der neueren narratologisch ausgerichteten Dramentheorie implementierte doppelte Verwendung von >episch<- erstens synonymisch zu >narrativ< und zweitens im Sinne des epischen, verfremdenden Theaters - weist Weber (s. Anm. 157), S. 3, 5 hin.
} 
als - im Sinne des epischen Theaters ${ }^{192}$ - narrativ entworfenes Bühnengeschehen mittelbar der innerlichen Imagination der Zuschauer anheimgestellt. Der dramatische Spieltext realisiert sich gleichsam als »in der Vergangenheit geschehen[e]«193 imaginierte Handlung. Diese Fiktionsleistung teilt die Gattung Fastnachtspiel mit anderen literarischen Formen imaginativer Theatralität. ${ }^{194}$ Dennoch unterscheidet sich die Präsentationsform der Reihenspiele dadurch von einem gegebenenfalls mündlichen, vor Publikum stattfindenden Vortrag dialogischer Literatur, ${ }^{195}$ insbesondere der nichtdramatischen Reden oder der »Reihummären $«{ }^{196}$ mit szenischer Darstellung, ${ }^{197}$ die sich »auf der Grenze von mündlicher Performanz und schriftlicher Inszenierung abspielen $«,{ }^{198}$ dass erstens der »theatrale Praxisraum ${ }^{199}$ durch Rollendifferenzierung, mehrere Darsteller, Kostümierung, Requisiten, Gesten und nicht zuletzt Strategien des unmittelbar präsenten fastnächtlichen Lachens, das die Rollen-Narren und die Zuschauer-Narren gemeinschaftlich vereint, sehr viel stärker etabliert ist als in der mündlichen Vortragssituation nur eines Sprechers, in dem alle Rollen zusammenfallen. ${ }^{200}$ Zweitens stellen die genannten Aspekte, sollen sie ihre reale

193 Lenk (s. Anm. 186), S. 38.

194 Vgl. etwa die Beiträge im Sammelband Kern, Manfred (Hg.): Imaginative Theatralität. Szenische Verfahren und kulturelle Potenziale in mittelalterlicher Dichtung, Kunst und Historiographie. Unter Mitarbeit von Felicitas Biller/Claudia Höckner/Anja-Mareike Klingbeil/Manuel Schwembacher. Heidelberg 2013. Das mittelalterliche Modell der »Kopfbühne« beschreibt auf Basis der Ventrikellehre (imaginatio, memoria, ratio, intellectus) Däumer, Matthias: Stimme im Raum und Bühne im Kopf. Über das performative Potenzial der höfischen Artusromane. Bielefeld 2013, S. 102-122 (Zitat S. 108), bes. S. 108f. zum »>innere[n] Auge< der imaginatio «, das in Verbindung mit dem Rezeptionsmodus kinästhetischer Wahrnehmung evoziert wird; Kragl, Florian: »Schaubühnen. Überlegungen zur erzählten Topographie und ihrer historischen Bedingtheit«. In: von Contzen/Kragl (s. Anm. 167), S. 125-164, bes. S. 145, $161 \mathrm{f}$.

195 Zur Schwierigkeit, dialogisch entfaltete Literatur und Spiele in Bezug auf die mimetisch-dramatische Dimension zu scheiden, vgl. z.B. Williams-Krapp (s. Anm. 46), S. 23-25; Neumann/Trauden (s. Anm. 115), S. 32, führen die »imaginäre Aufführungssituation« der Spiele an, welche die Lesedramen im Unterschied zu anderen Formen dialogischer Literatur kreierten, vgl. ebd., S. 37. Kritisch zu dem damit verbundenen Vorschlag, das imaginative Potenzial zum Gattungskriterium zu erheben, äußert sich Williams-Krapp (s. Anm. 115), S. 180: »Was sich Menschen bei einer Lektüre imaginieren, möchte ich aber ungern als Gattungskriterium verwerten, zumal man dabei voraussetzten müsste, dass die Lesenden irgendwann eine tatsächliche Aufführung erlebt haben müssten, um eine solche während der Lektüre >imaginieren< zu können. « Cornelia Herberichs schlägt demgegenüber vor, im Blick auf den medialen Status der Texte kulturwissenschaftliche und überlieferungsgeschichtliche Befunde zusammenzuführen, vgl. Herberichs, Cornelia: »Lektüren des Performativen. Zur Medialität geistlicher Spiele des Mittelalters «. In: Kasten/Fischer-Lichte (s. Anm. 145), S. 169-185, hier S. 172.

196 Die Bezeichnung folgt Schneider, Martin: Kampf, Streit und Konkurrenz. Wettkämpfe als Erzählformen der Pluralisierung in Mären. Göttingen 2020, S. 49. Schneider sieht im Setting einzelner Reihummären »das Setting eines Einkehrspiels gut ab[gebildet]« und erwägt für sie den »monodramatischen Vortrag [...], im Gegensatz zu den >polydramatischen< Fastnachtspielen« (ebd., S. 81 f.; vgl. auch ebd., S. 83).

$197 \mathrm{Zu}$ den von Franz K. Stanzel in Anlehnung an die Dramentheorie geprägten Begriffen >szenische Darstellung< (und >dramatisierte Szeneく) vgl. Urscheler (s. Anm. 43), S. 59f.; Martínez/Scheffel (s. Anm. 182), S. $50 \mathrm{f}$.

198 Schnyder, Mireille: »Schreibmacht vs. Wortgewalt. Medien im Kampf der Geschlechter«. In: Mark Chinca/Timo Reuvekamp-Felber/Christopher Young (Hg.): Mittelalterliche Novellistik im europäischen Kontext. Kulturwissenschaftliche Perspektiven. Berlin 2006, S. 108-121, hier S. 108.

199 Kramer/Dünne (s. Anm. 9), S. 21.

200 Die »Nähe der Reihummären zu den Nürnberger Einkehrspielen« in performativer Perspektive erörtert Schneider (s. Anm. 196), S. 78-82 (Zitat S. 73). Vgl. auch ebd., S. 71, 83, im Anschluss an Christoph Gerhardt zur Möglichkeit der Umgestaltung eines Märes in ein Reihenspiel (mit der Literatur). 
Bühnenwirksamkeit voll entfalten, den Akt intensiven Zuschauens heraus, den sie zugleich evozieren, und drittens sind ihnen »narrative, kohärente Handlungsstrukturen « inhärent. ${ }^{201}$

Dies zeigt sich vor allem an einem verbundenen Reihenspiel wie »Die sieben Farben « $(\mathrm{K} 103),{ }^{202}$ das strukturell und im Textbestand eng verwandt ist mit der literarischen Minnerede »Die sechs Farben I« von der topischen Farbensymbolik. ${ }^{203}$ Der »semantische Raum « ${ }^{204}$ wird nicht nur unmittelbar-konkret zur Anschauung gebracht, indem im körperausagierenden Rollenspiel der Darsteller die literarischen Personifikationen als reale Farb-Figuren sichtbar auf der Bühne erscheinen. Vielmehr bildet bereits der revueartige Auf- und -abtritt der Figuren, d.h. das Hervor- und Zurücktreten der simultan anwesenden Darsteller, ein raumzeitliches Bühnen-Arrangement, das die einzelnen Farbsemantisierungen (als Personifikationen) in chronologisch-additiver Abfolge präsentiert. Fortwährend anwesend ist Frau Sunnreich, welche die Selbstinterpretationen der Farb-Figuren jeweils in Frage stellt. Eine solche serielle Struktur entspricht im Rahmen der mittelalterlichen Hermeneutik der für die allegoretische Auslegung etablierten sukzessiven Deutung mehrerer auf einen Gesamtzusammenhang bezogener Einzelaspekte, hier der Farbenallegorese. Erst die Aufführungsform der aufeinanderfolgenden Einzelvorträge trägt durch die Bühnenpraxis sukzessive ausagierter Körperpräsenz diesem Semantisierungsmuster in besonderer performativer Weise Rechnung. Für die kommunikative Funktion der sprachlichen Äußerungen, die in diesem Sinne notwendig auf den »Erfahrungsraum der Zuschauer ${ }^{205}$ in der konkret-aktualen Bühnenanschauung angewiesen ist, bildet der bühnentopographisch mit dem ebenso einfachen wie effektvollen Mittel sukzessiver physisch-körperlicher Sprecherpräsenz konstituierte Spielraum den medialen Durchführungsrahmen.

Setzt man, ausgehend davon, eine in der Spielstruktur aufgehende sinnstiftende Form auch bei all jenen Revuen an, die zwar keine allegoretische Zielsetzung erkennen lassen, aber seriell vorgebrachte Einzelfälle auf eine gemeinsame Fragestellung ausrichten, wird unweigerlich das auch für weitere literarische Gattungen ${ }^{206}$ konstitutive Kompositionsprinzip der listenartigen Reihung ${ }^{207}$ augenfällig. Es findet seine symbolisch-semantische Entsprechung in den Personenlisten mit der nominalen oder ordinalen Enumeration der Sprecher (s. o. 4) und ebenso in der zeichenhaftgraphischen Indexierung der expliziten Rollenangaben, die den Figurenauftritten Ordinalzahlwörter oder Ziffern zuordnen.

\footnotetext{
201 Vgl. auch Herberichs (s. Anm. 195), S. 173 (Zitat ebd.), die für die Spieltexte »trotz diverser Analogien« einen »kategorial[en]« Unterschied zur Dialogliteratur herausstellt.

202 Zum Spiel vgl. Glier (s. Anm. 85), S. 567-570, 586 (mit weiterer Literatur).

203 Zur Minnerede s. mit weiterer Literatur Lenk (s. Anm. 186), S. 44-46; Klingner, Jacob/Lieb, Ludger (Hg.): Handbuch Minnereden. Mit Beiträgen von Iluia Emilia Dorobanţu u. a. 2 Bde. Berlin/Boston 2013, hier Bd. 1, S. 588. Vgl. auch Glier (s. Anm. 202).

204 Kramer/Dünne (s. Anm. 9), S. 21, Anm. 20.

205 Ebd.

206 Beispiele für die »anekdotenhafte[ ] Aneinanderreihung« nennt Lenk (s. Anm. 186), S. 38f. (Zitat S. 38).

207 Vgl. dazu von Contzen und Schaffrick/Werber (jeweils Anm. 136).
} 
Die unverbundenen Einzelfälle sind nicht nur auf ein gemeinsames Drittes, den thematisch-semantischen Vorwurf (z. B. äußere Erscheinung, Bußfertigkeit, Liebesdienst, Frauenpreis, Narrheit, Nachbarschaftsstreit, Ehezwist), bezogen, sondern sie spielen ihn einerseits in unterschiedlicher Perspektive akkumulierend durch und kontextualisieren und kommentieren sich dadurch gegenseitig. Die Einzelnarrationen erscheinen als kohärente erweiter- und austauschbare Elemente eines (unabgeschlossenen) Reservoirs literarischer Fiktion, das die Funktionsmöglichkeiten kasuistischen und schwankhaften Erzählens und ebenso des Wiedererzählens im narrativen Paradigma fastnächtlicher Komik, Hyperbolik und Verkehrung nachdrücklicher exponiert als jede isolierte Einzelnarration. Andererseits lässt die Präsentationsweise im kohärenten Verbund die epischen Kleinstformen gerade in Differenz zueinander treten. Die Differenzqualität macht das Prinzip der Vervielfältigung und Varianz einsichtig und eröffnet ein Paradigma der Episodenvielfalt im Sinne von in Thema und Struktur äquivalenten Erzähleinheiten, ${ }^{208}$ die als reziprok aufeinander ausgerichtete Elemente das Verfahren kasuistischen und novellistischen Erzählens und die Bedingungen der Textkohärenz schwankhafter Handlung vor Augen führen. Damit suchen die Spiele den Anschluss an das sich im 15. und 16. Jahrhundert von verschiedenen medialen Formen der Schwanksammlung getragene Experimentierfeld für ein »sequentielle[s] Erzählparadigma $\ll .209$

Bei dem Semantisierungsmuster der Reihe führt erst die Bespielung in der Performanzsituation der äußeren, durch den Spielort vorgegebenen Raumbühne die isolierten inneren, narrativ vermittelten kleinen Bühnenstücke einem besonderen Perzeptionszusammenhang zu. In ihm wird das serielle und kombinatorische Erzählprinzip mittelalterlicher Kurzerzählungen, »den gleichen Plot neu zu fassen oder dieselbe Moral in veränderter Erzähldisposition zu illustrieren $\ll,{ }^{210} \mathrm{im}$ Wortsinn durchgespielt und dadurch das poetische Mittel narrativer Vervielfältigung und Wiederholung überhaupt herausgestellt. So wird kommunikatives und symbolisches Handeln auch selbst Gegenstand der Inszenierung. Überträgt man die narrative Binnenkasuistik der Einzelvorträge insgesamt auf die äußere dramatische Kasuistik des Spielgeschehens, spielen auch viele handlungsorientierte Fastnachtspiele nichts anderes als variabel gestaltete Szenen gleich abstrahierter Problemfälle sozialer Normverletzung vor allem aus dem Aushandlungsfeld der Geschlechter- und Herrschaftshierarchie durch.

In diesem Sinne stellt das Verfahren der Kumulation exemplarischer Einzelfälle im Spiel mit der Spannung zwischen vereinzelnder Vielheit und ordnender Einheit eine komplexe, unabgeschlossene übersummative Ganzheit dar, die, intensiviert durch das Netz intratextueller motivischer Bezüge und Versatzstücke, das insgesamt für das Nürnberger Spielcorpus signifikant ist, die Basis literarischer und zugleich

\footnotetext{
208 Wenn auch die Serien kleinster Frauenlist- und Ehebruchschwänke nicht in eine übergreifende narrativprozessuale Tiefenstruktur eingebettet sind, wie dies im höfischen Roman der Fall ist, erinnert die Reihung zumindest ansatzweise an das »Erzählen im Paradigma«, vgl. dazu mit weiterführender Literatur Schulz, Arnim: Erzähltheorie in mediävistischer Perspektive. Studienausgabe. 2. Aufl. Berlin/München/Boston 2015, S. 344.

209 Vgl. dazu Plotke, Seraina/Seeber, Stefan: »Ko- und Kontexte. Kurzerzählungen zwischen Handschrift und Buchdruck«. In: Dies. (s. Anm. 168), S. 3-12, hier S. 7 (Zitat nach dem Titel des Sammelbandes).

210 Friedrich, Udo: »Trieb und Ökonomie. Serialität und Kombinatorik in mittelalterlichen Kurzerzählungen«. In: Chinca/Reuvekamp-Felber/Young (s. Anm. 198), S. 48-75, hier S. 58.
} 
theatraler Reflexion für kommunikative Strategien der Narration in Situationen des Konflikts mit der sozialen Norm zu bilden vermag. Wenn in der Rahmenhandlung für die beste Anekdote oder Darlegung zudem ein Preis ausgesetzt ist (K14, K16), wobei es nicht so sehr um das Überbietungs- als vielmehr um das Variationsprinzip geht, ${ }^{211}$ dann gerät die Inszenierung nicht nur zu einem >Erzähler-Wettstreit< vor der städtischen Fastnachtsgesellschaft, sondern das inszenierte Spiel, das genregenuin an der Aushandlung sozialer Ordnungen teilhat, ${ }^{212}$ ist auf der Ebene narrativer und zugleich theatraler Referenzialität auch Medium kultureller Selbstreflexion und sozialer Selbstverständigung.

Vor allem die Werber- und die Gerichtsspiele bringen - wie etwa im erwähnten Spiel »Buhlerrevue« (K13; s. o. 4) $)^{213}$ - zahlreiche kleine Modellszenen kasuistischen Erzählens auf die (narrative) Bühne, ${ }^{214}$ indem sie einen Problemfall (z. B. Frauenlist, Sexualität außerhalb der Ehe) aus verschiedenen Perspektiven beleuchten, dadurch ihr Sinnpotenzial wechselseitig erhellen und ihren als gleichartig präsentierten medialen Textstatus verstärkend konturieren. Vor diesem Hintergrund darf man gerade bei dem Erzählgefüge der Binnenvorträge, das sich nur plotmäßig auf einen gerüsthaften Aufriss und die nötigsten die Pointe gewährleistende Handlungsinformationen beschränkt, annehmen, dass das Fastnachtspublikum mit dieser Literaturform vertraut war und die innerdramatische Anspielung hierauf verstehen konnte. In der realen Inszenierung eröffnet dann das Fastnachtspiel-Dispositiv den Blick auf die mündliche Vortragssituation als (eine) Existenzweise kleiner epischer Genres und ebenso auf ihre kommunikative Funktion, die fastnächtlich-karnevaleske symbolische Ordnung einzuholen. ${ }^{215}$ Die kleinepische Literatur bildet nämlich ihrerseits ein mediales Gefüge im Diskurs von Norm und Konflikt, der, wenn auch teils unter anderen Vorzeichen, im Verhältnis von Fastnacht und Ordnung ${ }^{216}$ einen wesentlichen Fixpunkt hat und im Fastnachtspiel sein mediales, im scherzhaft-aggressiven Verlachen der düpierten Selbstdarsteller ${ }^{217}$ aufgehendes Residuum findet. Angesichts

211 Vgl. ähnlich das spezifische Konkurrenzverhältnis in den Streitreden der Reihummären, dazu Schneider (s. Anm. 196), S. 50f., 53.

212 Vgl. umfassend von Lüpke (s. Anm. 87).

213 Die einzelnen Geschichten sind der Zusammenfassung in Anm. 130 zu entnehmen.

214 Mit der strukturellen Ausrichtung der Fastnachtspiele, in den Sprachäußerungen für einen Ereignisfall gleichsam typische Modellsituation zu entwerfen, lässt sich auch die besonders in der frühen Fastnachtspieltradition häufige Integration von Sprichwörtern, Sentenzen und Redensarten erklären (z. B. das Sprichwort »Die Katze lässt das Mausen nicht « in der oben aufgeführten Sprechpartie aus »Die verhinderten Ehemänner« [KF86, R/S1]), insofern in Perspektive der Parömiologie die gnomischen Kleinstformen situationsmodellierende Funktion besitzen. Zu dieser Modellfunktion s. Grzybek, Peter: »G. L. Permjakovs Grammatik der sprichwörtlichen Weisheit«. In: Die Grammatik der sprichwörtlichen Weisheit von G. L. Permjakov. Mit einer Analyse allgemein bekannter deutscher Sprichwörter hg., übers. und bearb. von Peter Grzybek. Hohengehren 2000, S. 1-41; dazu auch (aus einem Überblick über weitere parömiologische Ansätze) Lewandowska, Anna: Sprichwort-Gebrauch heute. Ein interkulturell-kontrastiver Vergleich von Sprichwörtern anhand polnischer und deutscher Printmedien. Bern u. a. 2008, S. 102-106.

$215 \mathrm{Zu}$ Anspielungen der Versnovellistik auf die Fastnachtskomik s. Coxon, Sebastian: »Das geschach zu ainer fasnacht. Shrovetide in Late Medieval German Comic Tales«. In: Chinca/Reuvekamp-Felber/Young (s. Anm. 198), S. 192-206.

216 Vgl. dazu umfassend für das Fastnachtspiel von Lüpke (s. Anm. 87).

217 Vgl. Coxon (s. Anm. 67), S. 222, 232-236. 
dessen könnte in der dispositiven Struktur des novellistischen und anekdotenhaften Erzählens und ebenso der ekphrastischen Darlegung ein weiterer Grund - neben den Kriterien der Autor- und Gattungszentrierung - für die spezifische Verbindung von Fastnachtspielen mit Versnovellen, Schwankmären, Reden, Lobsprüchen und Priameln in den Rosenplütschen Sammelhandschriften liegen. ${ }^{218}$

Abschließend betrachtet, führt das beschriebene poetische Verfahren in den Spielen die Kulturpraxis des Sammelns und die Kulturpraxis des Erzählens erstens zusammen und überführt es zweitens in das Medium der Reihe oder Liste, d.h. in ein kontingentes, nicht-narratives, aber einen vornarrativen Kern enthaltendes, eigen-ästhetisches literarisches Ordnungsmedium formaler und sozialer Relevanz. ${ }^{219}$ Auf bühnendiegetischer Ebene erfolgt dies nach der mittelalterlichen Technik des »enzyklopädischen Erzählen-als-Aufzählens « ${ }^{220}$ und erlaubt, den Überlieferungsdivergenzen in Bestand und Reihenfolge der Sprechtexte zufolge, die Umsortierung, Erweiterung, Kürzung und Ersetzung der Elemente. Drittens werden beide Komplexe im Medium des theatralen Dispositivs jener nur im Vollzug der körpergebundenen Aufführung performativ wahrnehmbaren Perzeptionsform zugeführt, in der sich die Ebene »imaginativer Theatralität « (der inneren Schaubühne der Geschichten) der Ebene »konkreter Theatralität $\ll^{221}$ oder $»$ pragmatischer Theatralität $\ll^{222}$ (der sichtbaren Spielbühne des äußeren Settings) vollständig einschreibt. Denn vermittels der Ich-Perspektive, in welcher die Sprecher jeweils die erzählte Handlung präsentieren, gehen die imaginierten Körper der Aktanten und die durch die Leiblichkeit der imaginierenden Darsteller zur Anschauung gebrachte Körperpräsenz der Rollenfiguren ineinander auf. Imaginative Theatralität und theatrale Imaginativität ${ }^{223}$ fallen in der sichtbaren Aufführung des Reihenspiels in eins.

Ebendiese sukzessiv-expressive Qualität theatraler Unmittelbarkeit der Narration ist ein Charakteristikum des Spieldispositivs der Rosenplüt-Tradition. ${ }^{224}$ Sie bleibt dem monodramatischen Literaturvortrag nur eines Rede-Ichs und erst recht der Lektüresituation versagt. Vor diesem Hintergrund erweist sich auch die Enumeration der Rollen in den Sprechtexten als das im Dienst theatraler Semantisierungsstrategien stehende poetische Indexierungsverfahren des dispositiven narrativen Musters zeitlicher Sukzession. Im Schriftmedium, in dessen Rollenangaben sich der Ausweis

\footnotetext{
218 Vgl. etwa für die Handschrift P N[ikolaus] H[enkel]: »Mären, Priameln und Einkehrspiele zur Fastnacht in Nürnberg. Eine Sammlung mit Spiel- und Lesetexten des Hans Rosenplüt und Hans Folz«. In: Eva Horváth/Hans-Walter Stork (Hg.): Von Rittern, Bürgern und von Gottes Wort. Volkssprachige Literatur in Handschriften und Drucken aus dem Besitz der Staats- und Universitätsbibliothek Hamburg. Eine Ausstellung in der Staats- und Universitätsbibliothek Hamburg vom 26. September bis 23. November 2002. Kiel 2002, S. 122 f., Kat. Nr. 51.

219 Die poetologischen Merkmale einer Liste erläutern im Überblick Schaffrick/Werber (s. Anm. 136).

220 von Contzen: »Listen im Transferprozess « (s. Anm. 136), S. 197.

221 Kern, Manfred: »Einleitung«. In: Ders. (s. Anm. 194), S. 1-20, hier S. 9.

222 Becker, Anja: »Die Lieder der Geißler von 1349. Zum Zusammenhang von imaginativer und pragmatischer Theatralität«. In: Kern (s. Anm. 194), S. 300-323, hier S. 303, 316.

223 Zur Unterscheidung der beiden qualitativ differenten Prinzipien der Kommunikation vgl. Kern (s. Anm. 221), S. 2 f.

224 Auf die Folz-Tradition dürfte Ähnliches zutreffen, wäre aber im Blick auf die narrativen Strategien der Redetexte zu verifizieren.
} 
der Redewiedergabe in Zahlwörtern (Der erst, Der ander usw.) und in graphischer Bezifferung zeichenhaft materialisiert, reproduziert dann der Haupttext in seinen Geschichten die episierende Funktion der Nebentexte.

Die Ausführungen leiten mit Blick auf die inszenatorische Umsetzung zuletzt zu der Überlegung, dass, obwohl die Reihenspiele, zumal die unverbundenen, »nur wenig Bewegungsraum benötigten $«,{ }^{225}$ es dem Verfahren reziproker kasuistischer Kommentierung zuträglich wäre, wenn sich alle Sprecher - aufgereiht oder im Haufen - zugleich sichtbar auf der Darbietungsfläche befinden, auch vor und nach ihrem Einzelvortrag, für den sie jeweils hervortreten. Denn der räumlich-sukzessive Auftritt und Abgang der Figuren, der zeitlich-lineare Wechsel der Darsteller-Körper konstituieren den »theatrale(n) Praxisraum «:226 Bei einer Anzahl von mitunter 15, 20 und mehr Darstellern dient die massive Körperpräsenz des Sprecherkollektivs einem besonderen Verfahren der Raumdeixis, da die Sprecher die Bühne selbst physisch erzeugen, indem sie durch ihre körperliche Präsenz die horizontale Spielfläche gleichsam säumend oder ausfüllend begrenzen und in gleicher Weise die vertikale Bühnenwand markieren. Auch diese Simultanperspektive mit der Kopplung von körperbezogener Praxis und semantisierender Reihungsform bildet mit allen aufgezeigten medialen Implikationen ein charakteristisches dispositives Element der frühen Fastnachtspieltradition.

\section{Fazit}

Mit seiner genregenuinen Praxis inszenatorischer kultureller Vermittlung organisiert das dramatische Mediendispositiv der Rosenplütschen Fastnachtspiele Komplexe gesellschaftlicher Wahrnehmung, vorrangig von Herrschafts- und Geschlechterverhältnissen, Körperlichkeit und Sexualität, Sünde und Buße, Norm und Konflikt. In die dispositive Struktur des theatralen Schauens ist (neben impliziten Aufführungsvorgaben) der schrifttechnische Apparat der Nebentexte konstitutiv eingebunden. In der kommunikativen Praxis steuert er die Rezipientenwahrnehmung und erzeugt reale oder imaginäre performative Sichtbarkeit. Auch wenn die Rollen- und Regieangaben kaum an die Episierungstendenzen der späten Spieltradition heranreichen und weit davon entfernt sind, das sehr viel komplexere System impliziter Vorgaben der Sprechtexte zu ersetzen, ${ }^{227}$ treten sie in tragfähige Ergänzung zu diesen. Denn erst die regie- und rollenbezogenen Informationen verbinden die einzelnen Rollentexte, die ihren vormaligen realen Aufführungskontexten enthoben sind und daher theatrale Leerstellen zeitigen, im Schriftmedium zu einer linear fixierten Abfolge und führen sie einer neuen, imaginierten Performanzsituation mit teils deutlich unterschiedlichen Inszenierungen zu. Im redaktionellen Bearbeitungsprozess Resultat eines theatralen Erfahrungsdispositivs, erzielen sie dies durch ein basales, aber effektives narratives Funktionsspektrum, an dem auch die visuell-akustische Au-

\footnotetext{
225 Janota (s. Anm. 64), S. 384.

226 Kramer/Dünne (s. Anm. 9), S. 21.

227 Diese historische Entwicklung zeigt Detken (s. Anm. 13), S. 12, in Anhängigkeit von den je gültigen theatralen Konventionen auf.
} 
ra theatral-dramatischer Formelemente des schriftgraphischen und buchtechnischen Zeichendispositivs teilhat.

Die dominante Reihenspielform des inszenierten Narrations- oder Berichtsakts integriert eine epische und dramatische Literaturform in die dispositive liminale Auslotung von Erzähl- und Spielpraxis, welche die Existenz- und Funktionsbedingungen der beiden medialen Genres im mündlich-inszenatorischen Kommunikationszusammenhang wechselseitig einsichtig macht. Dabei übernimmt die einfache Rollen-Enumeration der Nebentexte für das poetische (und theatrale) Verfahren listenhaft angeordneter Narrationen eine wichtige Semantisierungsfunktion. Während hier das Spieldispositiv im Wesentlichen noch vollständig an die sichtbare theatrale Praxis gebunden ist, kann im Bereich literarischer Anpassungen der Transfer des theatralen in das dramatische Dispositiv erfolgen.

Nicht zuletzt evoziert die Ebene der inneren Imagination einerseits und die ästhetische Distanz gegenüber der transmedialen Struktur der Reihenspiele andererseits in Perspektive des Dispositivs des dramatischen fastnächtlichen Rollenspiels eine stärkere Trennung zwischen Spiel- und Zuschauersphäre. Sie steht dem auf die Lachgemeinschaft bezogenen Dispositiv der Fastnacht mit der Verwischung der Zuschauer- und Spielgrenze entgegen. Auf der Bühne kulminieren das dispositive Gefüge der Fastnacht und das des Fastnachtspiels hier in ihrer medialen Konkurrenz.

Funding Open Access funding enabled and organized by Projekt DEAL.

Open Access Dieser Artikel wird unter der Creative Commons Namensnennung 4.0 International Lizenz veröffentlicht, welche die Nutzung, Vervielfältigung, Bearbeitung, Verbreitung und Wiedergabe in jeglichem Medium und Format erlaubt, sofern Sie den/die ursprünglichen Autor(en) und die Quelle ordnungsgemäß nennen, einen Link zur Creative Commons Lizenz beifügen und angeben, ob Änderungen vorgenommen wurden.

Die in diesem Artikel enthaltenen Bilder und sonstiges Drittmaterial unterliegen ebenfalls der genannten Creative Commons Lizenz, sofern sich aus der Abbildungslegende nichts anderes ergibt. Sofern das betreffende Material nicht unter der genannten Creative Commons Lizenz steht und die betreffende Handlung nicht nach gesetzlichen Vorschriften erlaubt ist, ist für die oben aufgeführten Weiterverwendungen des Materials die Einwilligung des jeweiligen Rechteinhabers einzuholen.

Weitere Details zur Lizenz entnehmen Sie bitte der Lizenzinformation auf http://creativecommons.org/ licenses/by/4.0/deed.de. 